\title{
Avaliação da eficácia da máscara oronasal vs nasal com uso de pressão positiva para o tratamento da apneia obstrutiva do sono
}

Tese apresentada à Faculdade de Medicina da Universidade de São Paulo para obtenção de título de Doutor em Ciências

Programa de Pneumologia

Orientador: Prof. Dr. Geraldo Lorenzi Filho Co-orientador: Dr. Pedro Rodrigues Genta

SÃO PAULO 
Dados Internacionais de Catalogação na Publicação (CIP)

Preparada pela Biblioteca da

Faculdade de Medicina da Universidade de São Paulo

Creprodução autorizada pelo autor

Weaver, Fernanda Madeiro Leite Viana

Avaliação da eficácia da máscara oronasal vs

nasal com uso de pressão positiva para o tratamento

da apneia obstrutiva do sono / Fernanda Madeiro

Leite Viana Weaver. -- São Paulo, 2018.

Tese(doutorado)--Faculdade de Medicina da

Universidade de São Paulo.

Programa de Pneumologia.

Orientador: Geraldo Lorenzi Filho.

Coorientador: Pedro Rodrigues Genta.

Descritores: 1 .Apneia obstrutiva do sono

2. Pressão positiva contínua nas vias aéreas

3.Terapêutica 4.Máscaras 5.Endoscopia 6.Transtornos

do sono-vigília

$\mathrm{USP} / \mathrm{FM} / \mathrm{DBD}-524 / 18$

Responsável: Erinalva da Conceição Batista, CRB-8 6755 


\section{Dedicatória}

\section{Ao meu marido, Colin.}

"If this is what you want to do: I'll support you. If this is what makes you happy, then it makes me happy." E assim faz desde o dia em que decidimos seguir juntos a caminhada da vida. Caminhar com você é muito mais leve. Sem o seu apoio e suporte diário essa tese não seria possível.

À minha filha, Laura.

Que minha carreira como pessoa e como médica possam ser motivos de orgulho e inspiração para seus desafios na vida.

Aos meus pais, Auxiliadora e Fernando.

Essa tese é fruto de uma criação sólida. Obrigada pelo incentivo de sempre seguir em frente e encarar o mundo e seus desafios. "Criamos os filhos para o mundo" e no mundo eu me encontrei, graças a vocês.

\section{À minha família.}

Ao meu avô Jorge, aos meus tios e tias, primos e primas que no meu caso são

tão próximos que fazem parte de laços primários de uma base familiar. A torcida de vocês transpassou barreiras físicas.

Em memória à minha avó, Lêda.

Sua trajetória de vida pessoal e profissional serão sempre exemplos para que eu siga em frente com amor, carinho e dedicação. A senhora está presente mesmo quando ausente. 


\section{Agradecimentos}

Ao Prof. Dr. Geraldo Lorenzi Filho, orientador desta tese. Agradeço a confiança e oportunidade de construir meu caminho na Medicina do Sono. Sua inteligência, seu humor e sua positividade serão sempre inspiração na minha vida profissional.

Ao Prof. Dr. Pedro Rodrigues Genta, co-orientador desta tese. Sua disponibilidade e dedicação estão impressas em cada experimento realizado. Exemplo de pesquisador, sempre acessível. Obrigada pelo convívio, ensinamentos, apoio e incentivo na realização desse projeto.

Ao Prof. Eng. Henrique Takachi Moriya, pela disponibilidade e paciência ao me ajudar a atender algo completamente novo na minha vida: o software Spike. "Você precisa entender como funciona para assim entender os erros. A sistematização dos passos é o segredo para achar o erro."

Aos professores Dr. Rogério de Souza, Dr. Mario Terra Filho e Dr. Carlos Roberto Ribeiro de Carvalho, pela oportunidade de ter participado como aluna de um programa de pós-graduação de excelência como o da Pneumologia.

Ao meu marido Colin Weaver, pela ajuda não só emocional, mas também técnica neste projeto. Mesmo não sendo sua área de atuação, se esforçou para entender a pesquisa. Ofereceu suporte em inglês revisando as minhas inúmeras 
versões de artigos científicos e escutando com olhar crítico todas as minhas apresentações na língua inglesa.

Aos amigos Rafaela Andrade, Vívien Piccin e George Lago companheiros de protocolo. Obrigada por todo o apoio e dedicação na coleta de dados. A conclusão deste trabalho também se deve a vocês. Em especial Rafaela Andrade, de quem fui sucessora nesta linha de pesquisa.

As amigas Raquel Hirata e Melânia Marques. Sem a ajuda emocional e técnica de vocês essa tese não seria possível.

Aos amigos Juliana Araújo e Gustavo Graad os quais compartilharam comigo o equipamento para coleta de dados. Nosso aprendizado para entender 0 funcionamento do mesmo foi graças à colaboração mútua.

A amiga Lilian Khellen, que me apresentou ao laboratório do sono e incentivou o primeiro passo desta caminhada que foi minha especialização em Medicina do Sono.

A todos os amigos do Laboratório do Sono, onde compartilhei alegrias e tristezas. Vocês fizeram esta caminhada mais leve. Sempre incentivando diante das dificuldades e aplaudindo nas vitórias. Em especial ao amigo Daniel Queiroz, uma pessoa experiente em pesquisa e que sempre esteve disposto a ajudar quem iniciava na área. 
A Vanderléia, nossa Vandinha, obrigada por me ajudar em todas as burocracias, em todas as 'ordens de serviço' criadas para que eu conseguisse concluir minha pesquisa. Você sempre foi solícita e sua ajuda foi fundamental.

Aos técnicos de polissonografia Paulo e Fabiane, pela ajuda noturna em busca de zerar o vazamento da máscara. Por compartilharem comigo os embalos de domingo à noite e serem sempre solícitos em me ajudar.

Aos pacientes que participaram voluntariamente deste estudo. Por me permitirem monitorizar vocês por completo na busca do conhecimento. Nossa pesquisa possuía inúmeras intervenções, vocês deixaram o conforto de suas casas para dormir no Laboratório do Sono e fazer com que tudo fosse possível. Minha eterna gratidão. 
Normalização Adotada

Esta tese está de acordo com as seguintes normas, em vigor no momento desta publicação:

Referências: adaptado de International Commitee of Medical Journals Editors (Vancouver)

Universidade São Paulo. Faculdade de Medicina. Divisão de Biblioteca e Documentação. Guia de apresentação de dissertações, teses e monografias. Elaborado por Annelise Carneiro da Cunha, Maria Júlia de A. L. Freddi, Maria F. Crestana, Marinalva de Souza Aragão, Suely Campos Cardoso, Valéria Vilhena. $3^{a}$ ed. São Paulo: Divisão de Biblioteca e documentação; 2011.

Abreviaturas dos títulos dos periódicos de acordo com List of Journals Indexed in Index Medicus. 
Lista de Siglas e Símbolos

Lista de Tabelas

Lista de Figuras

Resumo

Abstract

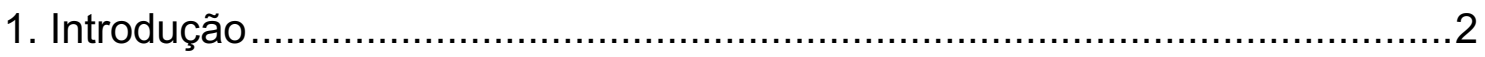

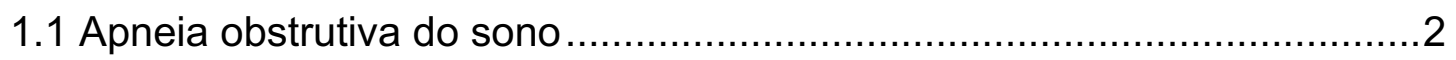

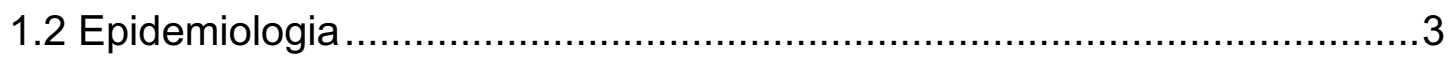

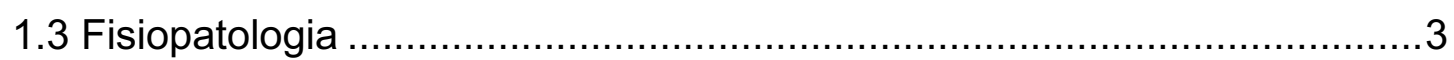

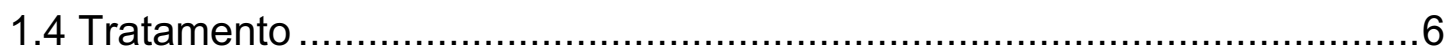

1.4.1 Tratamentos gerais ......................................................... 6

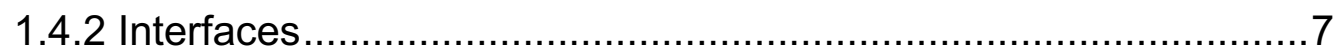

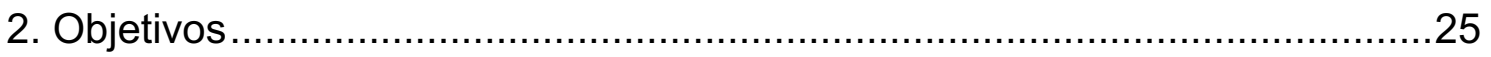

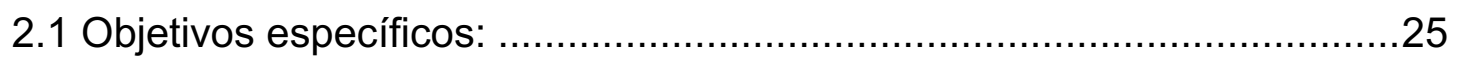

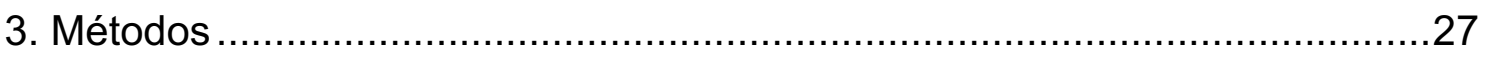

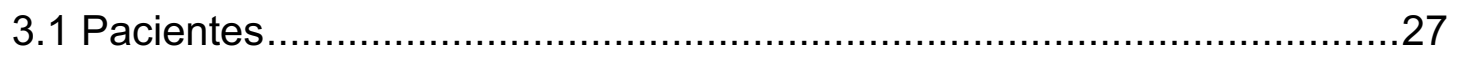

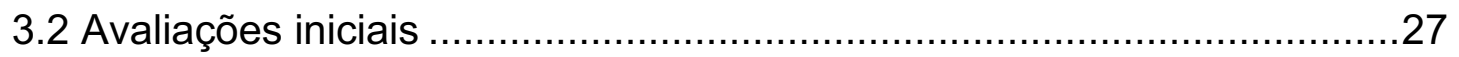


3.3 Polissonografia com sono induzido

3.4 Etapas do estudo 32

3.4.1Titulação de CPAP 33

3.4.2 Limitação de fluxo estável 33

3.4.3 Limitação de fluxo estável com fita selando a cavidade oral 37

3.5 Análise estatística 37

4. Resultados 39

4.1 Titulação de CPAP 40

4.2 Limitação de fluxo estável 42

4.3 Limitação de fluxo estável com uso de fita selando cavidade oral. 47

5. Discussão 51

6. Conclusão .58

7. Anexos 60

7.1 Parecer comissão científica 60

7.2 Termo de consentimento livre e esclarecido 60

7.3 Ficha de Avaliação 64

7.4 Questionário de sintomas faríngeos. 69

7.5 Escala de Sonolência diurna de Epworth. 70

7.6 Questionário de avaliação de resultados nasossinusais 71

8. Referências 74 


\section{Lista de Siglas e Símbolos}

AASM

AOS

AP

CPAP

CPAP oronasal

Oronasal

CPAP nasal

Pressão Positiva Contínua nas Vias Aéreas com Máscara

Nasal

CAPPesq

$\mathrm{cm}$

$\mathrm{cmH}_{2} \mathrm{O}$

$\mathrm{cmH}_{2} \mathrm{O} / \mathrm{L} / \mathrm{S}$

$\mathrm{IAH}$

IMC

InCor

$\mathrm{Kg} / \mathrm{m}^{2}$

Academia Americana de Medicina do Sono

Apneia Obstrutiva do Sono

Ântero-posterior

Pressão Positiva Contínua nas Vias Aéreas

Pressão Positiva Contínua nas Vias Aéreas com Máscara

Comissão de Ética para Análise de Projetos de Pesquisa

centímetros

centímetros de água

centímetros de água por litro por segundo

Índice de Apneia Hipopneia

Índice de Massa Corpórea

Instituto do Coração

quilogramas por metro quadrado 
L/s litros por segundo

$\mathrm{mm}$

milímetros

$\mathrm{mm}^{2}$

milímetros cúbicos

n

número

S

segundos

TCLE

Termo de consentimento livre e esclarecido

VAS

Via Aérea Superior

Vs

versus

USP

Universidade de São Paulo 


\section{Lista de Tabelas}

Tabela 1: Estudos que mostram a eficácia dos diferentes tipos de máscaras no tratamento da AOS.

Tabela 2: Estudos que mostram o impacto na adesão com os diferentes tipos de máscaras no tratamento da AOS 15

Tabela 3: Estudos elegíveis na meta análise comparando máscara nasal vs oronasal. 17

Tabela 4: Características basais de todos os estudos avaliados na meta análise comparando máscara nasal vs oronasal. 18

Tabela 5: Características antropométricas e da polissonografia basal. 39

Tabela 6: Efeitos da mudança aguda de rota de CPAP nasal para oronasal e oronasal para nasal durante limitação de fluxo estável.

Tabela 7: Subanálise da mudança aguda de rota de CPAP nos respiradores nasais, independente da ordem da mudança. 46

Tabela 8: Porcentagem de redução das dimensões de via aérea superior na rota oronasal 46 


\section{Lista de Figuras}

Figura1: Desenho esquemático do resistor de Starling ................................. 5

Figura 2: Ilustração funcionamento do CPAP desenvolvido por Sullivan ............7

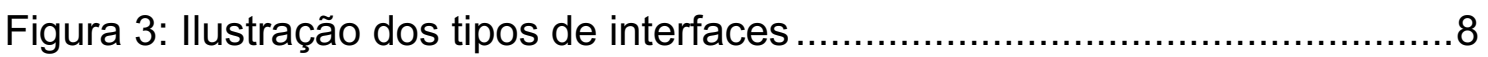

Figura 4: Desenho esquemático do funcionamento do CPAP com máscara

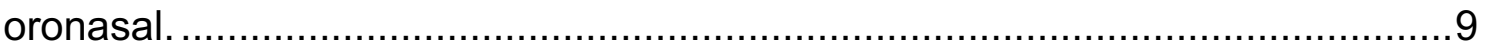

Figura 5: Hipnograma de uma titulação de CPAP com máscara nasal e oronasal acompanhada de nasoendoscopia 11

Figura 6: Gráfico com porcentagem de respiração nasal e oral com a máscara oronasal 20

Figura 7: Gráfico com distância entre a epiglote e base de língua e de área retroglossal com as rotas nasal, oronasal e oral. 21 Figura 8: Máscara oronasal com compartimentos oral e nasal separados e selados 29

Figura 9: Imagem com paciente com máscara oronasal e válvula multidirecional nas rotas nasal e oronasal. 30

Figura 10: Imagem ilustrando dia de coleta do protocolo. 32

Figura 11: Desenho esquemático do protocolo de pesquisa. 32

Figura 12: Ilustração do cálculo do delta de pressão faríngea. 34

Figura 13: Ilustração do cálculo da resistência da via aérea superior. 35

Figura 14: Exemplo do protocolo da avaliação da imagem durante as mudanças agudas de rota de CPAP 36 
Figura 15: Imagem de nasoendoscopia na região retropalatal e retroglossal com as marcações de medidas de comprimento e área. 36

Figura 16: Exemplo representativo de um paciente respirador oronasal durante titulação de CPAP nas rotas oronasal e nasal. 40

Figura 17: Gráfico com as pressões de CPAP com rota nasal e oronasal e correlação com a porcentagem de fluxo oral.

Figura 18: Exemplo representativo de mudança de rota de CPAP da rota nasal para oronasal durante limitação de fluxo estável.

Figura 19: Exemplo representativo de mudança aguda de rota de CPAP da rota oronasal para nasal durante limitação de fluxo estável. 44

Figura 20: Exemplo representativo de mudança aguda de rota de CPAP da rota oronasal para nasal durante limitação de fluxo estável com uso de fita selando a cavidade oral.

Figura 21: Efeitos das alterações agudas do CPAP no fluxo aéreo e na resistência da via aérea superior antes e depois de selar a boca com uma fita. 49

Figura 22: Representação do funcionamento variável da máscara oronasal.....56 
Weaver, FMLV. Avaliação da eficácia da máscara oronasal vs nasal com uso de pressão positiva para o tratamento da apneia obstrutiva do sono. [tese]. São Paulo: Faculdade de Medicina, Universidade de São Paulo; 2018.

Introdução: A aplicação de Pressão Positiva Contínua na Via Aérea Superior (CPAP) durante o sono é o tratamento padrão ouro para Apneia Obstrutiva do Sono (AOS) e foi primeiramente descrita utilizando uma máscara nasal. No entanto, na prática clínica a máscara oronasal é comumente utilizada e sua eficácia é variável devido a mecanismos desconhecidos. Nós formulamos a hipótese de que a respiração oral e a transmissão de pressão pela cavidade oral comprometem a eficácia do CPAP com máscara oronasal. Métodos: Treze pacientes com AOS, bem adaptados à máscara oronasal, foram monitorados com polissonografia completa, cateter de pressão faríngea e nasoendoscopia. Os pacientes dormiram com uma máscara oronasal com compartimentos nasal e oral separados e selados entre si. Cada compartimento nasal e oral foi conectado a um pneumotacógrafo e ambos foram conectados a uma válvula multidirecional a fim de ser possível modificar o fluxo de CPAP (nasal ou oronasal), sem a necessidade de acordar o paciente. Um cateter de pressão faríngea e broncoscópio pediátrico ultra-fino 
foram introduzidos por orifícios independentes através da máscara. O sono foi induzido com baixas doses de midazolam. O CPAP foi titulado até a pressão terapêutica durante as rotas oronasal e nasal. O CPAP foi então reduzido para induzir limitação de fluxo aéreo estável na rota oronasal e abruptamente mudado para a rota nasal e vice-versa. Adicionalmente, o experimento foi repetido com o uso de uma fita selando a boca do paciente a fim de bloquear a transmissão de pressão pela cavidade oral. Resultados: A pressão de titulação de CPAP foi maior na rota oronasal quando comparada à nasal $(p=0,005)$. Cinco de 11 pacientes, com uma alta porcentagem de respiração oral (>25\%), não obtiveram sucesso na titulação do CPAP com máscara oronasal. Durante limitação de fluxo aéreo estável o pico de fluxo inspiratório foi menor, o delta de pressão faríngea e a resistência inspiratória da via aérea superior foram maiores, enquanto as dimensões nas regiões retropalatal e retroglossal foram menores na rota oronasal comparada à nasal $(p<0,05$ para todas as comparações). As diferenças foram observadas mesmo em pacientes sem respiração oral e foram abolidas quando selamos a boca do paciente com uma fita $(n=6)$. Conclusão: Respiração oral e transmissão de pressão positiva pela cavidade oral comprometem a eficácia do CPAP com máscara oronasal. 
Descritores: apneia do sono tipo obstrutiva, pressão positiva contínua nas vias aéreas, terapêutica, máscaras, endoscopia, transtornos do sono. 


\section{Abstract}

Weaver, FMLV. Evaluation of the effectiveness of oronasal vs nasal mask with use of positive pressure for the obstructive sleep apnea treatment. [thesis]. São Paulo: "Faculdade de Medicina, Universidade de São Paulo"; 2018.

BACKGROUND: Continuous Positive Airway Pressure (CPAP) is the gold standard treatment for obstructive sleep apnea (OSA) and was conceived to be applied by nasal route only. Oronasal mask is frequently used in clinical practice but the effectiveness varies for unknown mechanisms. We hypothesized that oral breathing and pressure transmission through the mouth compromises oronasal CPAP efficacy. METHODS: Thirteen OSA patients, well adapted to oronasal CPAP, were monitored by full polysomnography, pharyngeal pressure catheter and nasoendoscopy. Patients slept with an oronasal mask with sealed nasal and oral compartments. Sleep was induced with low doses of midazolam. CPAP was titrated during both oronasal and nasal routes. CPAP was then reduced to induce stable airflow limitation and abruptly switched to the alternate route. In addition, a tape sealing the mouth was used to block pressure transmission to the oral cavity. RESULTS: Best titrated CPAP was higher in oronasal than nasal route $(p=0.005)$. Five out of 11 patients with a high percentage of oral breathing ( $>25 \%)$ failed to 
achieve stable breathing during oronasal CPAP titration. During stable flow limitation, inspiratory peak flow was lower, driving pressure and upper airway inspiratory resistance were higher, retropalatal and retroglossal dimensions were smaller in oronasal compared to nasal route ( $p<0.05$ for all comparisons). Differences were observed even among patients with no oral flow and were abolished when a tape sealing the mouth was used $(n=6)$. CONCLUSION: Oral breathing and transmission of positive pressure through the mouth compromises oronasal CPAP.

Descriptors: obstructive sleep apnea, continuous positive airway pressure, therapeutics, masks, endoscopy, sleep disorders. 
1. INTRODUÇÃO 


\section{Introdução}

1.1 Apneia obstrutiva do sono

A apneia obstrutiva do sono (AOS) é um distúrbio respiratório caracterizado por episódios repetidos de obstrução parcial ou total da via aérea superior (VAS) durante o sono, levando respectivamente a hipopneias e apneias $^{1}$. A polissonografia (PSG) é o exame padrão ouro para o diagnóstico da AOS e consiste no registro simultâneo de variáveis do eletroencefalograma, eletro-oculograma e do eletromiograma para estagiamento do sono e de variáveis respiratórias como oximetria de pulso, movimentação torácica e abdominal, cânula de pressão e termistor (para registro do fluxo aéreo) e roncos para avaliação dos eventos respiratórios ${ }^{1}$. Além do registro de posição corporal, movimentação de perna e eletrocardiograma para avaliação de outros distúrbios do sono. A apneia do sono se caracteriza por uma redução $\geq 90 \%$ no sinal de fluxo respiratório do termistor com duração mínima de 10 segundos $^{2}$. A hipopneia se caracteriza por uma redução parcial de fluxo aéreo $(\geq 30 \%)$ no sinal de fluxo respiratório da cânula de pressão nasal por pelo menos 10 segundos, associada a dessaturação de pelo menos $3 \%$ e/ou despertar ${ }^{2}$. Classificamos os eventos como obstrutivos quando há esforço respiratório identificado nas cintas torácica e abdominal durante o evento.

A gravidade da apneia do sono é classificada pelo número de eventos respiratórios registrados na polissonografia expressa através do índice de apneia 
e hipopneia por hora de sono (IAH). O IAH normal em indivíduos adultos varia de 0-5 eventos/h. O IAH de 5 - 14, $15-29,>30$ eventos /h classifica a AOS em leve, moderada e grave, respectivamente ${ }^{2}$. A síndrome da apneia obstrutiva do sono é definida por um IAH entre 5 e 15 associada a sintomas como sonolência excessiva diurna e fadiga ou um $\mid A H>15$ independente da presença de sintomas ${ }^{3}$.

\subsection{Epidemiologia}

A prevalência da AOS vêm aumentando nos últimos anos com o aumento da obesidade e envelhecimento da população ${ }^{4,5}$. Um estudo de base populacional realizou polissonografia em laboratório em uma amostra representativa dos adultos da cidade de São Paulo (1042 indivíduos), mostrou uma prevalência de AOS de $10 \%$ em mulheres e de $25 \%$ em homens (considerando $\mid \mathrm{AH}>15)^{6}$. Mais recentemente, um estudo na Suíça realizou polissonografia domiciliar em 2121 indivíduos (também considerando $\mid A H>15$ ) encontrou uma prevalência de AOS de $23 \%$ nas mulheres e $50 \%$ nos homens ${ }^{7}$.

A AOS quando não tratada pode levar a múltiplas consequências que impactam diretamente na qualidade de vida, como sonolência excessiva diurna, dificuldade de concentração, fadiga, irritabilidade e sintomas depressivos. A AOS pode também ter consequências metabólicas e cardiovasculares, podendo contribuir para aumento da resistência à insulina e hipertensão arterial sistêmica, arritmias cardíacas e aumento da morbimortalidade ${ }^{8,9}$.

1.3 Fisiopatologia 
As razões para o colapso da via aérea superior são múltiplas. Existem diversos fatores anatômicos e neuromusculares envolvidos. A anatomia da via aérea dos humanos é composta pela cavidade nasal, nasofaringe, orofaringe, hipofaringe, laringe, traqueia e pulmões. A orofaringe é a única região que não é composta por arcabouço cartilaginoso/ósseo, portanto é a estrutura colapsável da via aérea. Essa região pode ser dividida em: retropalatal e retroglossal. O mecanismo de obstrução da VAS pode ser entendido utilizando o modelo de resistor de Starling ${ }^{10,11}$. O mesmo compreende dois tubos rígidos (nasofaringe e traqueia) separados por um tubo colapsável (orofaringe) que passa através de uma caixa selada (tecidos ao redor da faringe) (Figura 1). O padrão de fluxo que passa por esse tubo depende das forças aplicadas dentro e fora do segmento colapsável. As forças que tendem a fechar o tubo são: a pressão negativa inspiratória e a pressão aplicada pelos tecidos ao redor da faringe (caixa selada). As forças que tendem a abrir o tubo são: a tração traqueal e, principalmente, a musculatura dilatadora da faringe. Quando a pressão nasal e a pressão na traqueia são maiores do que a pressão dentro da faringe, o fluxo ocorre normalmente (Figura 1B). Quando a pressão nasal é maior do que a pressão dentro da faringe, mas a pressão da faringe é maior ou igual à pressão da traqueia, ocorre limitação de fluxo (Figura 1C). Quando a pressão nasal é menor ou igual à pressão da faringe, o fluxo não ocorre (Figura 1D). Portanto, a pressão crítica de fechamento (Pcrit) é a pressão na qual ocorre o colapso da faringe. 


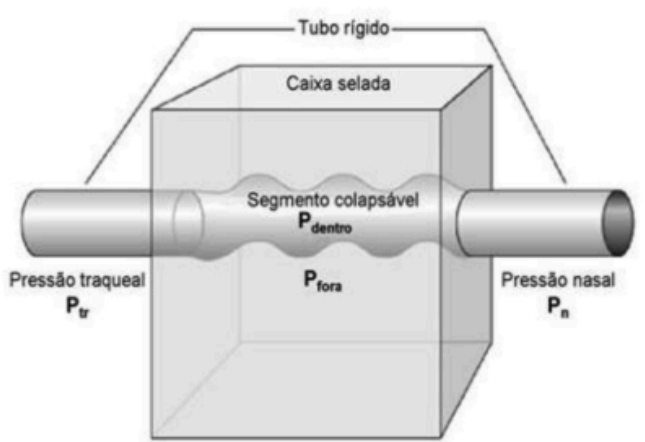

A

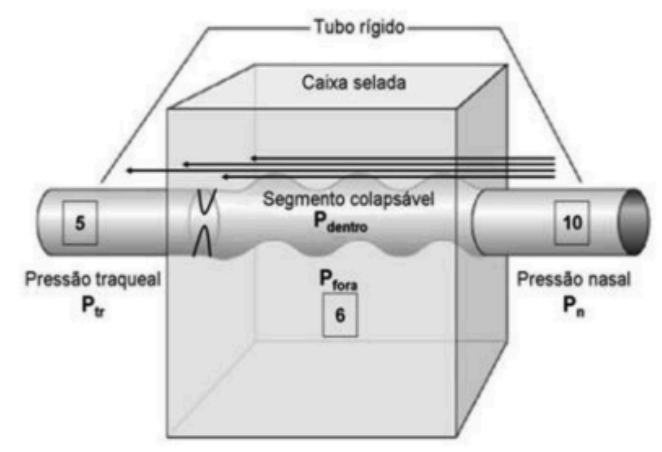

C

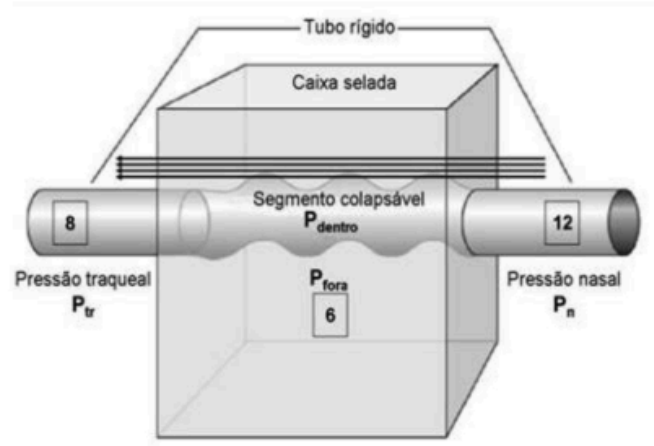

B

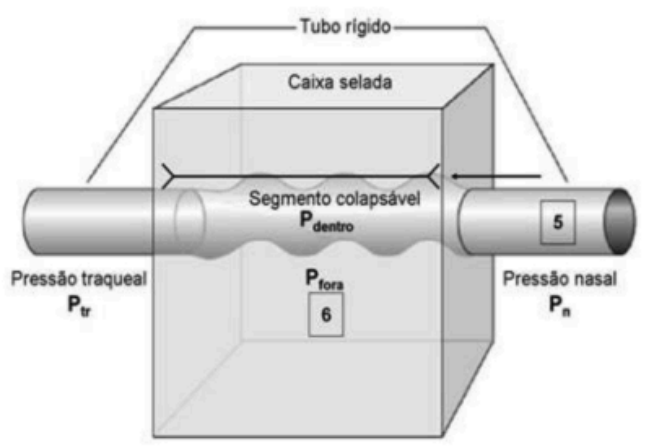

D

Figura 1: Desenho esquemático do resistor de Starling. A: caixa selada representa os tecidos ao redor da faringe, os dois tubos rígidos (nariz e traqueia) intermediados por um tubo colapsável (faringe). B: Sem limitação de fluxo, faringe pérvia. C: Com limitação de fluxo, colapso parcial da faringe. D: Colapso total da faringe. Esquema adaptado de Gleadhill et al. ${ }^{12}$

Vários fatores podem aumentar a colapsabilidade da VAS desde flexão da cabeça ${ }^{13}$, abertura da mandíbula, abertura de boca ${ }^{14}$ e respiração oral ${ }^{15}$. A respiração nasal é a via preferencial de pacientes saudáveis ${ }^{16,17}$. Nos pacientes com AOS estudos mostram um aumento da respiração oronasal ${ }^{18}$. A respiração oral aumenta a colapsabilidade da via aérea, pois desidrata a mucosa da faringe aumentando a tensão superficial ${ }^{19}$ e reduz a ativação de mecanorreceptores nasais e ativação do músculo genioglosso ${ }^{20}$. A abertura de boca desloca a mandíbula póstero-inferiormente reduzindo o diâmetro da VAS ${ }^{21}$ e o comprimento do músculo genioglosso ${ }^{22}$. A abertura da boca pode ou não estar relacionada com a respiração oral. 


\subsection{Tratamento}

\subsubsection{Tratamentos gerais}

O tratamento da AOS depende da avaliação da sua gravidade e do fenótipo do paciente. Em pacientes obesos ou com sobrepeso, a perda de peso é sempre incentivada independente da gravidade da $\mathrm{AOS}^{23}$. Evitar consumo de álcool, sedativos e dormir na posição lateral também devem ser recomendados.

Nos casos de AOS leve a moderada, existem várias opções terapêuticas como: aparelho de avanço mandibular ${ }^{24}$, terapia miofuncional ${ }^{25,26}$ e cirurgias como a uvulopalatofaringoplastia ${ }^{27}$, faringoplastia lateral ${ }^{28}$ e a estimulação do nervo hipoglosso ${ }^{29}$. O tratamento padrão ouro para a AOS moderada-grave é o CPAP $^{30}$. O CPAP foi idealizado por Sullivan em 1981, com o uso de uma máscara nasal ${ }^{31}$. A pressão seria transmitida na faringe posterior, projetando a língua e o palato mole anteriormente, assegurando a manutenção da abertura da VAS durante o sono, eliminando os eventos respiratórios obstrutivos (Figura 2). O uso regular do CPAP está associado com a diminuição dos sintomas da AOS, melhora da qualidade de vida e diminuição das complicações cardiovasculares ${ }^{32-34}$. 

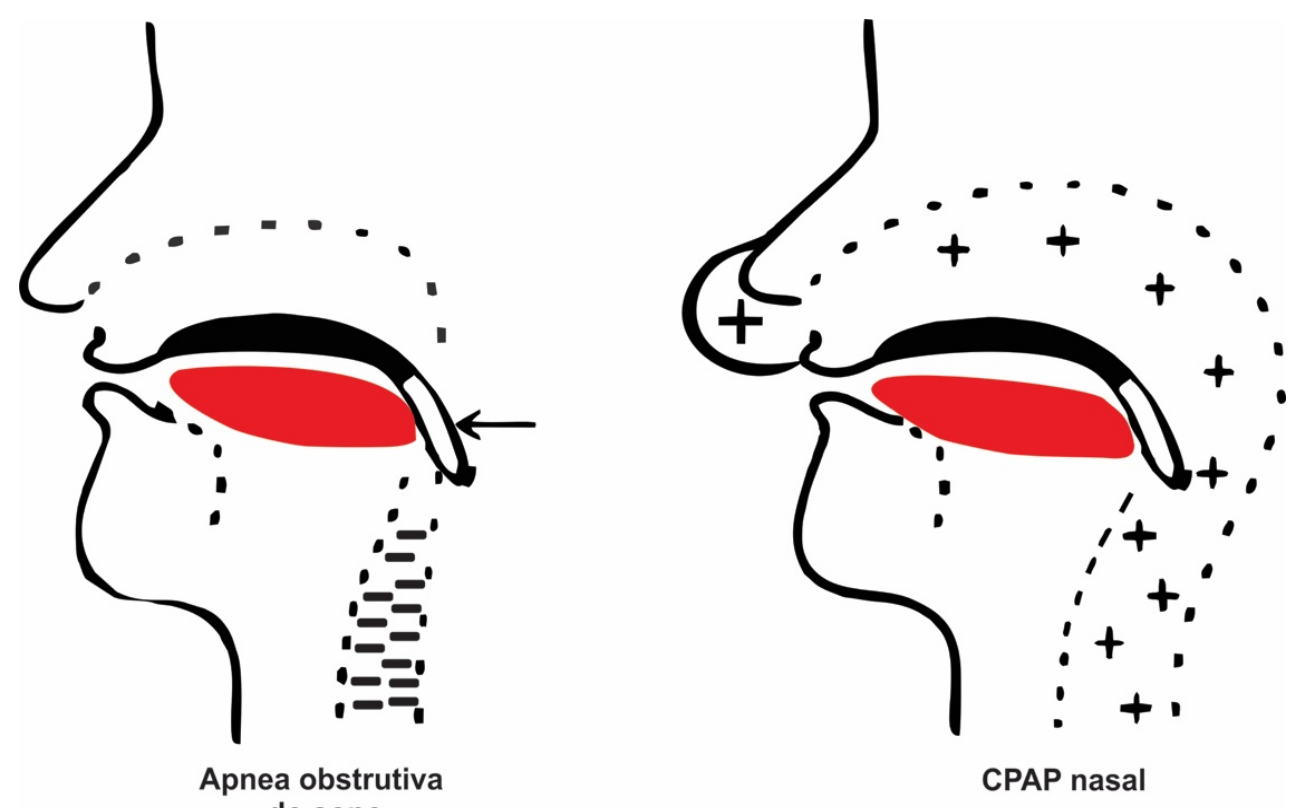

Figura 2: llustração funcionamento do CPAP desenvolvido por Sullivan. Fonte: Desenho adaptado de Sullivan, $1981^{31}$. llustra o paciente com apneia obstrutiva do sono (esquerda) e em seguida (à direita) em uso da pressão positiva com a via aérea superior completamente aberta

Porém os benefícios do tratamento da AOS com CPAP estão diretamente ligados ao seu uso regular. A adesão ao tratamento com CPAP é variável na literatura ${ }^{35,36}$. Vários fatores influenciam a adesão ao CPAP, incluindo nível sócio econômico, nível de compreensão da terapia, intensidade dos sintomas da AOS, nível de gravidades da AOS e a interface ${ }^{37-40}$.

\subsubsection{Interfaces}

Conforme descrito acima, o tratamento da AOS com CPAP foi idealizado utilizando máscara nasal. Com o passar dos anos novas interfaces surgiram na tentativa de aumentar a adesão ao tratamento com CPAP (Figura 3). 


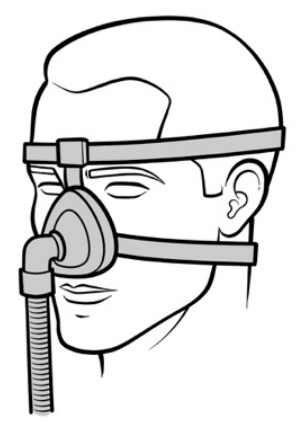

(A)

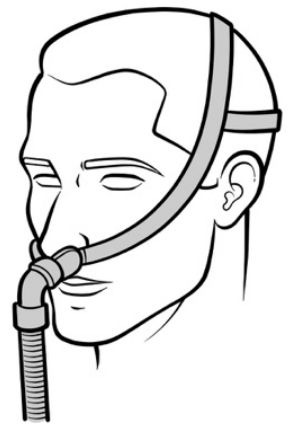

(B)

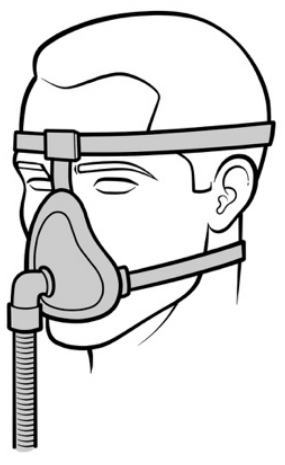

(C)

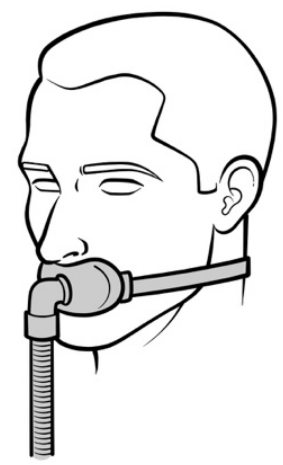

(D)

Figura 3: llustração dos tipos de interfaces. Máscara nasal $(A)$, pillow nasal $(B)$, máscara oronasal (C) e máscara oral (D). Fonte: Andrade et al. ${ }^{41}$

Muitos pacientes referem intolerância à máscara nasal devido a persistência de abertura bucal e respiração oronasal ${ }^{42}$. A máscara oronasal surgiu com o intuito de atender a esses pacientes e hoje representa $25 \%$ a $46 \%$ das máscaras utilizadas ${ }^{43,44}$. No entanto, a pressão transmitida pela cavidade oral viola os princípios propostos por Sullivan porque neutraliza a pressão positiva aplicada através do nariz ${ }^{45}$ (Figura 4). De acordo com essa visão, o CPAP com máscara oronasal poderia levar à falha na abertura da via aérea. 


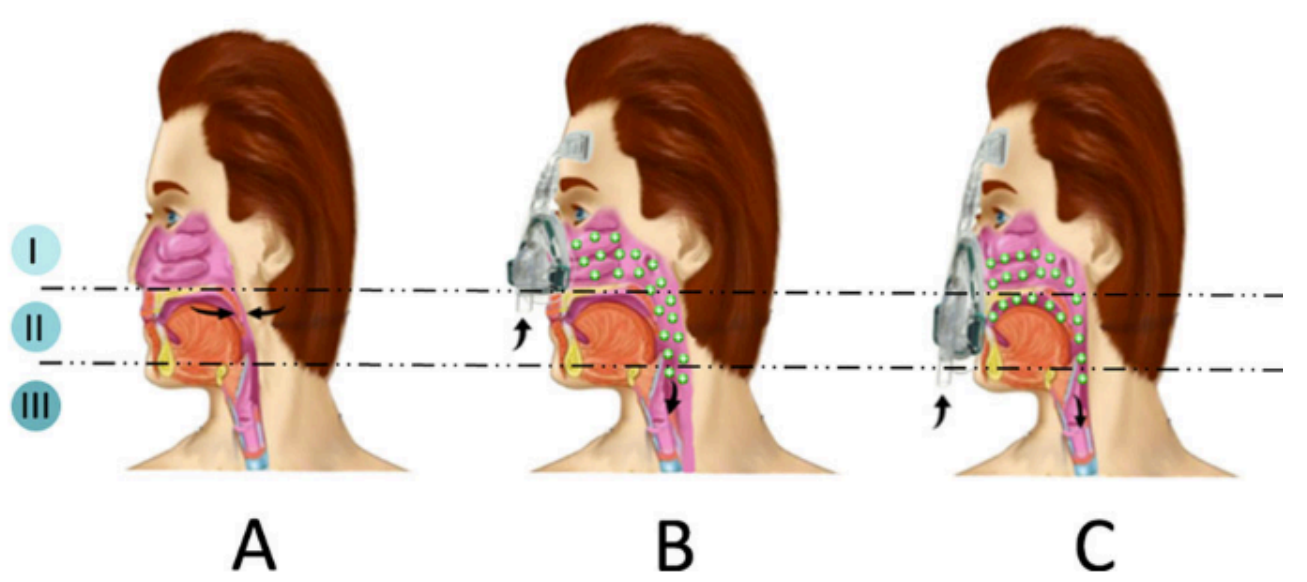

Figura 4: Desenho esquemático do funcionamento do CPAP com máscaras nasal e oronasal. Nível 1, cavidade nasal; nível 2, faringe; nível 3, traqueia. A- via aérea superior obstruída durante um evento obstrutivo. B- via aérea com o uso de PAP com máscara nasal, abrindo a via aérea superior efetivamente. C- via aérea com o uso de PAP com máscara oronasal que viola os princípios propostos por Sullivan, pois causa perda do gradiente pressórico - representado por círculos verdes. Fonte: Bahamman et al. ${ }^{45}$

Dando suporte a hipótese de que a máscara oronasal pode ser ineficaz para o tratamento da AOS com CPAP, Smith et al. ${ }^{11}$ estudaram seis pacientes com AOS grave e observaram que tanto a pressão utilizada em uma máscara nasal para abrir a VAS, quanto pressões maiores foram insuficientes para abrir a VAS quando utilizado uma máscara oronasal. Essa preocupação foi inicialmente descartada por Sanders et al. ${ }^{46}$ e Prosise et al. ${ }^{47}$ que estudaram pacientes intolerantes à máscara nasal e concluíram que a máscara oronasal era bem tolerada e capaz de tratar AOS adequadamente na pratica clínica. Após essa controvérsia há mais de 20 anos, houve uma lacuna na literatura que coincidiu com o aumento e popularização da máscara oronasal.

Nosso grupo do Laboratório do Sono passou a se interessar pelo assunto a partir da observação de um paciente de 69 anos, com AOS grave que mantinha queixa de sonolência excessiva diurna a despeito do tratamento adequado de CPAP com máscara oronasal ${ }^{48}$. Foi realizado um exame de titulação de CPAP 
com a máscara oronasal que evidenciou um IAH residual de 32 eventos/hora a despeito de uma pressão de $16 \mathrm{cmH}_{2} \mathrm{O}$. Levantada a hipótese de que a máscara oronasal poderia influenciar a efetividade; realizamos uma titulação de CPAP, onde na primeira metade da noite foi utilizada uma máscara nasal e na segunda metade uma oronasal. Com a máscara nasal, uma pressão de $7 \mathrm{cmH}_{2} \mathrm{O}$ foi suficiente para eliminar a AOS. Em contraste, na segunda metade, com a máscara oronasal não foi possível eliminar os eventos obstrutivos (Figura 5). Para esclarecer os mecanismos envolvidos, foi realizada uma sonoendoscopia com as duas máscaras estudadas e observado o colapso em região retroglossal quando a máscara oronasal foi utilizada. 


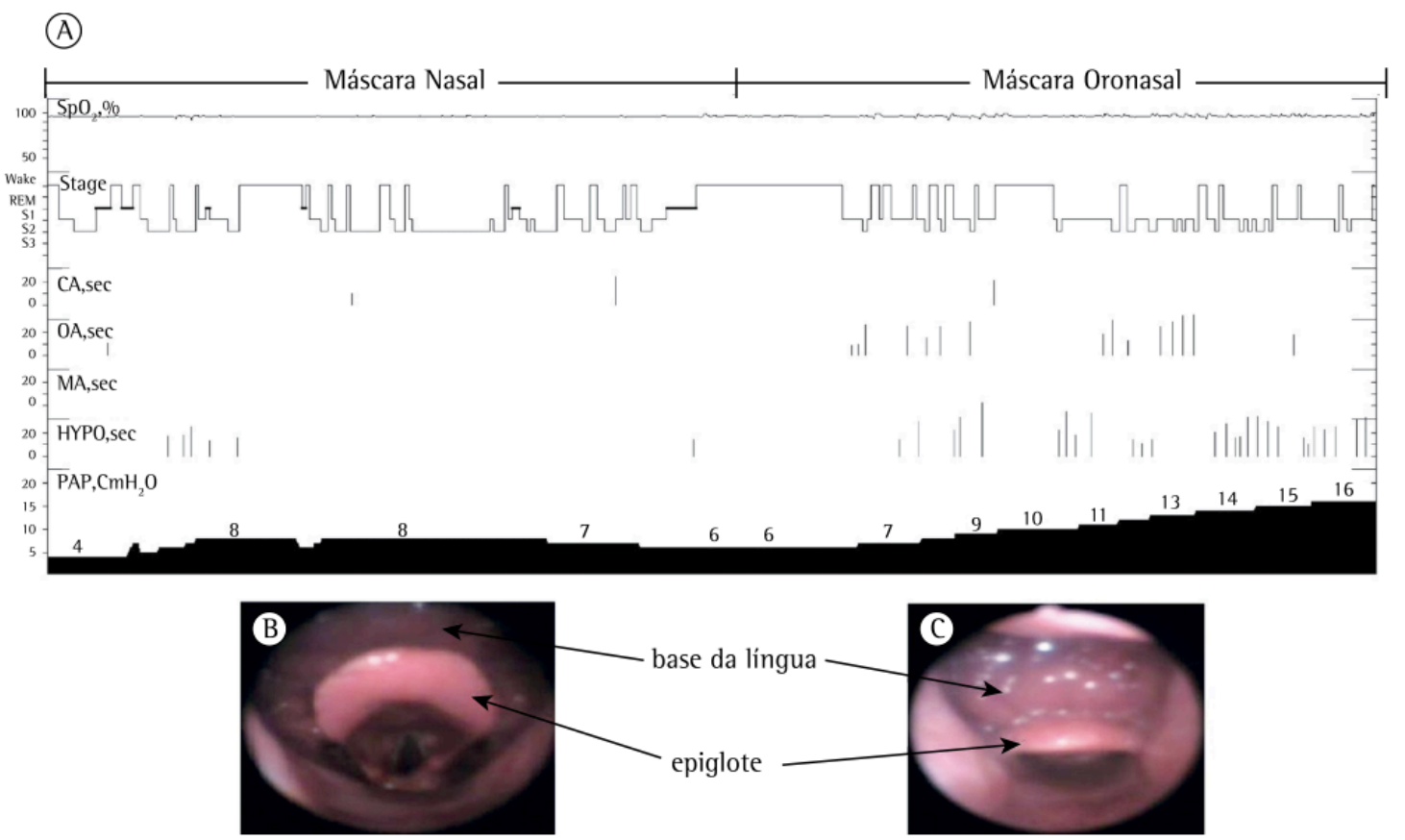

Figura 5: Em A, o hipnograma da polissonografia com titulação de CPAP com máscara nasal e oronasal acompanhada de nasoendoscopia. Imagens da sonoendoscopia - na parte inferior, usando máscara nasal e oronasal. Durante a primeira parte do exame de titulação, CPAP nasal de $7 \mathrm{cmH}_{2} \mathrm{O}$ controlou adequadamente os eventos obstrutivos. Durante a segunda parte do exame com a máscara oronasal houve persistência dos eventos obstrutivos, a despeito de uma elevação da pressão até $16 \mathrm{cmH}_{2} \mathrm{O}$. $\mathrm{Em} \mathrm{B}$, a imagem de endoscopia capturada com máscara nasal mostra uma orofaringe aberta. Em contraste, em $\mathrm{C}$, a imagem tirada com a máscara oronasal com pressão de $16 \mathrm{cmH}_{2} \mathrm{O}$ mostra a base da língua disposta posteriormente, empurrando a epiglote e estreitando significativamente a luz da via aérea. Definição das abreviaturas: $\mathrm{SpO}_{2}=$ saturação arterial de oxigênio medido por oxímetro de pulso. $\mathrm{CA}=$ apneia

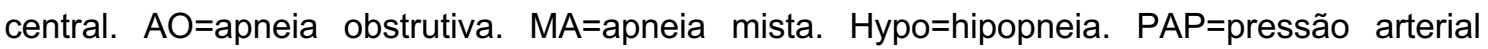
pulmonar. REM=movimento rápido dos olhos. Os eventos respiratórios são mostrados em segundos. Fonte: Schorr et al. ${ }^{48}$

Após esse relato de caso, realizamos uma revisão de literatura sobre o impacto das interfaces utilizadas no tratamento com PAP, publicada no Jornal Brasileiro de Pneumologia ${ }^{49}$. Encontramos seis estudos que avaliavam a eficácia das máscaras no uso de CPAP (Tabela 1). 
Tabela 1: Estudos que mostram a eficácia dos diferentes tipos de máscaras no tratamento da AOS

\begin{tabular}{|c|c|c|c|c|c|c|}
\hline Autores & $\begin{array}{c}\text { Desenho } \\
\text { Experimental }\end{array}$ & $\mathbf{n}$ & Máscara & $\begin{array}{l}\text { IAH basal } \\
(\mathrm{e} / \mathrm{h})\end{array}$ & $\begin{array}{l}\text { IAH residual/Pressão de } \\
\text { CPAP }\end{array}$ & Desempenho \\
\hline \multirow{2}{*}{$\begin{array}{l}\text { Beecroft, } \\
\text { et } \\
\text { al., } 2003^{50}\end{array}$} & \multirow[t]{2}{*}{ Observacional } & \multirow[t]{2}{*}{98} & \multirow[t]{2}{*}{$\begin{array}{l}\mathrm{N}, \mathrm{ONe} \\
\mathrm{O}\end{array}$} & \multirow[t]{2}{*}{$40,6 \pm 25,8$} & $\begin{array}{l}\text { Pressão de CPAP: nasal } \\
7,7 \pm 2,1 \text { vs oronasal } 9,7 \pm 3,2 \text { vs } \\
\text { oral } 8,8 \pm 2,0 \mathrm{cmH}_{2} \mathrm{O}(\mathrm{ns})\end{array}$ & \multirow[t]{2}{*}{$\mathrm{N} \approx \mathrm{O} N \approx \mathrm{O}$} \\
\hline & & & & & $\begin{array}{c}\text { IAH residual: nasal } 6,7 \pm 13,3 \text { vs } \\
\text { oronasal } 9,8 \pm 12,8 \text { vs oral } \\
10,9 \pm 20,1 \mathrm{e} / \mathrm{h}(\mathrm{ns})\end{array}$ & \\
\hline \multirow[t]{2}{*}{$\begin{array}{l}\text { Borel, et } \\
\text { al., } 2013^{43}\end{array}$} & \multirow[t]{2}{*}{ Observacional } & \multirow[t]{2}{*}{2311} & \multirow[t]{2}{*}{$\begin{array}{l}\text { N, ON E } \\
\text { PN }\end{array}$} & $41,0 \pm 21,0$ & $\begin{array}{c}\text { Pressão de CPAP } \\
\text { aproximada: nasal } 8,8 \text { vs } \\
\text { oronasal } 9,6(p<0,05) \text { vs pillow } \\
8,3 \mathrm{cmH}_{2} \mathrm{O}(p<0,05) .\end{array}$ & \multirow[t]{2}{*}{$\mathrm{P}>\mathrm{N}>\mathrm{ON}$} \\
\hline & & & & & IAH residual: ND & \\
\hline \multirow[t]{2}{*}{$\begin{array}{l}\text { Bettinzoli, } \\
\text { et al., } \\
2014^{51}\end{array}$} & \multirow[t]{2}{*}{ Observacional } & \multirow[t]{2}{*}{109} & \multirow[t]{2}{*}{$\mathrm{NeON}$} & \multirow[t]{2}{*}{$41,1 \pm 20,5$} & $\begin{array}{c}\text { Pressão de CPAP: nasal } \\
10,0 \pm 2,0 \text { vs oronasal } 11,2 \pm 2,1 \\
\mathrm{CmH}_{2} \mathrm{O}(\mathrm{p}<0,05)\end{array}$ & \multirow[t]{2}{*}{$\mathrm{N}>\mathrm{ON}$} \\
\hline & & & & & $\begin{array}{l}\text { IAH residual: nasal } 2,6 \pm 2,5 \text { vs } \\
\text { oronasal } 4,5 \pm 4,4 \mathrm{e} / \mathrm{h}(\mathrm{p}<0,05)\end{array}$ & \\
\hline \multirow[t]{2}{*}{$\begin{array}{l}\text { Teo, et } \\
\text { al.,2011 }\end{array}$} & \multirow[t]{2}{*}{$\begin{array}{c}\text { Randomizado } \\
\text { Cross Over }\end{array}$} & \multirow[t]{2}{*}{24} & \multirow[t]{2}{*}{$\mathrm{Ne} \mathrm{ON}$} & \multirow[t]{2}{*}{$47,0 \pm 15,2$} & $\begin{array}{c}\text { Pressão de CPAP: nasal } \\
11,4 \pm 1,9 \text { vs oronasal } 11,8 \pm 2,4 \\
\mathrm{cmH}_{2} \mathrm{O} \text { (ns) }\end{array}$ & \multirow[t]{2}{*}{$N>O N$} \\
\hline & & & & & $\begin{array}{l}\text { IAH residual: nasal } 5,3 \pm 3,4 \text { vs } \\
\text { oronasal } 11,0 \pm 10,4 \mathrm{e} / \mathrm{h}(\mathrm{p}=0,01)\end{array}$ & \\
\hline \multirow[t]{2}{*}{$\begin{array}{l}\text { Bakker, et } \\
\text { al., } 2012^{53}\end{array}$} & \multirow[t]{2}{*}{$\begin{array}{c}\text { Randomizado } \\
\text { Cross Over }\end{array}$} & \multirow[t]{2}{*}{12} & \multirow[t]{2}{*}{$\begin{array}{l}\mathrm{N}, \mathrm{ON} \mathrm{e} \\
\mathrm{ONQ}\end{array}$} & \multirow[t]{2}{*}{$59,8 \pm 28,6$} & $\begin{array}{l}\text { Pressão de CPAP: nasal } 11,0 \\
\text { vs oronasal } 11,1 \text { vs oronasal } \\
\text { +queixeira } 11,1 \text { (ns). }\end{array}$ & \multirow[t]{2}{*}{$N>O N \approx O Q$} \\
\hline & & & & & $\begin{array}{c}\text { IAH residual: nasal } 0,61 / / \mathrm{QR} \\
1,1 \mathrm{vs} \text { oronasal } 2,4 / \mathrm{IQR} 3,7 \mathrm{vs} \\
\text { oronasal + queixeira } 1,7 / \mathrm{IQR} \\
4,0 \mathrm{e} / \mathrm{h}(\mathrm{p}=0,03) .\end{array}$ & \\
\hline \multirow[t]{2}{*}{$\begin{array}{l}\text { Ebben, et } \\
\text { al., } 2012^{54}\end{array}$} & $\begin{array}{l}\text { Randomizado } \\
\text { Aberto }\end{array}$ & \multirow[t]{2}{*}{55} & \multirow[t]{2}{*}{$\begin{array}{l}\mathrm{N}, \mathrm{ON} \text { e } \\
\mathrm{PN}\end{array}$} & \multirow[t]{2}{*}{ ND } & $\begin{array}{l}\text { Pressão de CPAP: na AOS } \\
\text { moderada a máscara oronasal } \\
\text { requereu }+2,8 \pm 2,1 \mathrm{cmH}_{2} \mathrm{O} \text { e na } \\
\text { AOS grave }+6,0 \pm 3,2 \mathrm{cmH}_{2} \mathrm{O} \text { do } \\
\text { que a máscara nasal }(\mathrm{p}<0,001) \text {. }\end{array}$ & \multirow[t]{2}{*}{$\mathrm{N} \approx \mathrm{P}>\mathrm{ON}$} \\
\hline & & & & & IAH residual: ND & \\
\hline
\end{tabular}

- Estes artigos serão citados na tabela 2. ND = Dado não disponível. $\mathrm{N}=$ máscara nasal, $\mathrm{ON}=$ máscara oronasal, $\mathrm{O}=$ máscara oral, $\mathrm{P}=$ pillow nasal, $\mathrm{OQ}=$ oronasal + queixeira, $\mathrm{ns}=$ diferença não estatisticamente significante. $I Q R=$ intervalo interquartil. $>$ (superior) $\mathrm{e} \approx$ (semelhante). $A$ coluna desempenho representa uma síntese do artigo. Fonte: Andrade et al. ${ }^{49}$

Dos seis estudos descritos na Tabela 1, encontramos três randomizados e três observacionais ${ }^{43,50,51}$. Dois estudos randomizados eram cruzados ${ }^{52,53}$ e um 
era aberto ${ }^{54}$. Apenas um estudo avaliou a máscara oral que é pouco utilizada na prática clínica ${ }^{50}$. Nos três estudos observacionais, os pacientes incluídos tinham AOS de moderada a grave. Beecroft et al. ${ }^{50}$, estudaram 98 pacientes que tiveram a opção de escolher as máscaras nasal, oral e oronasal para o tratamento com PAP. Não só a maior parte dos pacientes escolheu a máscara nasal (66\%), como um terço dos pacientes que optaram pela máscara oral decidiram trocar para máscara nasal durante o seguimento. Apesar das diferenças em pressão terapêutica e IAH residual entres as máscaras não terem atingido valor significativo, é importante observar que a máscara nasal utilizou menores pressões de CPAP, em média $2 \mathrm{~cm} \mathrm{H} 2 \mathrm{O}$ menor, e obteve menor IAH residual. Borel et al. ${ }^{43}$ realizou um estudo observacional com uma coorte de 2.311 pacientes onde a proporção de uso de máscara nasal, oronasal e pillow nasal foi de, respectivamente, $62 \%, 26 \%$ e $11 \%$. A pressão de CPAP foi estatisticamente diferente nos três grupos, sendo, em ordem decrescente, maior no grupo oronasal, nasal e pillow nasal. Análise multivariada observou que a máscara oronasal foi associada a uma pior adesão ao CPAP. Bettinzoli et al. ${ }^{51}$ avaliaram 109 pacientes que escolheram entre a máscara nasal $(61 \%)$ e oronasal $(38 \%)$. A máscara oronasal foi associada à maior pressão e maior IAH residual. Todos os estudos observacionais apontaram um pior desempenho da máscara oronasal $^{43,50,51}$.

Os estudos randomizados também encontraram resultados semelhantes. Teo et al. ${ }^{52}$ randomizaram pacientes sem obstrução nasal, virgens de tratamento para duas noites de titulação: uma com máscara nasal e outra oronasal. A máscara oronasal apresentou um IAH residual aumentado. Apesar de não atingir valor estatístico significativo $(p=0,46), 43 \%$ dos pacientes apresentaram um 
aumento de $2 \mathrm{cmH}_{2} \mathrm{O}$ na pressão de CPAP quando a máscara oronasal foi utilizada. Bakker et al. ${ }^{53}$ randomizaram pacientes com AOS com indicação para tratamento com CPAP para as máscaras nasal e oronasal utilizando CPAP automático e fixo. Adicionalmente, para avaliar se a diferença de performances entre as máscaras era associada a um deslocamento posterior da mandíbula, foi acrescentado um estabilizador de mandíbula associado à máscara oronasal. Resultados semelhantes foram obtidos entre a máscara oronasal e oronasal com estabilizador, sendo essas duas inferiores à máscara nasal quanto ao IAH residual. Ebben et al. ${ }^{54}$ randomizou 55 pacientes para máscara nasal e oronasal. Os pacientes realizaram titulação de CPAP com as máscaras iniciais e após três semanas houve mudança para a máscara complementar, porém sem nova titulação. Desta forma foi encontrado um IAH residual aumentado com a máscara oronasal, sugerindo que uma nova titulação deve ser realizada quando ocorrer qualquer mudança de interface. Os estudos randomizados também apontaram para um pior desempenho da máscara oronasal. Porém é importante ressaltar que os pacientes não foram avaliados quanto à rota de respiração preferencial. Dois estudos não avaliaram adequadamente presença de obstrução em VAS ${ }^{53,54}$ e em um estudo os pacientes com obstrução nasal (que seriam os que teoricamente apresentariam beneficio com a máscara oronasal) foram excluídos ${ }^{52}$.

Quanto à adesão às máscaras nasal e oronasal, foram encontrados oito estudos (Tabela 2) que também apontaram um pior desempenho na máscara oronasal. 
Tabela 2: Estudos que mostram o impacto na adesão com os diferentes tipos de máscaras no tratamento da AOS

\begin{tabular}{|c|c|c|c|c|c|c|}
\hline Autores & $\begin{array}{l}\text { Desenho } \\
\text { Experimental }\end{array}$ & $\mathbf{n}$ & Máscara & $\begin{array}{l}\text { IAH basal } \\
(\mathrm{e} / \mathrm{h})\end{array}$ & Adesão & Desempenho \\
\hline $\begin{array}{l}\text { Beecroft, et } \\
\text { al.,2003 }\end{array}$ & Observacional & 98 & $\begin{array}{c}\mathrm{N}, \mathrm{ON} \text { e } \\
\mathrm{O}\end{array}$ & $40,6 \pm 25,8$ & $\begin{array}{c}\text { Nasal } 5,8 \pm 1,7 \text { vs oronasal } \\
3,8 \pm 3,0 \text { vs oral } 6,6 \pm 0,8 \\
\text { noites/semana do período } \\
\text { de aclimatização }(p<0,01) \text {. }\end{array}$ & $\mathrm{N} \approx \mathrm{O}>\mathrm{ON}$ \\
\hline $\begin{array}{l}\text { Borel, et } \\
\text { al., } 2013^{43}\end{array}$ & Observacional & 2311 & $\begin{array}{l}\text { N, ON e } \\
\text { PN }\end{array}$ & $41,0 \pm 21,0$ & $\begin{array}{l}\text { Nasal } 5,7 \pm 2,2 \text { vs oronasal } \\
5,1 \pm 2,3 \mathrm{~h} / \text { noite }(p<0,0001)\end{array}$ & $\mathrm{N} \approx \mathrm{P}>\mathrm{ON}$ \\
\hline $\begin{array}{l}\text { Bachour, et } \\
\text { al., } 2013^{55}\end{array}$ & Observacional & 703 & $\begin{array}{l}\mathrm{N}, \mathrm{ON} \text { e } \\
\mathrm{PN}\end{array}$ & ND & $\begin{array}{c}\text { Nasal } 5,8 \pm 2,8 \text { vs oronasal } \\
4,7 \pm 2,8 \text { vs pillow } 4,7 \pm 3,2 \\
\text { h/noite } \\
(p<0,001) .\end{array}$ & $N>P \approx O N$ \\
\hline $\begin{array}{l}\text { Mortimore, } \\
\text { et al., } 1998^{40}\end{array}$ & $\begin{array}{l}\text { Randomizado } \\
\text { Cross Over }\end{array}$ & 20 & $\mathrm{Ne} \mathrm{ON}$ & $34,0 \pm 5,2$ & $\begin{array}{l}\text { Nasal } 5,3 \pm 0,4 \text { vs oronasal } \\
4,3 \pm 0,5 \mathrm{~h} / \text { noite }(p=0,01) .\end{array}$ & $N>O N$ \\
\hline $\begin{array}{l}\text { Massie e } \\
\text { Hart, } 2003^{56}\end{array}$ & $\begin{array}{l}\text { Randomizado } \\
\text { Cross Over }\end{array}$ & 39 & $\mathrm{~N}$ e PN & $47,1 \pm 35,4$ & $\begin{array}{c}\text { \% Dias utilizados: nasal } \\
85,7 \pm 23,5 \text { vs pillow } \\
94,1 \pm 8,3 \%(\mathrm{p}=0,02)\end{array}$ & $P>N$ \\
\hline $\begin{array}{l}\text { Ryan, et al., } \\
2011^{57}\end{array}$ & $\begin{array}{l}\text { Randomizado } \\
\text { Cross Over }\end{array}$ & 21 & $\mathrm{~N}$ e PN & $52,4 \pm 21,6$ & $\begin{array}{c}\text { Nasal } 5,1 \pm 1,9 \text { vs pillow } \\
5,0 \pm 1,7(\mathrm{~ns})\end{array}$ & $P \approx N$ \\
\hline $\begin{array}{l}\text { Anderson, } \\
\text { et al., } 2003^{58}\end{array}$ & $\begin{array}{l}\text { Randomizado } \\
\text { Cross Over }\end{array}$ & 25 & $\mathrm{NeO}$ & $85,0 \pm 36,0$ & $\begin{array}{c}\text { Nasal } 3,8 \text { vs oral } 3,5 \mathrm{~h} / \text { noite } \\
\text { (ns). }\end{array}$ & $\mathrm{N} \approx 0$ \\
\hline $\begin{array}{l}\text { Khanna, et } \\
\text { al., } 2003^{59}\end{array}$ & $\begin{array}{l}\text { Randomizado } \\
\text { Aberto }\end{array}$ & 38 & $\mathrm{NeO}$ & $\begin{array}{c}\text { Nasal } \\
63,0 \pm 39 \text { Oral } \\
58,5 \pm 34,8\end{array}$ & $\begin{array}{l}1^{\circ} \text { mês: nasal } 4,3 \pm 2,6 \text { vs } \\
\text { oral } 4,6 \pm 2,1 \mathrm{~h} / \text { noite (ns). } \\
2^{\circ} \text { mês: nasal } 4,6 \pm 2,5 \text { vs } \\
\text { oral } 5,5 \pm 2,6 \mathrm{~h} / \text { noite (ns). }\end{array}$ & $N \approx 0$ \\
\hline
\end{tabular}

$\mathrm{ND}=$ Dado não disponível. $\mathrm{N}=$ máscara nasal, $\mathrm{ON}=$ máscara oronasal, $\mathrm{O}=$ máscara oral, $\mathrm{P}=$ pillow nasal, $\mathrm{ns}=$ diferença não estatisticamente significante. $>$ (superior) e $\approx$ (semelhante). $\mathrm{A}$ coluna desempenho representa uma síntese do artigo. Fonte: Andrade et al. ${ }^{49}$

Dois desses estudos também foram descritos na Tabela 1, pois apresentavam também dados relevantes quanto à efetividade ${ }^{43,50}$. Dos 8 estudos incluídos na Tabela 2, três eram observacionais, cinco randomizados sendo quatro cruzados e um aberto. Os três estudos observacionais somam 3.112 pacientes e revelam uma pior adesão com o uso da máscara oronasal quando comparada à nasal ${ }^{43,50,55}$. Dos estudos randomizados, apenas um compara máscara nasal vs oronasal ${ }^{40}$. Mortimore et al. ${ }^{40}$ realizou titulação com a máscara nasal e depois randomizou os pacientes para as máscaras nasal e oronasal por 
dois períodos de quatro semanas. A adesão com a máscara nasal foi 1 hora maior e 19 dos 20 pacientes preferiram a máscara nasal ao final do estudo. Os demais estudos avaliaram a máscara nasal com a tipo pillow ou a máscara oral, sendo que a última é pouco utilizada na prática clínica.

Com o surgimento de novos estudos avaliando o impacto das interfaces, nosso grupo expandiu a revisão sistemática e publicou uma metanálise comparando o CPAP com máscara nasal (CPAP nasal) vs CPAP com máscara oronasal (CPAP oronasal) em 2018 ${ }^{60}$. Por entendermos que a máscara oral é pouco utilizada na prática clínica, a mesma não foi estudada.

Foram avaliados cinco estudos randomizados e oito não randomizados que avaliavam nível de CPAP e/ou IAH residual e/ou adesão ao CPAP. As informações de cada estudo estão descritas nas Tabelas 3 e 4. 
Tabela 3: Estudos elegíveis na metanálise comparando máscara nasal vs oronasal

\begin{tabular}{|c|c|c|c|c|c|c|c|}
\hline Estudo & $\begin{array}{l}\text { Tipo de } \\
\text { estudo }\end{array}$ & $\begin{array}{l}\text { Critério de } \\
\text { inclusão }\end{array}$ & $\mathbf{n}$ & Máscara & $\begin{array}{l}\text { Tempo } \\
\text { com cada } \\
\text { máscara }\end{array}$ & $\begin{array}{c}\text { Tipo de } \\
\text { titulação }\end{array}$ & $\begin{array}{c}\text { Avaliação } \\
\text { final }\end{array}$ \\
\hline $\begin{array}{l}\text { Mortimore } \\
1998^{40}\end{array}$ & Randomizado & AOS & 20 & $\begin{array}{l}\text { Nasal vs } \\
\text { oronasal }\end{array}$ & 4 noites & Automático & $\begin{array}{l}\text { Adesão } \\
\text { CPAP }\end{array}$ \\
\hline $\begin{array}{l}\text { Teo } \\
2011^{52}\end{array}$ & Randomizado & IDR>15 e/h & 24 & $\begin{array}{l}\text { Nasal vs } \\
\text { oronasal }\end{array}$ & 1 noite & Automático & $\begin{array}{l}\text { Nível } \\
\text { CPAP } \\
\text { IAH } \\
\text { residual }\end{array}$ \\
\hline $\begin{array}{l}\text { Ebben } \\
2012^{54}\end{array}$ & Randomizado & $\mathrm{IAH}>5 \mathrm{e} / \mathrm{h}$ & 55 & $\begin{array}{l}\text { Nasal vs } \\
\text { oronasal } \\
\text { vs pillow }\end{array}$ & 1 noite & Manual & $\begin{array}{l}\text { Nível } \\
\text { CPAP } \\
\text { IAH } \\
\text { residual }\end{array}$ \\
\hline $\begin{array}{l}\text { Bakker } \\
2012^{53}\end{array}$ & Randomizado & $\mathrm{IAH}>30 \mathrm{e} / \mathrm{h}$ & 12 & $\begin{array}{c}\text { Nasal vs } \\
\text { oronasal } \\
v s \\
\text { oronasal+ } \\
\text { queixeira } \\
\end{array}$ & $\begin{array}{l}2 \text { ou } 3 \\
\text { noites }\end{array}$ & $\begin{array}{l}\text { Automático/ } \\
\text { CPAP com } \\
\text { pressão titulada } \\
\text { manualmente }\end{array}$ & $\begin{array}{l}\text { Nível } \\
\text { CPAP } \\
\text { IAH } \\
\text { residual }\end{array}$ \\
\hline $\begin{array}{l}\text { Ebben } \\
2014^{61}\end{array}$ & Randomizado & $\mathrm{IAH} \geq 16 \mathrm{e} / \mathrm{h}$ & 14 & $\begin{array}{l}\text { Nasal vs } \\
\text { oronasal }\end{array}$ & 1 noite & Manual & $\begin{array}{l}\text { Nível } \\
\text { CPAP } \\
\text { IAH } \\
\text { residual }\end{array}$ \\
\hline $\begin{array}{l}\text { Beecroft } \\
2003^{50}\end{array}$ & $\begin{array}{c}\text { Não- } \\
\text { Randomizado }\end{array}$ & $\mathrm{IAH}>5 \mathrm{e} / \mathrm{h}$ & 98 & $\begin{array}{c}\text { Nasal vs } \\
\text { oronasal } \\
\text { vs oral }\end{array}$ & 1 noite & Manual & $\begin{array}{l}\text { Nível } \\
\text { CPAP } \\
\text { Adesão } \\
\text { CPAP }\end{array}$ \\
\hline $\begin{array}{l}\text { Bachour } \\
2013^{55}\end{array}$ & $\begin{array}{c}\text { Não- } \\
\text { Randomizado }\end{array}$ & $\mathrm{NI}$ & 730 & $\begin{array}{c}\text { Nasal vs } \\
\text { oronasal } \\
\text { vs nasal } \\
\text { pillow }\end{array}$ & $>3$ semanas & Automático & $\begin{array}{l}\text { Adesão } \\
\text { CPAP }\end{array}$ \\
\hline Borel $2013^{43}$ & $\begin{array}{c}\text { Não- } \\
\text { Randomizado }\end{array}$ & $\begin{array}{l}\geq 18 \text { anos } \\
\text { AOS } \\
\text { CPAP há 1-24 } \\
\text { meses }\end{array}$ & 2311 & $\begin{array}{l}\text { Nasal vs } \\
\text { oronasal } \\
\text { vs nasal } \\
\text { pillow }\end{array}$ & $\begin{array}{l}\text { Informações da } \\
\text { base de dados } \\
\text { de uso de CPAP }\end{array}$ & Automático & $\begin{array}{c}\text { Nível } \\
\text { CPAP } \\
\text { Adesão } \\
\text { CPAP }\end{array}$ \\
\hline $\begin{array}{l}\text { Casanova } \\
2013^{62}\end{array}$ & $\begin{array}{c}\text { Não- } \\
\text { Randomizado }\end{array}$ & $\begin{array}{l}\text { Usuários do } \\
\text { serviço de } \\
\text { assistência } \\
\text { domiciliar }\end{array}$ & 761 & $\begin{array}{l}\text { Nasal vs } \\
\text { oronasal }\end{array}$ & $\begin{array}{l}\text { Informações da } \\
\text { base de dados } \\
\text { de uso de CPAP }\end{array}$ & Automático & $\begin{array}{c}\text { IAH residual } \\
\text { Adesão } \\
\text { CPAP }\end{array}$ \\
\hline $\begin{array}{l}\text { Kamisnka } \\
2014^{63}\end{array}$ & $\begin{array}{c}\text { Não- } \\
\text { Randomizado }\end{array}$ & $\begin{array}{c}\text { AOS não } \\
\text { tratada } \\
\text { adequadamente } \\
\text { com CPAP } \\
\text { oronasal } \\
\end{array}$ & 6 & $\begin{array}{l}\text { Nasal vs } \\
\text { oronasal }\end{array}$ & 1 noite & Manual & $\begin{array}{l}\text { Nível } \\
\text { CPAP }\end{array}$ \\
\hline $\begin{array}{l}\text { Benttizoli } \\
2014^{51}\end{array}$ & $\begin{array}{c}\text { Não- } \\
\text { Randomizado }\end{array}$ & $\mathrm{IAH}>15 \mathrm{e} / \mathrm{h}$ & 109 & $\begin{array}{l}\text { Nasal vs } \\
\text { oronasal }\end{array}$ & 3 ou 4 noites & Automático & $\begin{array}{l}\text { Nível } \\
\text { CPAP } \\
\text { IAH } \\
\text { residual }\end{array}$ \\
\hline $\begin{array}{l}\text { Westhoff } \\
2015^{64}\end{array}$ & $\begin{array}{c}\text { Não- } \\
\text { Randomizado }\end{array}$ & $\begin{array}{c}\text { IDR>15 } \\
\text { e/ou sono não } \\
\text { restaurador } \\
\text { com CPAP ON }\end{array}$ & 65 & $\begin{array}{l}\text { Nasal vs } \\
\text { oronasal }\end{array}$ & $\begin{array}{c}\text { CPAP/ } \\
\text { APAP/ } \\
\text { SVA/ nível }\end{array}$ & Automático & $\begin{array}{l}\text { Nível } \\
\text { CPAP } \\
\text { IDR } \\
\text { residual }\end{array}$ \\
\hline $\begin{array}{l}\text { Deshpande } \\
2016^{44}\end{array}$ & $\begin{array}{c}\text { Não- } \\
\text { Randomizado }\end{array}$ & $\mathrm{IAH}>5 \mathrm{e} / \mathrm{h}$ & 358 & $\begin{array}{c}\text { Nasal vs } \\
\text { oronasal } \\
\text { vs nasal } \\
\text { pillow }\end{array}$ & 1 noite & Manual & $\begin{array}{l}\text { Nível } \\
\text { CPAP } \\
\text { IAH } \\
\text { residual }\end{array}$ \\
\hline
\end{tabular}

IAH=índice de apneia-hipopneia; IDR=índice de distúrbio respiratório. APAP=Pressão positiva automática; SVA=servo ventilação; $\mathrm{NI}=$ não informado. Fonte: Andrade et al. ${ }^{60}$ 


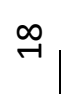

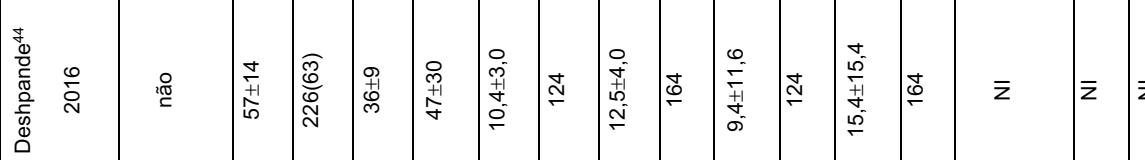

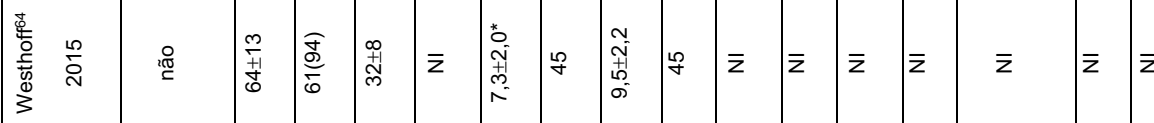

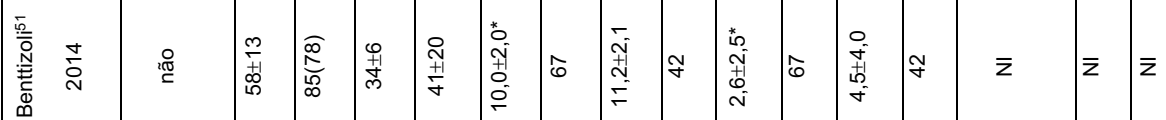

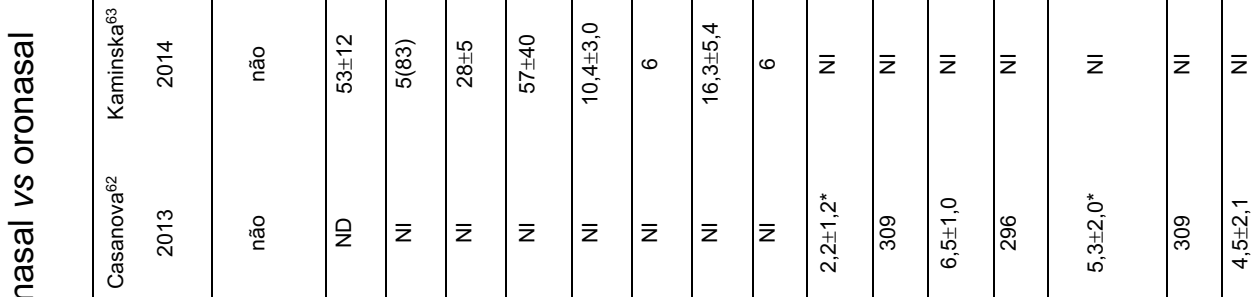

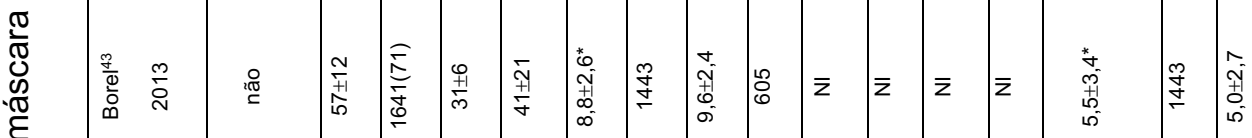

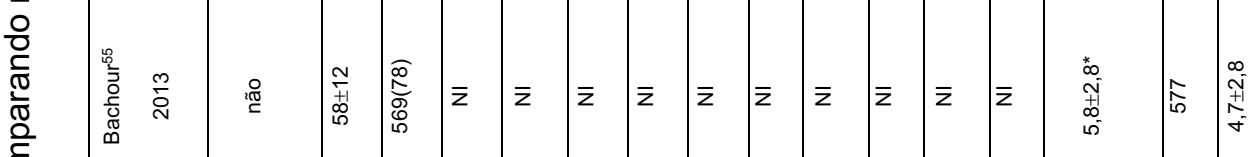

¿ิ

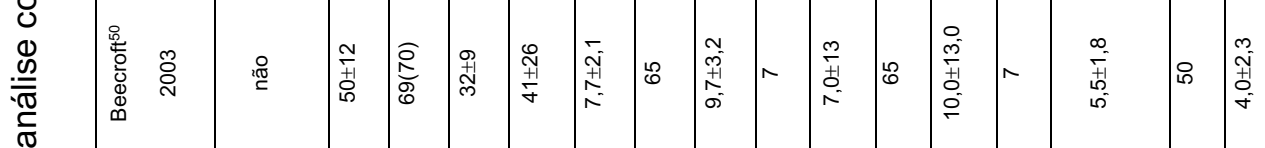

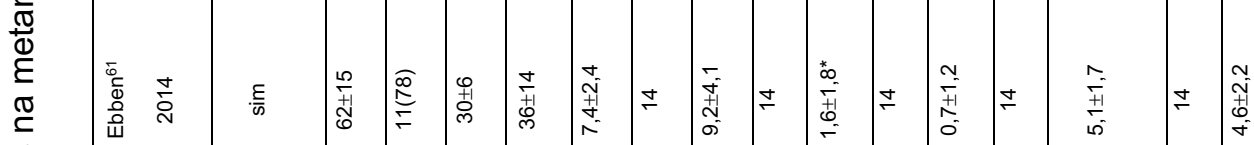

용

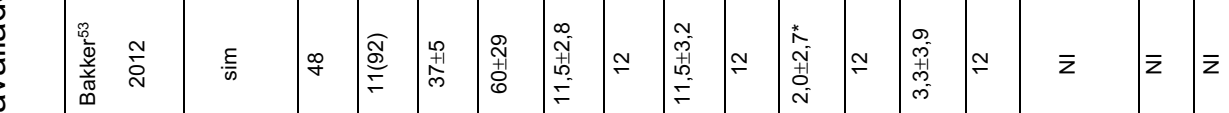

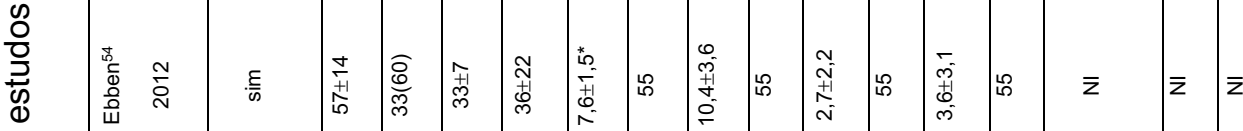

\&

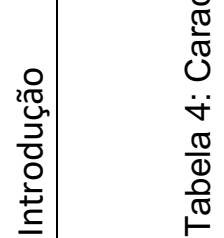

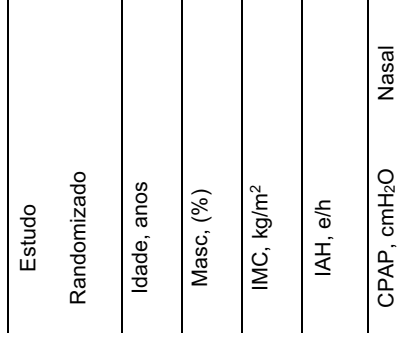

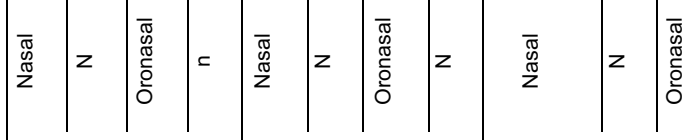

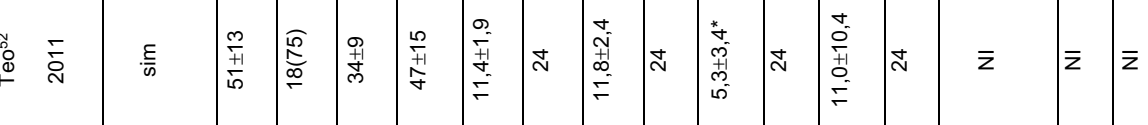

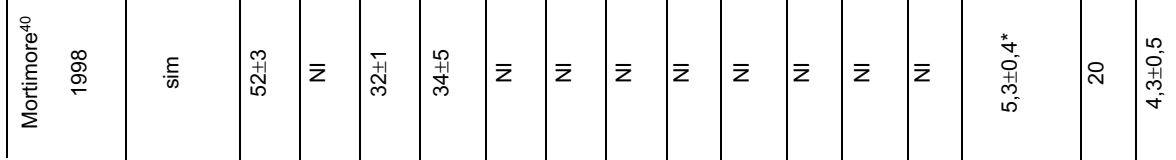

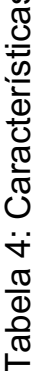

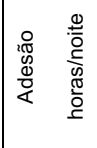

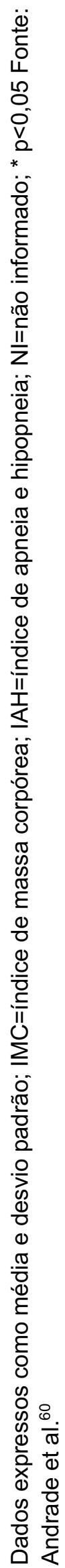


O principal achado desta metanálise é que, quando comparado a máscara nasal, o tratamento com CPAP e máscara oronasal está associado a maiores pressões de CPAP (em média $+1,5 \mathrm{cmH}_{2} \mathrm{O}$ ), associadas a um maior IAH residual (2,8 eventos/h) e uma pior adesão (-48 minutos/noite).

Essa linha de pesquisa nos motivou a realizar um estudo para entender os mecanismos exatos pelos quais a interface oronasal compromete a eficácia e acaba por gerar pior adesão e comprometimento da efetividade do tratamento da AOS. Estudamos 18 pacientes sem obstrução nasal, recém diagnosticados com AOS e virgens de tratamento ${ }^{65}$. Realizamos sonoendoscopia, com o endoscópio localizado na região retroglossal. Titulamos o CPAP na rota nasal, utilizando uma máscara com compartimento nasal e oral selados e separados. Desta forma, após a titulação na rota nasal, o fluxo de CPAP foi mudado agudamente para oronasal $(n=18)$ e oral $(n=16)$. Dos 18 pacientes, 12 (de 18) e 14 (de 16) tiveram eventos obstrutivos quando o CPAP foi mudado para a rota oronasal e oral respectivamente. Quando avaliados quanto à rota de respiração predominante, todos os pacientes que tiveram mais de $50 \%$ de respiração oronasal evoluíram com eventos obstrutivos na rota oronasal. Além disso, mesmo os pacientes com respiração 100\% nasal também apresentaram eventos obstrutivos (Figura 6). 


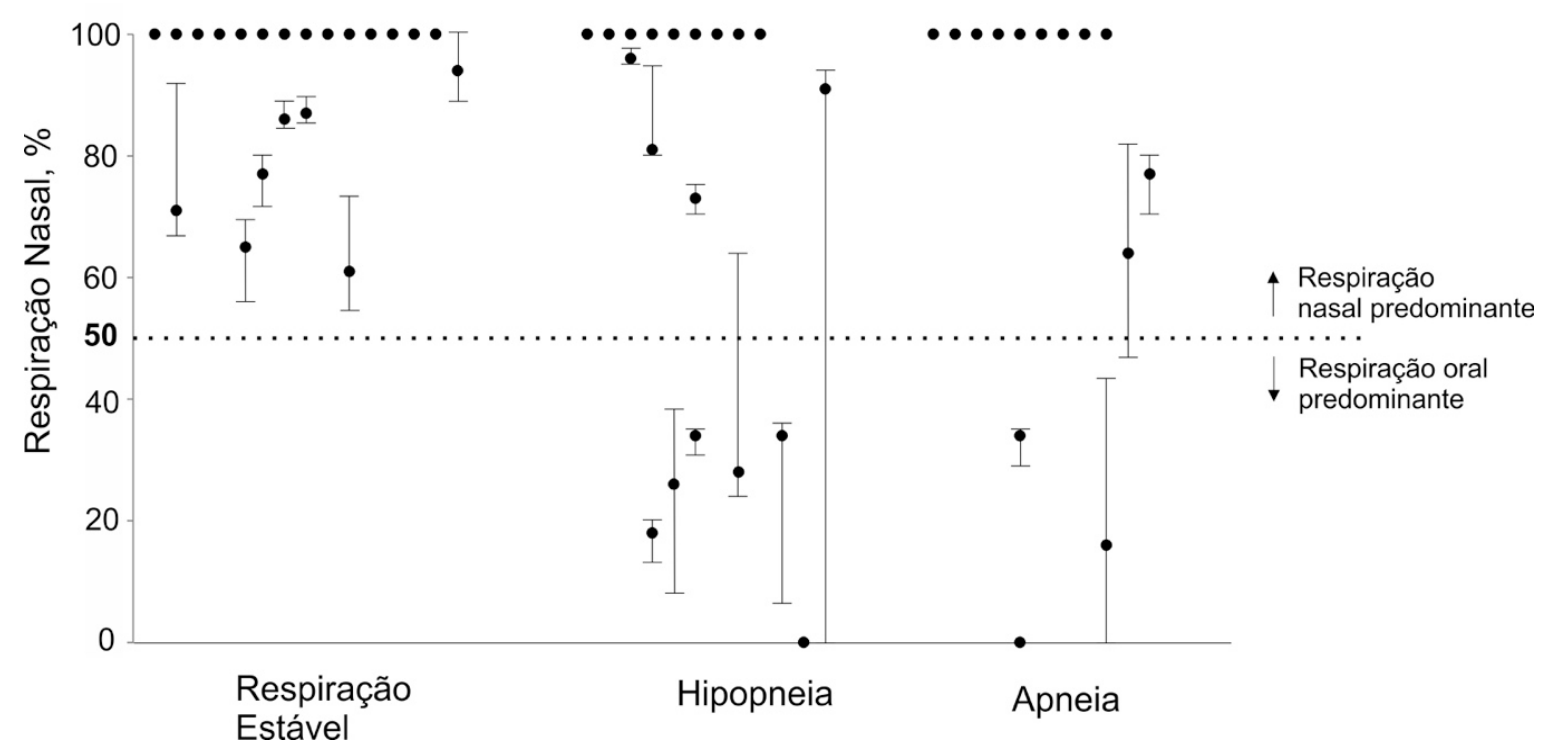

Figura 6: Gráfico com porcentagem de respiração nasal e oral com a máscara oronasal. Cada ponto representa um único ensaio durante o CPAP oronasal. Os ensaios foram agrupados em respiração estável, hipopneia e apneia de acordo com o padrão respiratório observado durante o CPAP oronasal (eixo x). Cada ponto é a mediana ( 25 - 75 centil) da porcentagem de respiração nasal durante os 30 segundos logo após a mudança para rota oronasal ou antes do primeiro evento respiratório observado (hipopneia ou apneia). Os pontos no topo do gráfico representam os ensaios com $100 \%$ de respiração nasal (a ausência de barras de erro nestes pontos indica a ausência de variabilidade na porcentagem de respiração nasal). O gráfico mostra que todos os ensaios com $<50 \%$ de respiração nasal resultou em eventos obstrutivos. A respiração estável ocorreu exclusivamente quando a respiração nasal foi predominante (>50\%). Entretanto eventos respiratórios foram observados em alguns ensaios mesmo quando a respiração nasal foi predominante ou $100 \%$. Fonte: Andrade et al. ${ }^{65}$

Nesse estudo, foram avaliadas/selecionadas apenas as imagens de menor calibre em cada rota, porém não foi possível avaliar em qual momento do ciclo respiratório o paciente se encontrava. As dimensões de orofaringe mostraram uma progressiva redução da via aérea com as rotas oronasal e oral (Figura 7). 
A

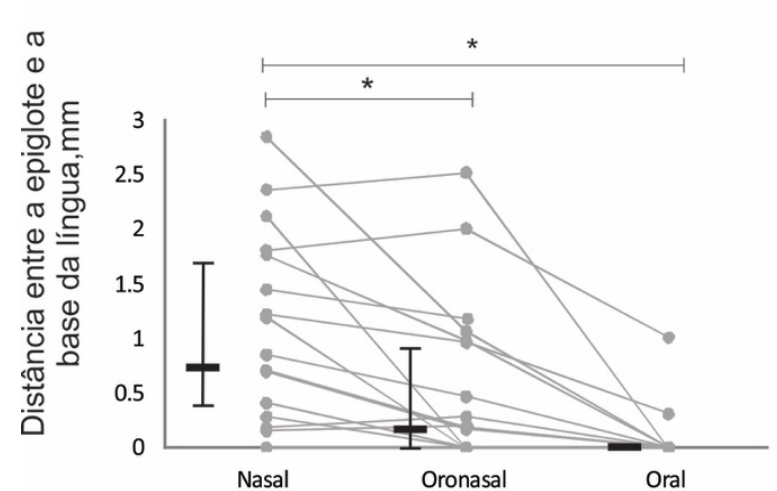

B

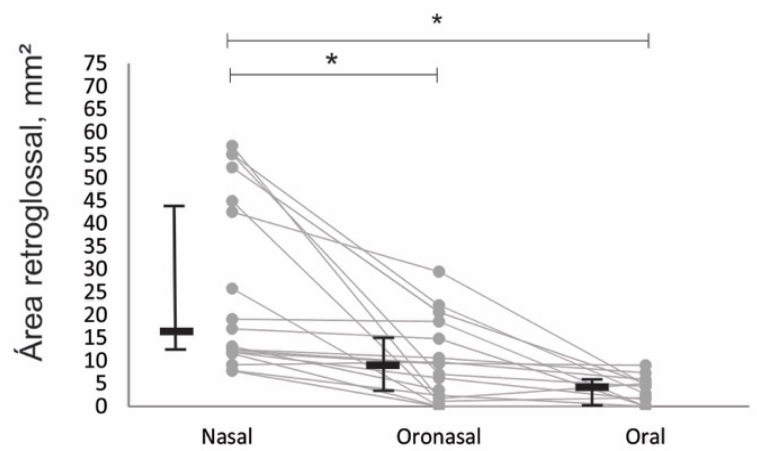

Figura 7: Gráfico com distância entre a epiglote e base de língua e área retroglossal com as rotas nasal, oronasal e oral. Em A, a distância entre a epiglote e a base da língua, em B, área retroglossal durante o CPAP transmitido pelas rotas nasal, oronasal e oral. Cada ponto representa a media da distância entre a epiglote e a base da língua $(A)$ e a media da área retroglossal (B) obtida dos 3 ensaios de cada paciente nas rotas nasal, oronasal e oral. As barras representam a mediana ( $25-75$ centil) do grupo. ${ }^{*} p<0,05$. Fonte: Andrade et al. ${ }^{65}$

Nossos achados nos fizeram questionar ainda mais a eficácia da máscara oronasal. Porém, algumas questões não foram respondidas: 1. Os pacientes estudados não tinham obstrução nasal e nunca haviam sido tratados. Portanto, não tinham indicação de máscara oronasal. É, portanto, difícil extrapolar os resultados para os pacientes com indicação de máscara oronasal, visto que o comportamento da via aérea pode ser diferente em pacientes com obstrução nasal e bem adaptados ao CPAP oronasal ${ }^{66-68}$. 2. As mudanças agudas de fluxo de CPAP no estudo acima foram feitas todas na pressão titulada na rota nasal. É possível que o fracasso da máscara oronasal fosse decorrente da falta de titulação adequada do CPAP com a mesma. 3. As mudanças de rota nasal, oronasal e oral foram feitas sempre na mesma ordem, sendo impossível avaliar se o fenômeno se repetiria em caminho inverso. 4. O local de obstrução da VAS não foi elucidado, pois apenas a área retroglossal foi observada. 5. A pressão na faringe não foi monitorada, impossibilitando a mensuração do esforço e da 
resistência da VAS. 6. Por último, como se poderia prever, os pacientes com uma alta porcentagem de respiração oral tiveram o pior desempenho no CPAP oronasal. No entanto, não foi possível explicar porque vários pacientes que respiravam exclusivamente pelo nariz, apresentaram eventos obstrutivos quando a rota de CPAP foi alternada de nasal para oronasal.

Diante do exposto acima, fica claro que estamos diante de um paradoxo não esclarecido. Por um lado, estudos experimentais sugerem que todos os pacientes que usam a máscara oronasal têm resultados desastrosos ${ }^{11,65}$, pois a pressão transmitida pela cavidade oral obstrui a VAS. Por outro lado, por mais que tenhamos apontado na metanálise recente que a máscara oronasal possui desempenho inferior à nasal ${ }^{60}$, muitos pacientes utilizam a máscara oronasal e estão bem adaptados. É tanto que a mesma correspondeu a $27 \%$ das máscaras vendidas pela RESMED Brasil no ano de 2015 (comunicação pessoal). No presente estudo, testamos uma explicação unificadora que concilia a teoria de que o CPAP oronasal não deve ser eficaz no tratamento da $\mathrm{AOS}^{11}$, com a observação de que o CPAP oronasal apresenta resultados mistos na prática clínica ${ }^{43,46,63,69}$. Para este fim, nós estudamos pacientes com AOS que utilizavam o CPAP oronasal há pelo menos três meses. Pacientes que apresentavam obstrução nasal não foram excluídos, pois entendemos que são os pacientes que teoricamente mais se beneficiam da máscara oronasal. Nossas hipóteses são de que: 1. Todos os pacientes serão titulados adequadamente quando CPAP ofertado pela rota nasal, 2. A titulação com a rota oronasal terá resultados variáveis, 3. A eficácia da titulação na rota oronasal será inversamente proporcional à porcentagem de respiração, 4. A rota oronasal terá pior performance do que a rota nasal mesmo em pacientes respirando 
exclusivamente pelo nariz, devido a transmissão de pressão no compartimento oral, 5. A diferença de performance será melhor avaliado em condições de limitação de fluxo estável. 
2.OBJETIVOS 


\section{Objetivos}

Comparar a desempenho do CPAP com máscara oronasal e nasal em pacientes com AOS grave e bem adaptados à máscara oronasal.

2.1 Objetivos específicos:

1. Comparar a pressão de titulação de CPAP nas rotas oronasal e nasal.

2. Correlacionar a diferença entre as pressões de titulação nas rotas oronasal e nasal com a porcentagem de fluxo oral do CPAP oronasal

3. Avaliar os efeitos agudos de mudança de rota de CPAP (oronasal para nasal e vice-versa) durante a limitação de fluxo estável através do pico de fluxo inspiratório, pressão faríngea, resistência inspiratória da via aérea superior e dimensões da via aérea em região retropalatal e retroglossal.

4. Avaliar os efeitos agudos de mudança de rota de CPAP (oronasal para nasal e vice-versa) durante a limitação de fluxo estável impedindo a transmissão de pressão positiva à cavidade oral através do uso de uma fita selando a boca do paciente. 
3. MÉTODOS 


\section{Métodos}

\subsection{Pacientes}

Foram recrutados pacientes de ambos os sexos, maiores de 18 anos, com diagnóstico de AOS moderada ou grave, em uso regular ( $>4$ horas/noite) de CPAP com máscara oronasal há pelo menos três meses que estavam em acompanhamento no Grupo de Distúrbios do Sono da Disciplina de Pneumologia do Instituto do Coração - InCor. Critérios de exclusão: idade >80 anos, índice de massa corpórea $(\mathrm{IMC})>40 \mathrm{~kg} / \mathrm{m}^{2}$, uso concomitante de oxigênio, presença de outros distúrbios do sono associados (como apneia central do sono). O Comitê de Ética do Instituto do Coração aprovou o protocolo (SDC 4149/14/129) (Anexo 7.1). Todos os pacientes foram informados sobre o protocolo e seus procedimentos e assinaram o termo de consentimento livre e esclarecido antes de iniciar qualquer etapa do estudo (Anexo 7.2).

\subsection{Avaliações iniciais}

Todos os pacientes foram submetidos a uma avaliação clínica e antropométrica que incluiu as circunferências cervical e abdominal, peso e altura. A orofaringe foi classificada conforme o índice de Mallampati modificado, foi realizada uma avaliação da cavidade nasal, das alterações anatômicas da face 
e uma avaliação dentária. Os pacientes foram questionados quanto aos sintomas nasofaríngeos, antecedentes mórbido-pessoais, medicações em uso, informações sobre polissonografia basal e de titulação (caso existente), posição preferencial de dormir, o uso de CPAP e máscaras já utilizadas (Anexos 7.3 e 7.4).

Foram aplicados os questionários de Sonolência Excessiva Diurna de Epworth (Anexo 7.5), questionário de Berlim e o questionário de Avaliação de Resultados Nasossinusais (SNOT 20) (Anexo 7.6).

\subsection{Polissonografia com sono induzido}

O paciente era convidado a dormir no laboratório do sono na noite anterior para assegurar uma noite do sono adequada precedente ao protocolo. Pela manhã, foi realizada uma indução do sono no laboratório do sono do InCor. O paciente foi monitorado usando todos os canais da PSG, exceto pela cânula nasal e termistor.

Foi utilizada uma máscara oronasal com os compartimentos nasal e oral separados e selados (Hans Rudolph, EUA) (Figura 8), a mesma foi ajustada no rosto do paciente com o auxílio de um silicone moldável (Silagum, DMG, Hamburg, Germany) para evitar vazamentos. 


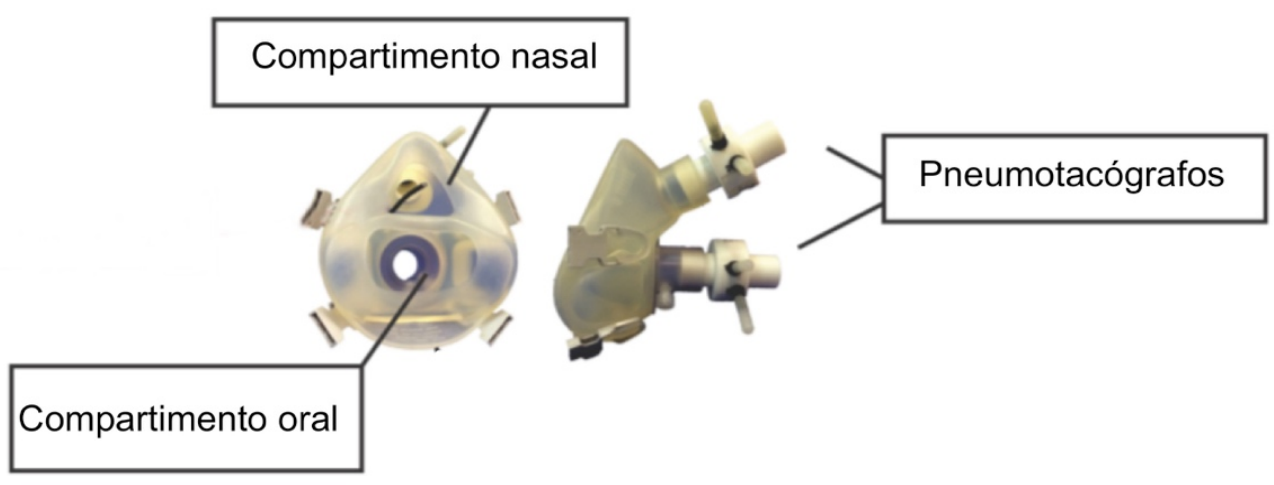

Figura 8: Máscara oronasal com compartimentos oral e nasal separados e selados. Cada compartimento foi conectado a um pneumotacógrafo e a um transdutor de pressão

Em cada compartimento da máscara foi conectado um pneumotacógrafo idêntico, aquecido, (3700A, Hans Rudolph, EUA) e um transdutor de pressão (MP45-14-871, Validyne, Northbridge, CA) para quantificação do fluxo aéreo e pressão do compartimento. $\mathrm{O}$ conjunto de transdutor diferencial de pressão/pneumotacógrafo foi calibrado utilizando uma seringa de $1 \mathrm{~L}$ (Hans Rudolph, Kansas City, MO). Os sinais de fluxo foram registrados por um sistema de aquisição de dados com uma frequência de amostragem de $200 \mathrm{~Hz}$. Os compartimentos nasal e oral foram conectados ao CPAP (Philips, Respironics, Murrysvil, PA) por meio de uma válvula multidirecional (2100, Hans Rudolph, Kansas City, MO) que permitiu mudança de rota de CPAP mimetizando um CPAP com máscara nasal e oronasal. A válvula foi suspensa por um braço mecânico, a fim de proporcionar conforto ao paciente e permitir que 0 pesquisador pudesse mudar a rota de fluxo sem contato com o paciente (Figura $9)$. 


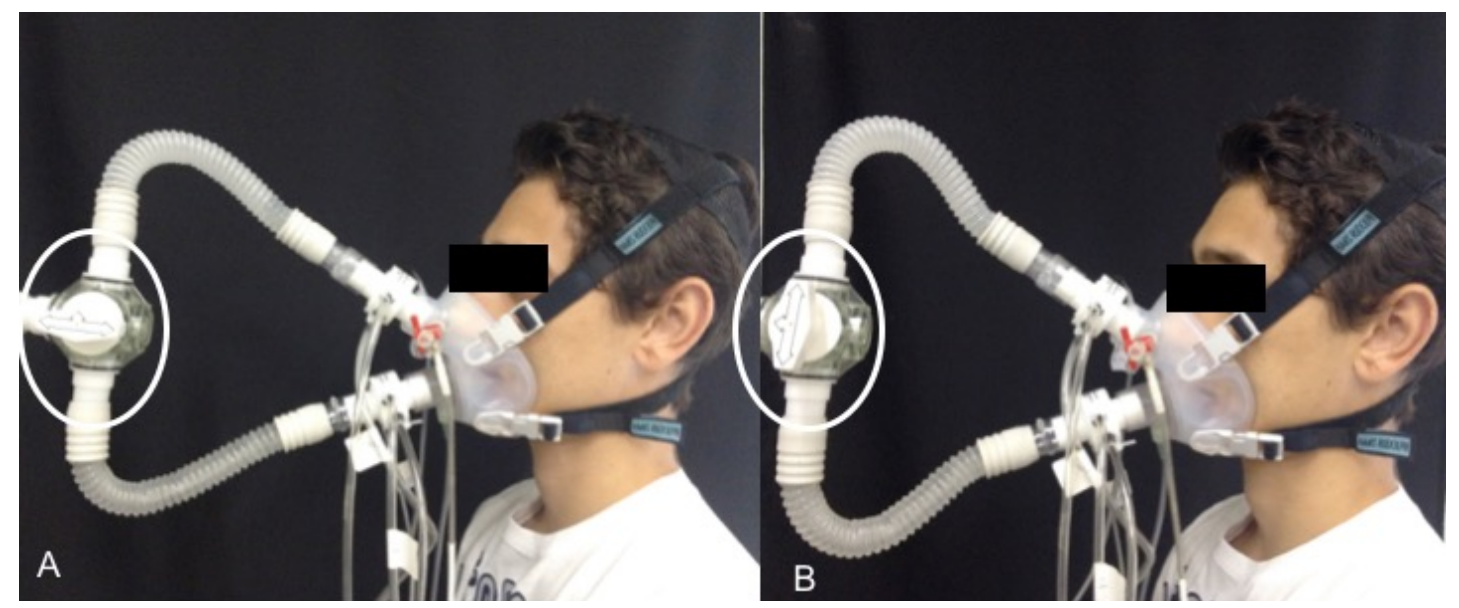

Figura 9: Imagem com paciente com máscara oronasal e válvula multidirecional aberta para as rotas nasal e oronasal. Na figura A podemos observar a válvula aberta para o compartimento nasal. Em figura B podemos observar a válvula aberta para os compartimentos nasal e oral

Os vazamentos de ar da máscara e entre os compartimentos internos da máscara foram meticulosamente excluídos por uma série de testes:

- Inspeção por palpação e visão pelos investigadores

- Com o CPAP em $5 \mathrm{cmH}_{2} \mathrm{O}$ acoplado à válvula multidirecional com rota oronasal, foi solicitado ao paciente que respirasse exclusivamente pelo nariz e observado se existia algum fluxo no compartimento oral. Depois o procedimento foi repetido com o paciente respirando exclusivamente pela boca e observado se existia algum fluxo no compartimento nasal. Desta foram foi excluído que não havia vazamentos entre os compartimentos.

- Com o CPAP em $5 \mathrm{cmH}_{2} \mathrm{O}$ acoplado à válvula multidirecional com rota nasal foi solicitado ao paciente que simulasse uma apneia por alguns segundos. Foi então observado se existia algum fluxo pelo pneumotacógrafo nasal e oral. O procedimento foi repetido com a rota oral. 
Para indução do sono, o midazolam foi diluído em uma solução salina com concentração de $1 \mathrm{mg} / 10 \mathrm{ml}$ e infundido em uma veia periférica gota a gota até ser observado o início do sono pela PSG. A indução do sono foi iniciada com a infusão de $5 \mathrm{ml}$ de solução durante $5 \mathrm{~min}$, que foi repetida quando necessário até que o primeiro estágio de sono fosse detectado online na monitorização do eletroencefalograma (EMBLA, Philips Respironics,Murrysville,PA). A infusão do midazolam para manutenção do sono só era reiniciada quando o paciente despertava e não conseguia retornar ao sono novamente em $10 \mathrm{~min}^{70}$.

Após a indução do sono, um cateter de pressão faríngea (MPR-500, Millar Instruments, Houston, TX) foi inserido na narina direita através da máscara oronasal em uma entrada específica, selada e foi então alojado ao nível da epiglote. Um broncoscópio pediátrico de 2,8mm de diâmetro (BFXP-160F, Olympus, Tokyo, Japan) foi inserido na narina esquerda do paciente através de uma entrada específica e selada. O broncoscópio foi alojado na região retroglossal e posteriormente na região retropalatal da via aérea. $O$ mesmo investigador realizou todas as endoscopias. As medidas de fluxo nasal e oral, pressão na máscara nos compartimentos oral e nasal, pressão faríngea e imagens de via aérea superior foram captadas e sincronizadas em um sistema de aquisição de dados (Power 1401, Cambridge Electronic Design, Cambridge, England) (Figuras 10 e 11). 


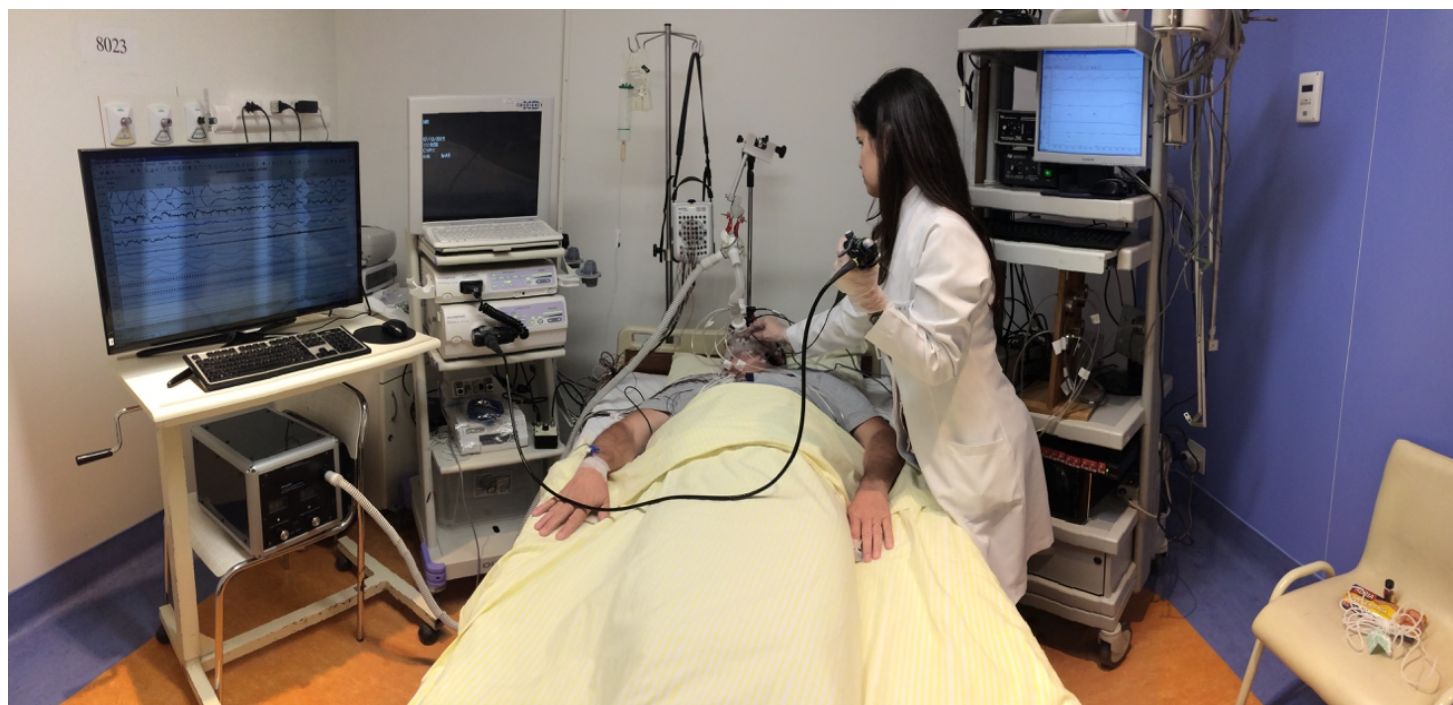

Figura 10: Imagem ilustrando dia de coleta do protocolo. Paciente em posição supina sendo monitorado com polissonografia, canais de fluxo respiratório, pressão faríngea e nasoendoscopia

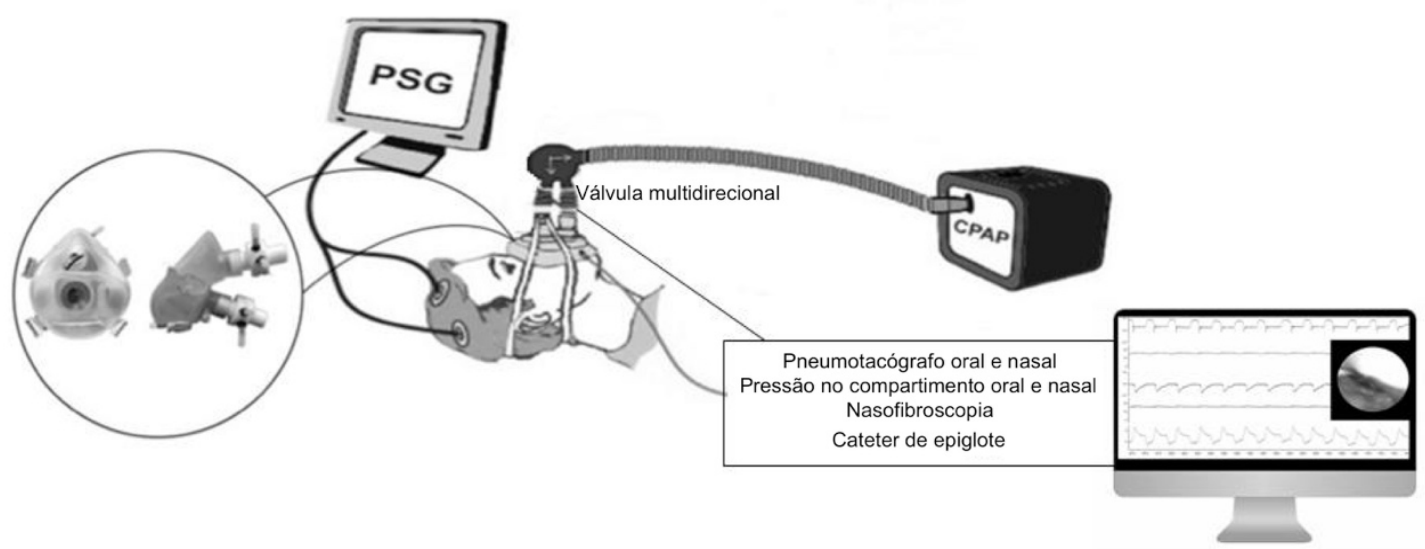

Figura 11: Desenho esquemático do protocolo de pesquisa. Paciente em posição supina, monitorado com polissonografia, utilizando máscara oronasal acoplada a dois pneumotacógrafos, válvula multidirecional e CPAP. Sinais de fluxo, pressão da máscara em cada compartimento, pressão faríngea e imagens de nasoendoscopia sendo capturados e sincronizados em computador exclusivo

\subsection{Etapas do estudo}

O estudo foi realizado na fase 2 do sono NREM, com o paciente dormindo em posição supina e o pescoço em uma posição neutra. O estudo foi realizado em três etapas: 


\subsubsection{Titulação de CPAP}

O CPAP foi titulado para obter a pressão ideal para abertura da VAS nas duas rotas: oronasal e nasal. Caso a titulação não fosse efetiva para estabilizar a via aérea, a pressão máxima tolerada era considerada.

Foi avaliada durante um minuto a proporção de fluxo oral na titulação de CPAP utilizando a fórmula: pico inspiratório oral/ (pico inspiratório nasal+oral) $x 100$. Pacientes com fluxo oral $>25 \%$ foram classificados como respiradores orais.

\subsubsection{Limitação de fluxo estável}

A pressão de CPAP foi reduzida até atingir limitação de fluxo estável, definida por: aumento do tempo inspiratório com achatamento da curva inspiratória, havendo ausência de aumento de fluxo aéreo a despeito de aumento da pressão negativa faríngea.

Todos os pacientes foram submetidos à mudança aguda na rota de CPAP de oronasal para nasal e vice-versa com o endoscópio localizado na região retropalatal e retroglossal. Pico de fluxo inspiratório, pressão faríngea, resistência de VAS, porcentagem de fluxo oral e dimensões da VAS foram avaliadas em três respirações antes e três respirações após cada mudança aguda de rota. 
O delta de pressão faríngea foi calculado pela diferença entre a pressão faríngea no final da expiração e no seu nadir (Figura 12).
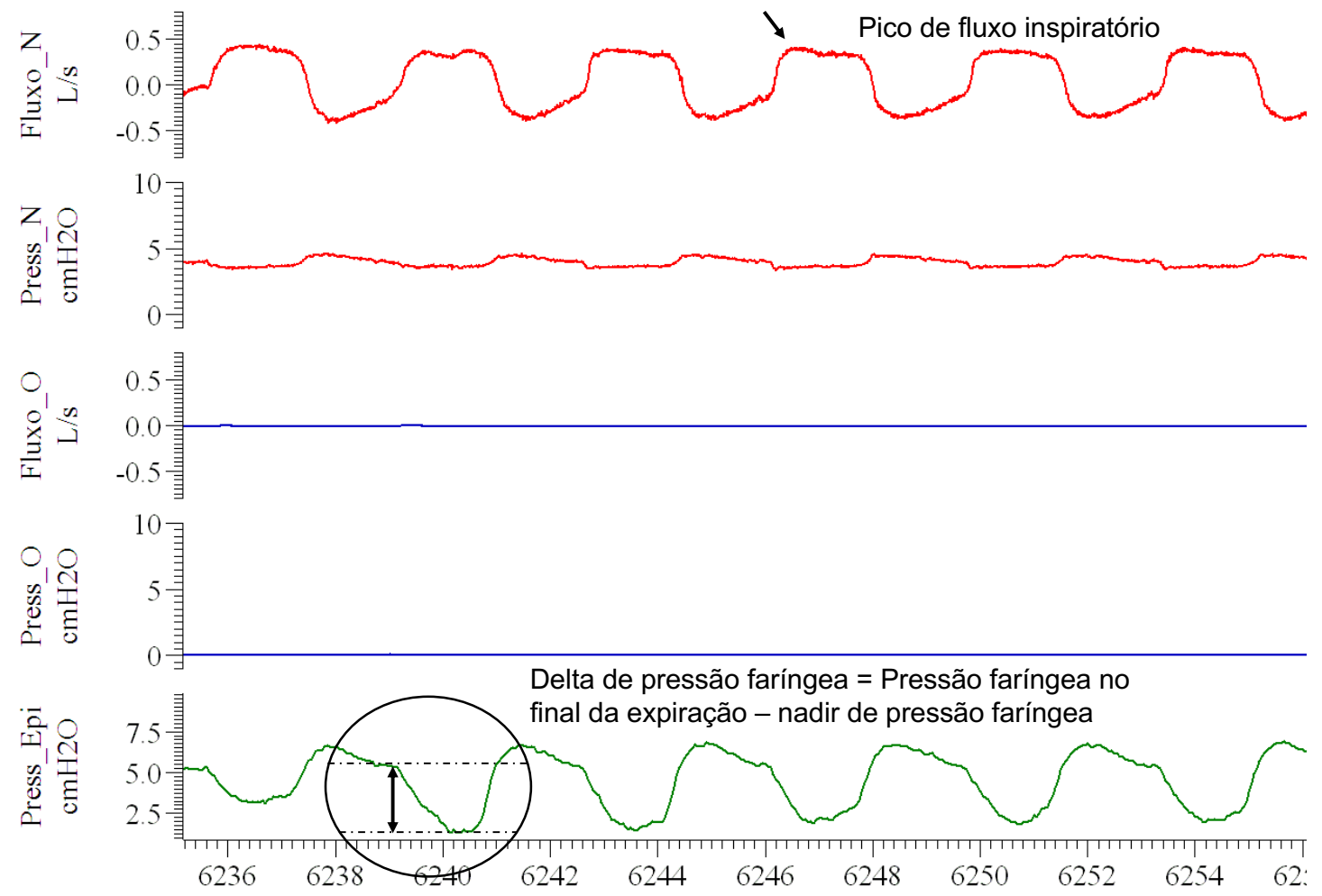

Figura 12: llustra o cálculo do delta de pressão faríngea. As setas inferiores apontam para a pressão faríngea no final da expiração e no seu nadir. A seta superior aponta para o pico de fluxo inspiratório. Fluxo_N= fluxo nasal, Press_ $\mathrm{N}$ = pressão no compartimento nasal da máscara, Fluxo_O = fluxo oral, Press_O = pressão no compartimento oral da máscara, Press_Epi = pressão de epiglote

A resistência da VAS foi calculada pelo delta de pressão faríngea dividido pelo fluxo inspiratório nasal no momento do nadir de pressão faríngea (Figura 13). 


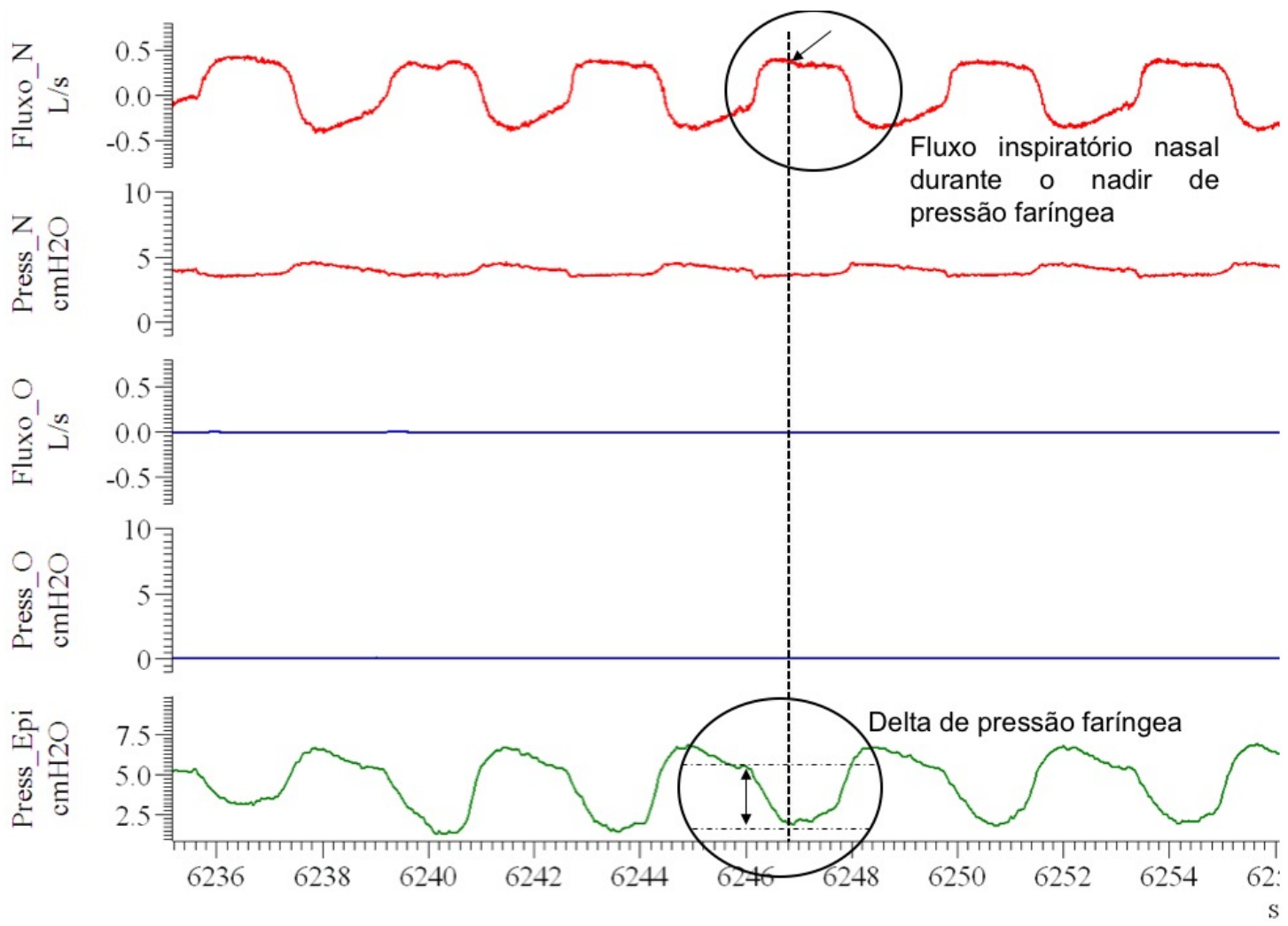

Figura 13: llustra o cálculo da resistência da via aérea superior. Delta de pressão faríngea (setas na parte inferior da imagem) dividido pelo fluxo inspiratório nasal durante o nadir de pressão faríngea (setas na parte superior da imagem). Fluxo_N= fluxo nasal, Press_N = pressão no compartimento nasal da máscara, Fluxo_O = fluxo oral, Press_O = pressão no compartimento oral da máscara, Press_Epi = pressão de epiglote

As dimensões da VAS foram delimitadas manualmente (ImagePro Plus 4.5.0.29, USA). Foram realizadas seis medidas no final da expiração: 1. Área retropalatal; 2. Área retroglossal; 3. Distância ântero-posterior retropalatal (AP); 4. Distância AP retroglossal; 5. Distância látero-lateral retropalatal; 6. Distância látero-lateral retroglossal (Figuras 14 e 15). As medidas foram definidas em pixels. Um investigador cego quanto à rota de CPAP avaliou todas as imagens da VAS. 


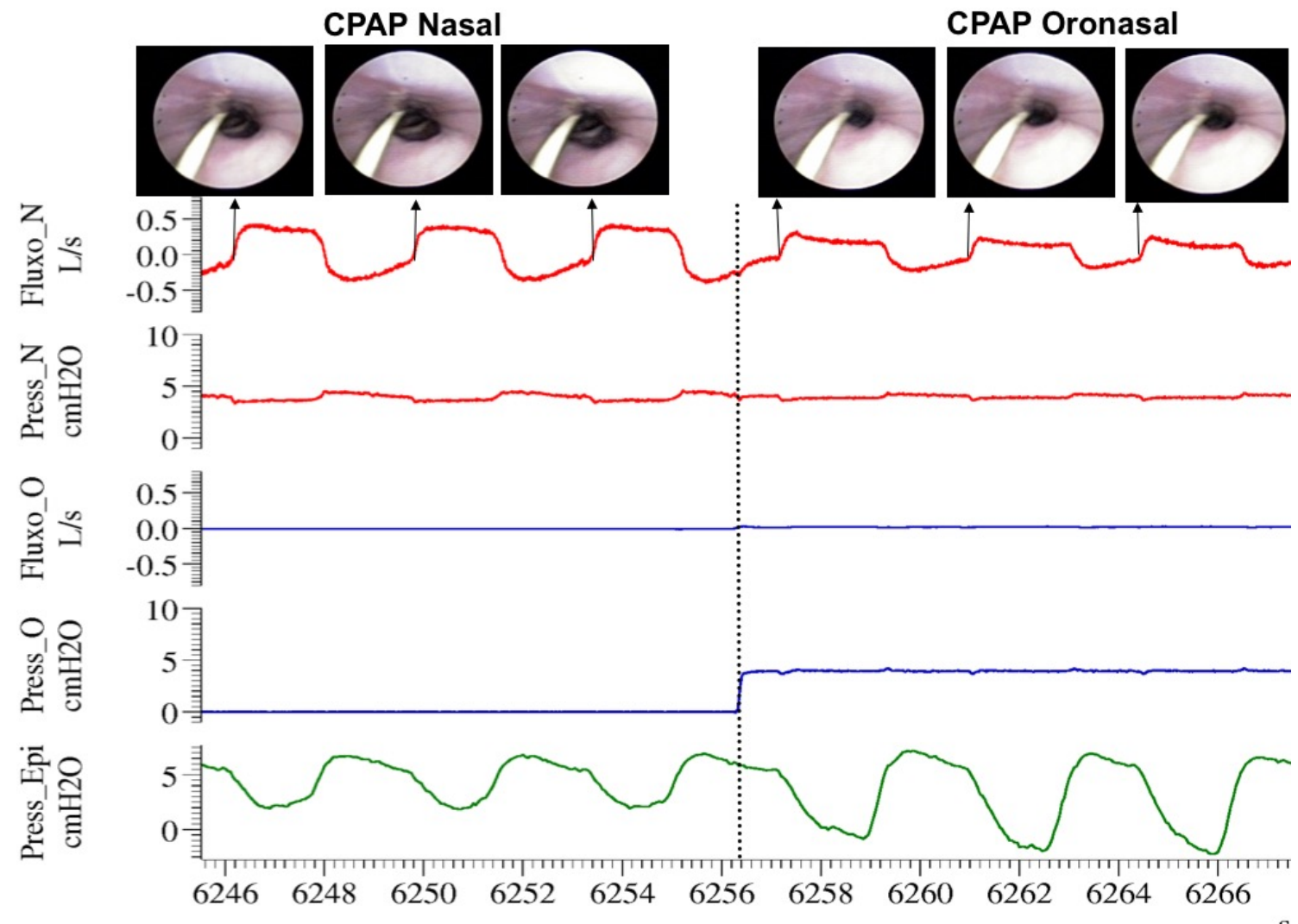

Figura 14: Exemplo do protocolo da avaliação da imagem durante as mudanças agudas de rota de CPAP. Foram analisadas as imagens de via aérea superior em região retropalatal no final da expiração em 3 respirações antes e 3 respirações depois da mudança aguda de rota (marcada pela linha tracejada). Fluxo_N= fluxo nasal, Press_N = pressão no compartimento nasal da máscara, Fluxo_O = fluxo oral, Press_O = pressão no compartimento oral da máscara, Press_Epi $=$ pressão de epiglote

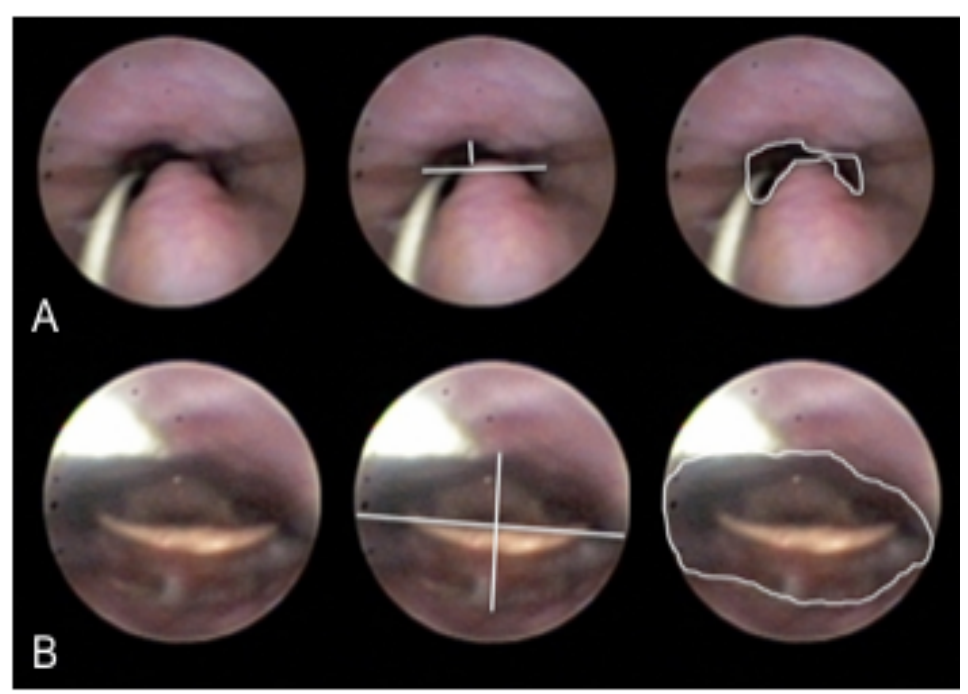

Figura 15: Imagem de nasoendoscopia na região retropalatal e retroglossal com as medidas de comprimento e área. Região retropalatal $(A)$ e retroglossal $(B)$, medidas de distância ânteroposterior, látero-lateral e área 
3.4.3 Limitação de fluxo estável com fita selando a cavidade oral

Para testar a hipótese de que a máscara oronasal seria negativamente influenciada pela transmissão de pressão positiva na cavidade oral, selamos a boca de um subgrupo de pacientes durante limitação de fluxo estável com uma fita adesiva.

3.5 Análise estatística

Os dados foram expressos em média \pm desvio padrão ou mediana (25-75 percentil) quando apropriado. A normalidade da distribuição dos dados foi testada pelo teste de Kolmogorov-Smirnov. O teste $t$ de Student pareado e o teste Wilcoxon pareado foram utilizados para comparar as variáveis: pico de fluxo inspiratório, delta de pressão faríngea, resistência de VAS e dimensões da VAS nas duas rotas de CPAP. Para avaliar a influência da porcentagem de fluxo oral no aumento da pressão de titulação na rota oronasal, foi utilizada a correlação de Spearman. O pacote estatístico utilizado foi SPSS (Version 20, SPSS Inc., Chicago, IL). A significância estatística foi estabelecida em $p<0,05$. 
4. RESULTADOS 


\section{Resultados}

De um total de 200 pacientes em uso de CPAP do ambulatório de Distúrbios do Sono da Disciplina de Pneumologia do InCor, que em algum momento havia sido prescrito uma máscara oronasal, apenas 36 estavam em uso da mesma. Vinte pacientes foram excluídos devido ao uso de oxigênio $(n=7)$, uso de bi-nível PAP $(n=4), I M C>40 \mathrm{~kg} / \mathrm{m}^{2}(n=6)$, idade $>80$ anos $(n=3)$. Dois pacientes não concordaram em participar do estudo e em um paciente não foi possível induzir o sono. Foi incluído no estudo um total de 13 pacientes (Tabela 5). A nasofibrolaringoscopia evidenciou alteração anatômica em 12 pacientes, classificada de acordo com Cottle ${ }^{71}$ como: leve $(n=7)$, moderada $(n=4)$ e severa $(n=1)$.

Tabela 5: Características antropométricas e da polissonografia basal

Mínimo - máximo

$\mathrm{N}^{\circ}$ de pacientes

Homens, \%

Idade, anos

IMC, $\mathrm{kg} / \mathrm{m}^{2}$

Circunferência cervical, cm

Escala de Sonolência de Epworth

$\mathrm{IAH}$, eventos/h

Tempos de uso de CPAP oronasal, anos

Nível de CPAP utilizado no tratamento atual, $\mathrm{cmH}_{2} \mathrm{O}$
13

61

$63 \pm 8$

$30,4 \pm 4,2$

$41 \pm 3,8$

$12 \pm 3,4$

$43 \pm 18$

$5 \pm 4$

$10,5 \pm 1,5$
45-77

$23,4-38,9$

35-49

6-17

19-75

$1-14$

7-13

IMC = índice de massa corpórea, IAH = índice de apneia-hipopneia 
O sono foi induzido com uma dose média de midazolam de 3,1士2,2 mg. O tempo médio de duração do estudo foi de $3,5 \pm 0,5 \mathrm{hs}$.

\subsection{Titulação de CPAP}

O CPAP foi titulado com sucesso em todos os pacientes estudados durante a rota nasal (CPAP nasal): 12 [9-13] $\mathrm{cmH}_{2} \mathrm{O}$. De acordo com o padrão de respiração durante a titulação de CPAP na rota oronasal, os pacientes foram classificados como: respiradores nasais $(n=6)$ e respiradores orais $(n=5)$. Dois pacientes não apresentaram sono estável o suficiente para titulação na rota oronasal.

Todos os respiradores nasais foram titulados com sucesso na rota oronasal. Em contraste, todos os respiradores orais permaneceram com eventos obstrutivos mesmo com máxima pressão de CPAP tolerada (18 a $22 \mathrm{cmH}_{2} \mathrm{O}$ ). Um exemplo representativo de respirador oral, com eventos obstrutivos persistentes mesmo com CPAP a $20 \mathrm{cmH}_{2} \mathrm{O}$, está demonstrado na Figura 16. O paciente apresentou melhora dos eventos obstrutivos com respiração estável após a mudança para a rota nasal. 


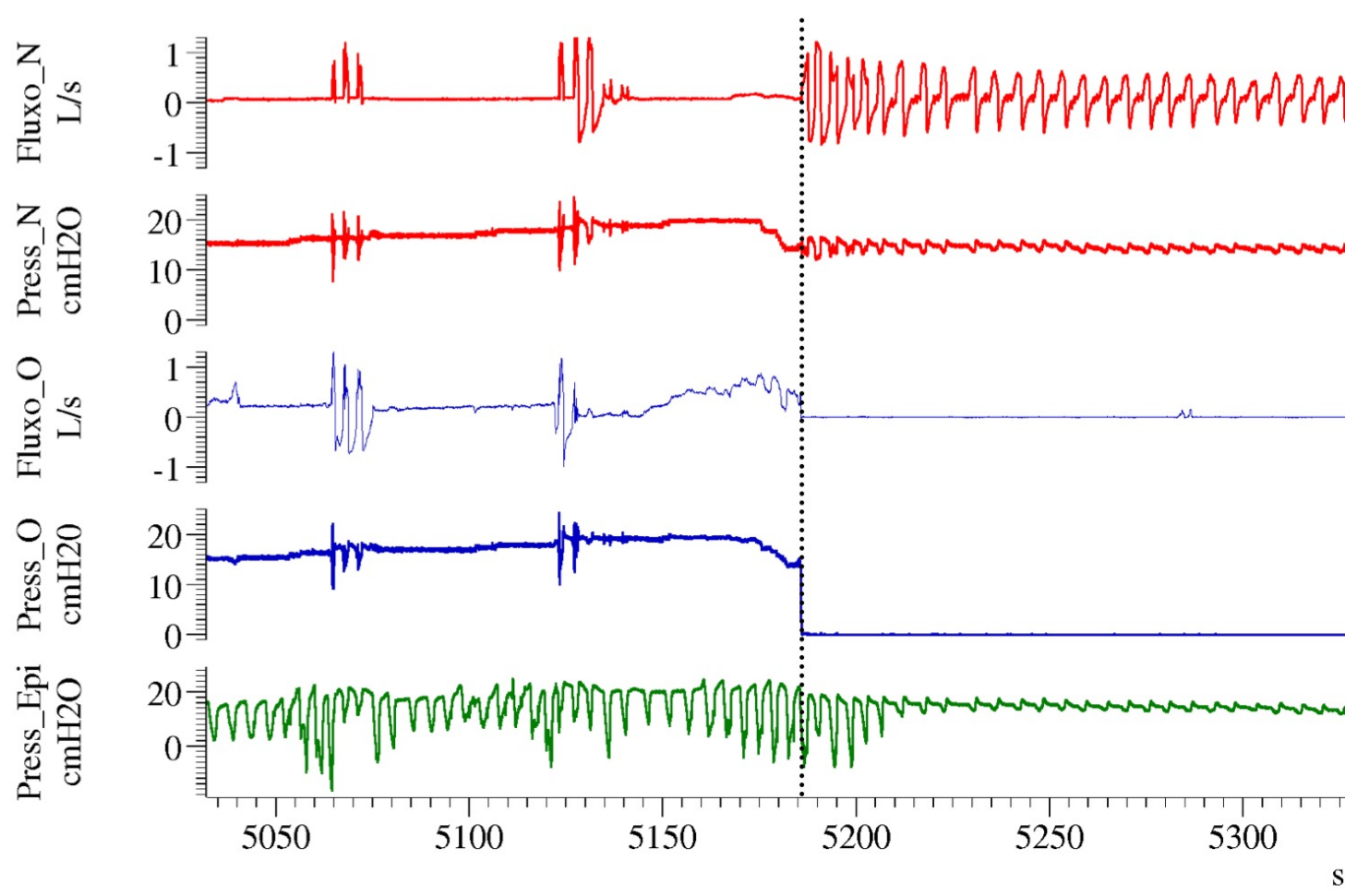

Figura 16: Exemplo representativo de um paciente respirador oral durante titulação de CPAP oronasal e nasal. Fluxo oral deste paciente $=75 \%$. Observe a persistência de apneias obstrutivas, apesar de CPAP em altos níveis de pressão $\left(20 \mathrm{cmH}_{2} \mathrm{O}\right)$ na rota oronasal (primeira metade da figura). A linha vertical tracejada indica a transição para a rota nasal, resultando em uma estabilização da respiração e uma diminuição no delta de pressão faríngea, mesmo com a redução do CPAP de 20 a $14 \mathrm{~cm} \mathrm{H} \mathrm{H}_{2} \mathrm{O}$. \%. Fluxo_N= fluxo nasal, Press_N = pressão no compartimento nasal da máscara, Fluxo_O $=$ fluxo oral, Press_O $=$ pressão no compartimento oral da máscara, Press_Epi = pressão de epiglote

A pressão titulada de CPAP $(n=11)$ foi maior na rota oronasal quando comparada à nasal (Figura 17A). Mesmo entre pacientes respiradores nasais $(n=6)$ a pressão de CPAP foi maior na oronasal: 13 [7,5-13,2] vs 12 [8,5-13] $\mathrm{cmH}_{2} \mathrm{O}, \mathrm{p}=0,039$, oronasal vs nasal respectivamente.

A Figura 17B mostra a relação entre a porcentagem de respiração oral e o $\triangle$ CPAP (pressão de CPAP na rota oronasal- pressão de CPAP na rota nasal). A porcentagem de respiração oral durante a rota oronasal se correlacionou positivamente com o aumento do nível de CPAP oronasal $(r=0,75, p=0,0073)$. 
A.

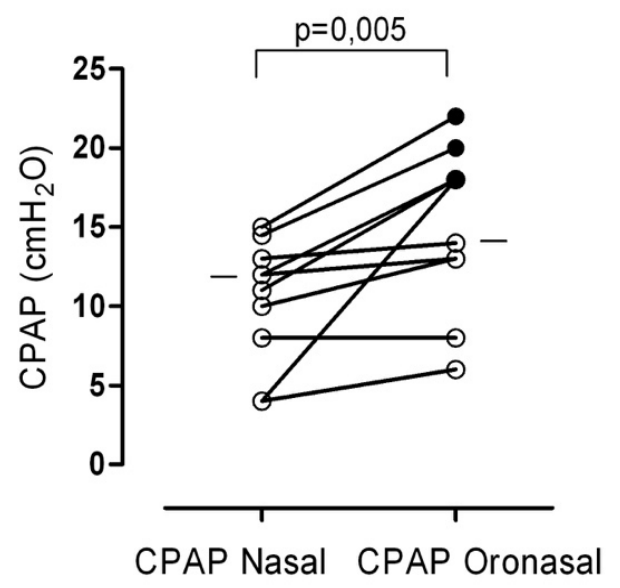

B.

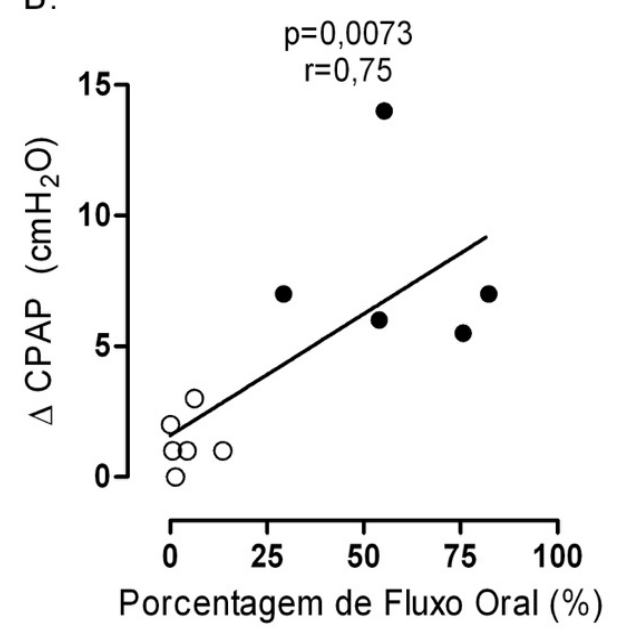

Figura 17: Gráfico com as pressões de CPAP nasal e oronasal e correlação com a porcentagem de fluxo oral. A. Pressão de CPAP em rota nasal e oronasal. B. Porcentagem do fluxo oral plotado contra o $\triangle$ CPAP (diferença entre CPAP oronasal e nasal). A porcentagem de fluxo oral foi calculada como: (pico de fluxo oral / (pico de fluxo nasal + oral) X 100) durante um minuto. Círculos abertos $(\circ)$ representam pacientes que foram titulados com sucesso. Círculos fechados ( ) representam pacientes que não obtiveram sucesso na titulação de CPAP

\subsection{Limitação de fluxo estável}

Limitação de fluxo estável foi obtida em todos 13 pacientes durante a rota nasal de CPAP. Os mesmos cinco respiradores orais que não obtiveram sucesso na titulação de CPAP oronasal devido a eventos obstrutivos, também não conseguiram atingir limitação de fluxo estável em pressões menores de CPAP devido a eventos obstrutivos. Desta forma, não foi possível realizar mudança de rota de CPAP oronasal para nasal nestes pacientes. As Figuras 18 e 19 mostram exemplos representativos de mudança de rota nasal para oronasal e vice-versa durante limitação de fluxo estável. 


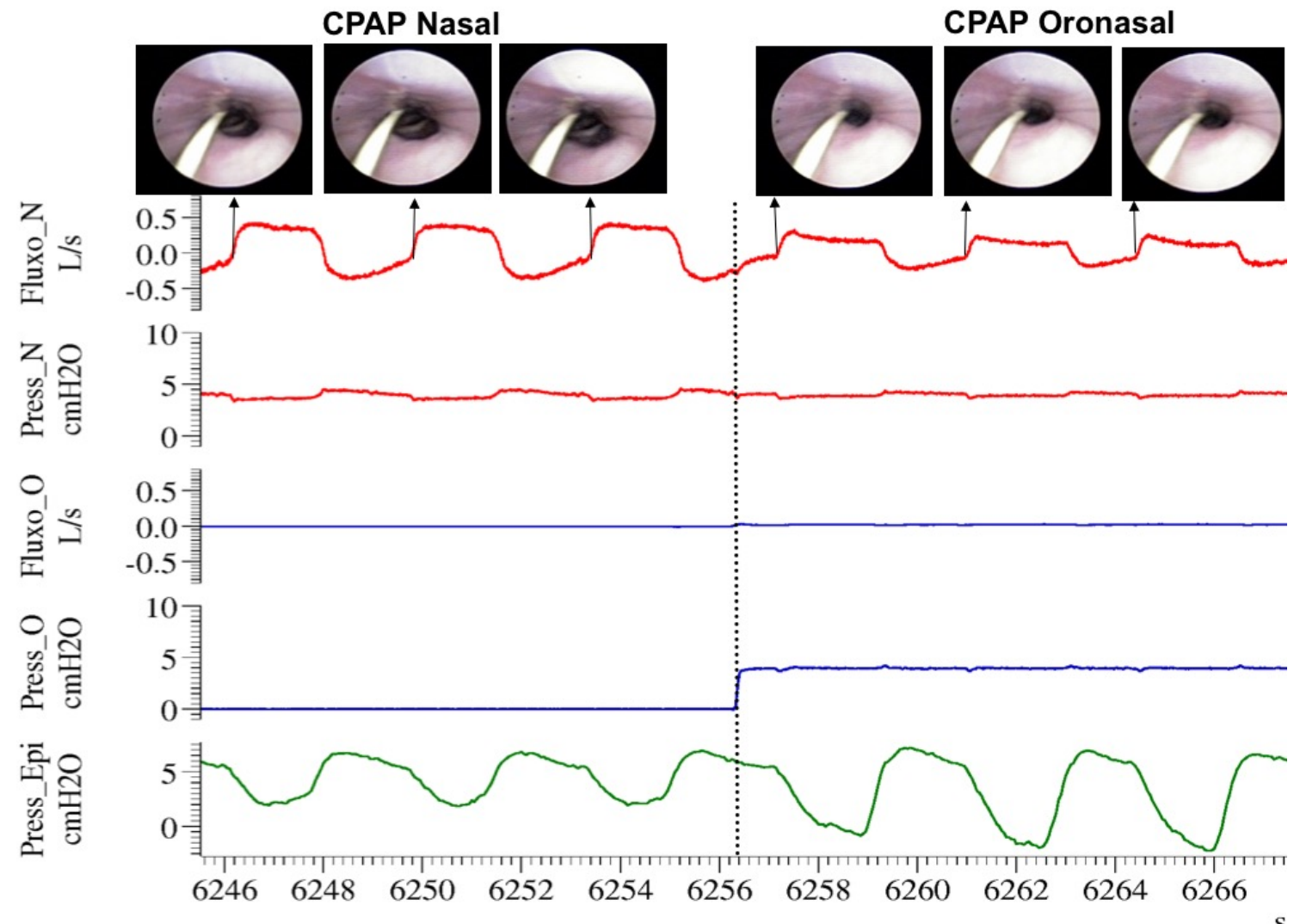

Figura 18: Exemplo representativo de mudança de rota de CPAP nasal para oronasal durante limitação de fluxo estável. Imagens na região retropalatal obtidas no final da expiração. A linha vertical tracejada indica a transição do CPAP nasal para o oronasal. Apesar da ausência de fluxo oral, a transição do CPAP nasal para o oronasal levou a uma redução das dimensões da via aérea superior e do pico de fluxo inspiratório e ao aumento concomitante do delta de pressão. Fluxo_N= fluxo nasal, Press_N = pressão no compartimento nasal da máscara, Fluxo_O = fluxo oral, Press_O = pressão no compartimento oral da máscara, Press_Epi $=$ pressão de epiglote 


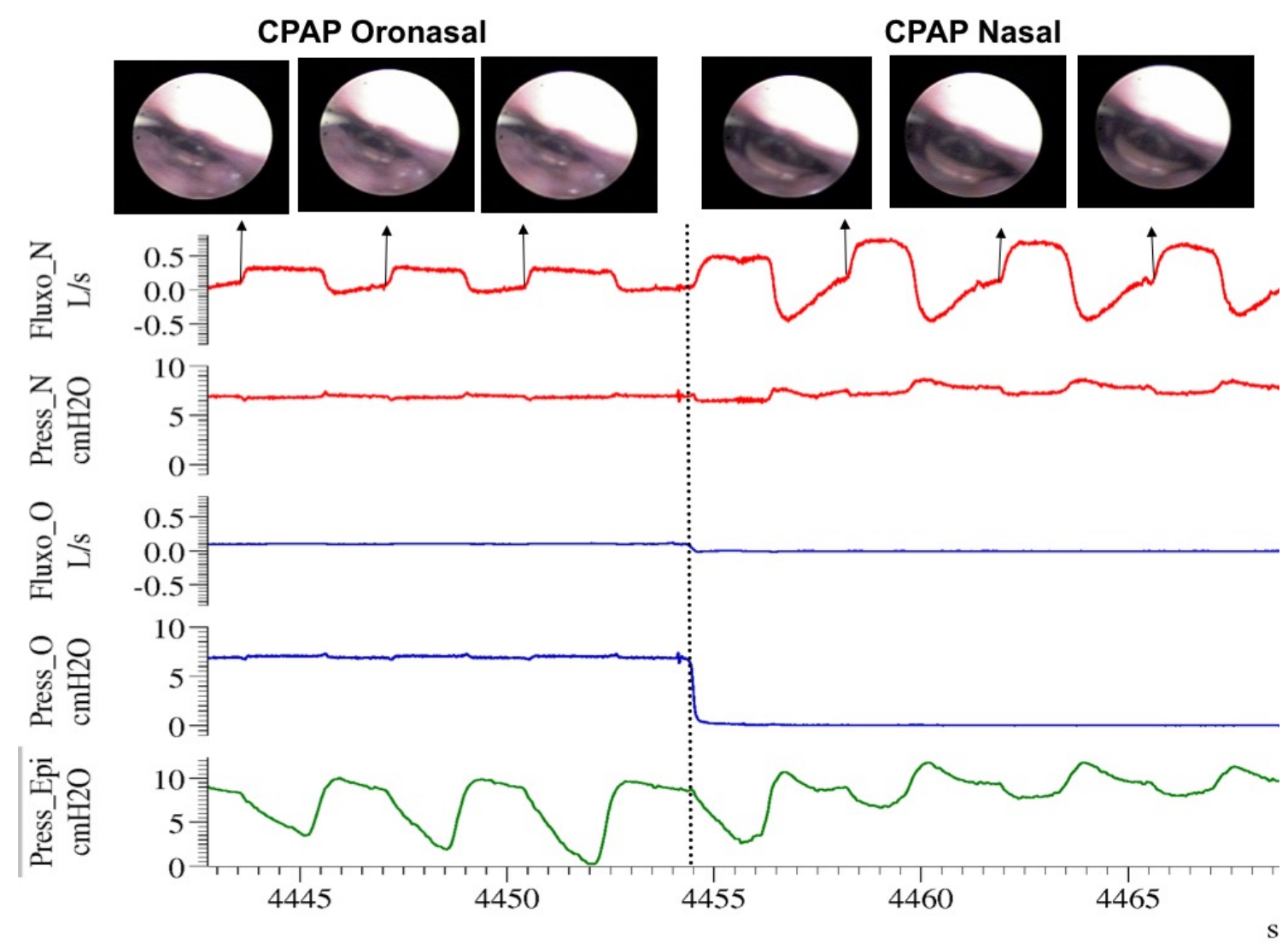

Figura 19: Exemplo representativo de mudança aguda de rota de CPAP oronasal para nasal durante limitação de fluxo estável. Imagens na região retroglossal obtidas no final da expiração. A linha vertical tracejada indica a transição do CPAP oronasal para o nasal. A transição do CPAP oronasal para o nasal levou a um aumento das dimensões da via aérea superior e do pico de fluxo inspiratório e a diminuição concomitante do delta de pressão faríngea. Fluxo_N= fluxo nasal, Press_N = pressão no compartimento nasal da máscara, Fluxo_O = fluxo oral, Press_O = pressão no compartimento oral da máscara, Press_Epi = pressão de epiglote

As medidas de fluxo aéreo e de área de VAS foram consistentemente piores em todos os pacientes durante a rota oronasal em relação à nasal, independentemente da ordem de alteração da rota (nasal para oronasal ou oronasal para nasal), mesmo entre respiradores predominantes nasais ou exclusivos (Tabelas 6 e 7). 


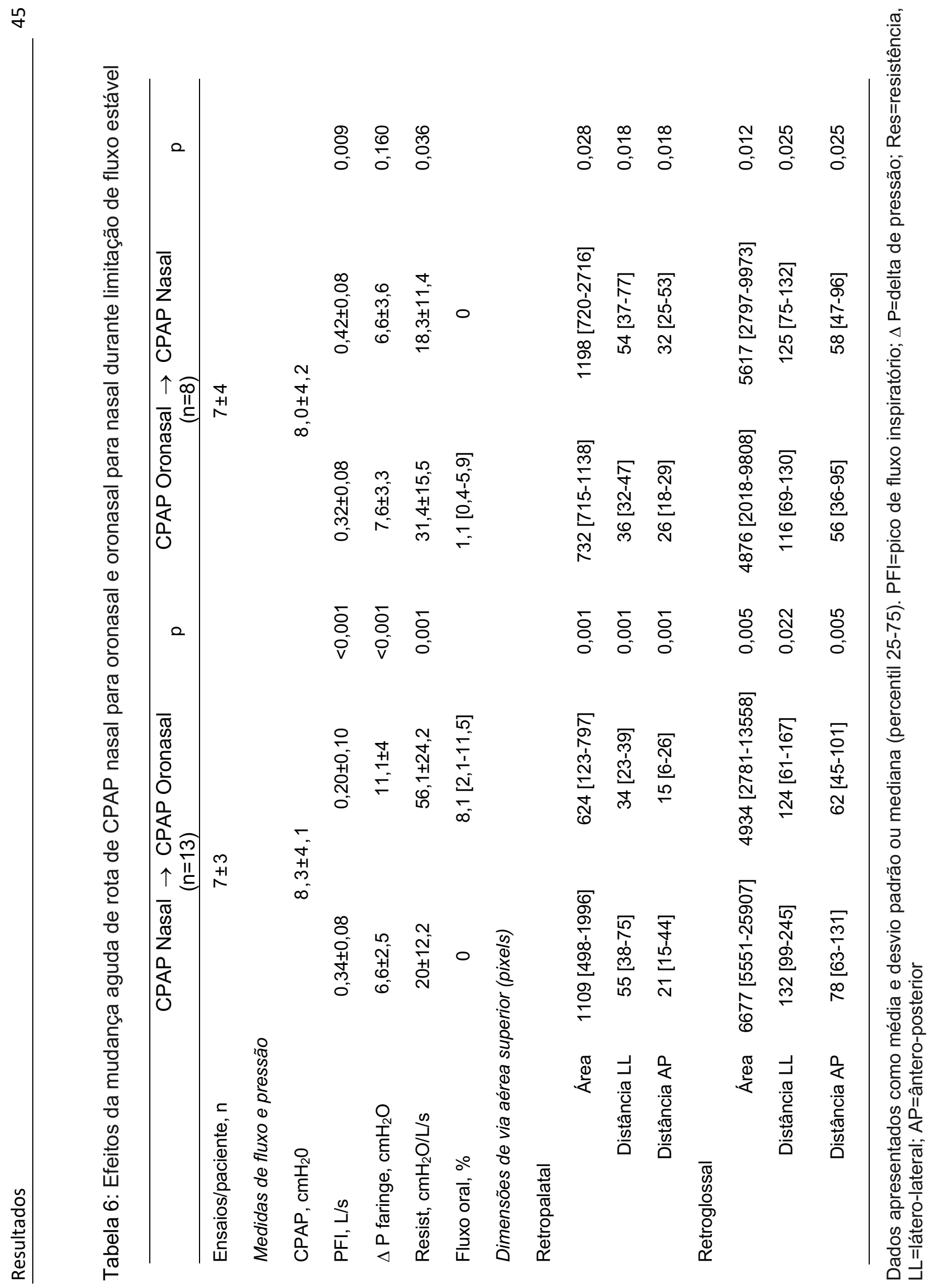


Tabela 7: Subanálise da mudança aguda de rota de CPAP nos respiradores nasais e oronasais, independente da ordem da mudança

\begin{tabular}{|c|c|c|c|c|c|c|}
\hline & \multicolumn{2}{|c|}{ Respiradores nasais $n=8$} & \multirow[b]{2}{*}{$\mathrm{p}$} & \multicolumn{2}{|c|}{ Respiradores oronasais $n=5$} & \multirow[b]{2}{*}{$\mathrm{p}$} \\
\hline & CPAP Nasal & CPAP Oronasal & & CPAP Nasal & CPAP Oronasal & \\
\hline PIF L/s & $0,39 \pm 0,08$ & $0,27 \pm 0,07$ & $<0,001$ & $0,31 \pm 0,04$ & $0,15 \pm 0,12$ & 0,040 \\
\hline$\Delta \mathrm{P}$ faríngea, $\mathrm{cmH}_{2} \mathrm{O}$ & $6,34 \pm 2,9$ & $8,6 \pm 3$ & 0,005 & $7,4 \pm 1,3$ & $14,6 \pm 3,2$ & 0,019 \\
\hline Resist, $\mathrm{cmH}_{2} \mathrm{O} / \mathrm{L} / \mathrm{s}$ & $18,4 \pm 9,5$ & $79,4 \pm 91,3$ & 0,012 & $19,5 \pm 9,6$ & $148 \pm 127$ & 0,043 \\
\hline
\end{tabular}

Dados apresentados como média e desvio padrão. $\mathrm{PFI}=$ pico de fluxo inspiratório, $\Delta \mathrm{P}=$ delta de pressão, Resist=resistência.

Quando avaliado independente da ordem da mudança de rota, os dados mostraram que: o pico de fluxo inspiratório foi menor, o delta de pressão e a resistência inspiratória das vias aéreas foram maiores, as medidas das áreas retropalatal e retroglossal foram menores na rota oronasal quando comparada com a nasal, respectivamente ( $p<0,05$ para todas as comparações). A Tabela 8 abaixo mostra a redução das dimensões da VAS na rota oronasal quando comparada com a nasal em porcentagem (considerando a rota nasal $100 \%$ ). O estreitamento da VAS foi mais pronunciado na região retropalatal do que na região retroglossal.

Tabela 8: Porcentagem de redução das dimensões de via aérea superior na rota oronasal

\begin{tabular}{cccc}
\hline Medidas & $\begin{array}{c}\text { \% de redução } \\
\text { Retropalatal }\end{array}$ & $\begin{array}{c}\text { \% de redução } \\
\text { Retroglossal }\end{array}$ & $\mathrm{p}$ \\
\hline Área & $59,4[46,4-72,4]$ & $24,1[9,4-38,9]$ & 0,002 \\
Distância ântero-posterior & $45[30,4-59,9]$ & $18,3[3,9-32,7]$ & 0,002 \\
Distância látero-lateral & $43,4[27,9-58,9]$ & $11,8[-1,2-24,9]$ & 0,005 \\
\hline
\end{tabular}

Dados apresentados como média e intervalo de confiança 
4.3 Limitação de fluxo estável com uso de fita selando cavidade oral

Em seis pacientes com baixos percentuais ou mesmo ausência de respiração oral (\% de respiração oral: $6 \pm 4 \%$, IC 1,8 - 10,3), o protocolo de limitação de fluxo foi repetido com uma fita selando a boca do paciente para evitar a transmissão do CPAP para a cavidade oral. Realizamos $6,5 \pm 2,6$ ensaios de mudança aguda de rota de CPAP por paciente. A Figura 20 mostra um exemplo representativo de uma mudança aguda de rota em limitação de fluxo estável com uso da fita. As diferenças no pico de fluxo inspiratório e na resistência inspiratória da VAS entre as rotas nasal e oronasal foram abolidas com o uso da fita selando a boca do paciente (Figuras $21 \mathrm{~A}$ e B). 


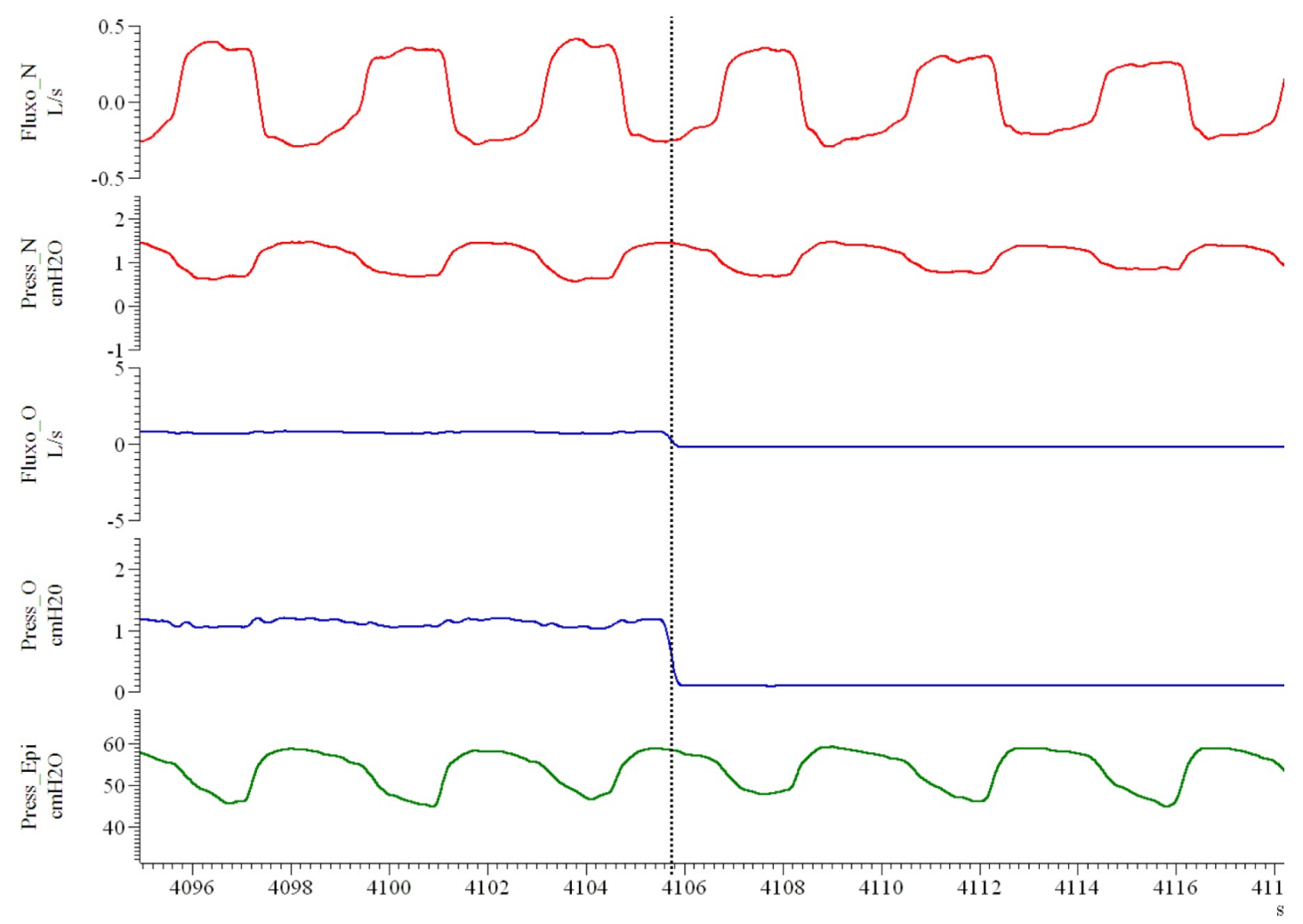

Figura 20: Exemplo representativo de mudança aguda de rota de CPAP oronasal para nasal durante limitação de fluxo estável com uso de fita oral. A linha vertical tracejada indica a transição do CPAP oronasal para o nasal. O uso da fita oral, impedindo a transmissão de pressão oral, eliminou as diferenças entre rota oronasal e nasal. Fluxo_N= fluxo nasal, Press_N = pressão no compartimento nasal da máscara, Fluxo_O $=$ fluxo oral, Press_O $=$ pressão no compartimento oral da máscara, Press_Epi = pressão de epiglote 
A.

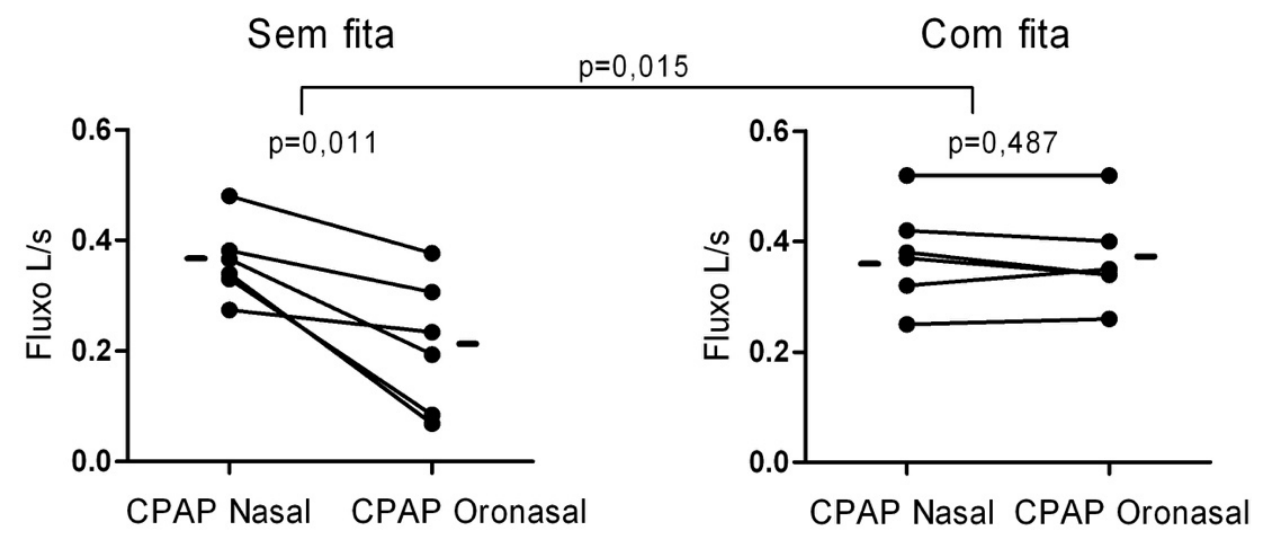

B.

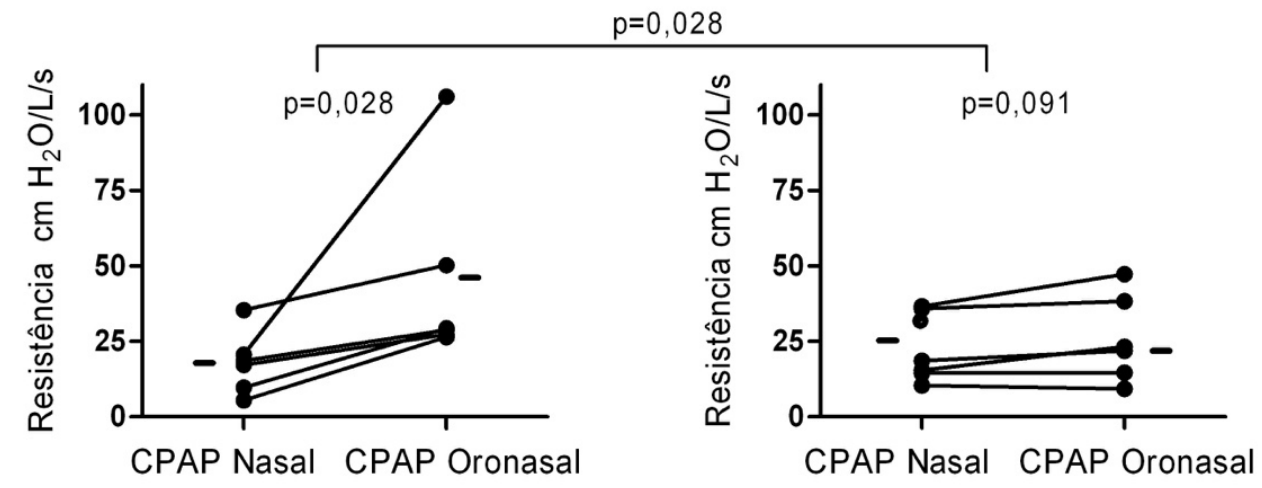

Figura 21: Efeitos das alterações agudas do CPAP no fluxo aéreo e na resistência da via aérea superior antes e depois de bloquear a cavidade oral do paciente. Os pontos representam a média do pico de fluxo de cada paciente (A) e resistência da via aérea superior (B) na limitação do fluxo estável no CPAP nasal e oronasal com e sem fita bucal. A queda significativa do pico de fluxo e o aumento da resistência da via aérea superior do CPAP nasal para o oronasal foram eliminados pelo uso de fita adesiva na boca 


\section{Discussão}

Nosso estudo fornece evidências consistentes de que a pressão transmitida pela cavidade oral durante o CPAP oronasal compromete a eficácia do tratamento da AOS. Nossos principais achados foram: 1. Como esperado, o CPAP nasal foi titulado com sucesso em todos os pacientes. Em contraste, o CPAP oronasal aboliu os eventos respiratórios obstrutivos apenas nos respiradores nasais. Todos os respiradores orais (respiração oral >25\%) tiveram eventos obstrutivos, mesmo com o aumento da pressão do CPAP oronasal até o nível máximo tolerado; 2. A pressão titulada de CPAP foi significativamente maior durante o CPAP oronasal quando comparado ao nasal, mesmo no subgrupo de respiradores nasais; 3. A diferença entre as pressões tituladas de CPAP nasal e oronasal foi diretamente associada à porcentagem de respiração oral; 4. Durante as mudanças agudas de rota de CPAP sob limitação de fluxo estável, o desempenho do CPAP oronasal foi pior do que o CPAP nasal. Em comparação ao CPAP nasal, o oronasal levou a um pico de fluxo inspiratório menor, um delta de pressão faríngea e resistência inspiratória maiores. Essas alterações fisiológicas foram associadas a menores dimensões da VAS nas áreas retropalatal e retroglossal; 5. Finalmente, as diferenças causadas pela mudança da rota de CPAP durante a limitação de fluxo estável entre os pacientes com baixa ou nenhuma porcentagem de respiração oral foram eliminadas pelo uso de uma fita impedindo a transmissão de pressão para a cavidade oral. 
Em um estudo recente feito no Laboratório do Sono, mostramos que o CPAP com rotas oronasal e oral induziu a obstrução progressiva da VAS entre pacientes com AOS sem obstrução nasal ${ }^{65}$. No entanto, o comportamento da VAS durante o sono poderia ser diferente entre pacientes com obstrução nasal. Por esta razão, todos os pacientes incluídos no presente estudo tinham história de ser respiradores oronasais e estavam bem adaptados ao CPAP oronasal por pelo menos um ano. Apesar de uma indicação teoricamente adequada de uma máscara oronasal, todos os pacientes foram titulados com sucesso com uma máscara nasal. Quando objetivamente medimos o padrão de fluxo respiratório durante o sono com CPAP durante rota oronasal, 6 dos 11 pacientes estavam respirando predominantemente pelo nariz durante a titulação. É possível que todos os pacientes tenham sido inicialmente respiradores oronasais e o padrão de respiração tenha mudado após o início do CPAP, como anteriormente mostrado ${ }^{66-68}$. Bachour et al. ${ }^{66}$ avaliaram a porcentagem de respiração oral em pacientes voluntários sem obstrução nasal e observaram uma queda de $62 \%$ da respiração oronasal após três meses de CPAP. Ruhle et al. ${ }^{67}$ estudaram a porcentagem de respiração oronasal antes e após a adaptação de CPAP com máscara nasal em 11 pacientes. Os pacientes realizaram uma polissonografia com pneumotacógrafo acoplado a uma máscara oral e prongs nasais para medida de fluxo oral e nasal. Em uma segunda noite, o CPAP com máscara nasal foi adaptado ao paciente. Houve redução imediata da frequência de respiração oral, o índice de respiração oral por tempo total de sono reduziu 97\% (de $26,9 \pm 15,7$ para $0,8 \pm 1,2$ ). Essa observação de mudança no padrão de respiração após o início do CPAP também reconcilia o recente estudo randomizado cruzado, que não mostrou diferenças no desempenho entre CPAP 
nasal e oronasal entre pacientes já estabelecidos no tratamento ${ }^{72}$. Tal achado também pode ser justificado pela recente observação de que, ao contrário do que se esperava, o CPAP oronasal teve a maior adesão entre pacientes com baixos sintomas de obstrução nasal ${ }^{73}$.

Na prática clínica, outra possível utilidade para o CPAP oronasal é que a máscara oronasal pode funcionar como um suporte de mento. Porém isto também não está livre de potenciais consequências deletérias. Ao menos um estudo indica que a máscara oronasal pode empurrar o mento e a língua para trás, induzindo a obstrução da $\mathrm{VAS}^{74}$. Em nosso estudo, essa variável foi controlada, uma vez que as titulações nasal e oronasal de CPAP foram realizadas com a mesma máscara. Portanto, é possível que o CPAP seja ainda mais comprometido pela máscara oronasal na prática clínica devido a mudanças na posição do queixo.

Deve-se ressaltar que, mesmo entre os respiradores predominantemente nasais, o CPAP oronasal titulado foi em média $1 \mathrm{cmH}_{2} \mathrm{O}$ maior que o CPAP nasal. Essa observação é consistente com a hipótese de que a pressão pode ser transmitida pela cavidade oral mesmo entre os respiradores predominantemente nasais. A necessidade de níveis mais elevados de CPAP oronasal em comparação com o nasal pode ser explicada pela perda de gradiente de pressão que é proporcional à porcentagem de respiração oral (Figura 1B). Esse achado é consistente com os estudos que mostram que a pressão de CPAP oronasal é superior à CPAP nasal na prática clínica ${ }^{44,51,54,61}$. O uso generalizado de máscara oronasal para tratar a AOS é potencialmente prejudicial pelo fato de ser geralmente utilizada em pacientes com altos níveis de sintomas de obstrução nasal ${ }^{75}$ onde a porcentagem de respiração oral durante o sono é desconhecida. 
Respiração oral (> 25\%) resultou em falha na titulação da CPAP oronasal em todos os pacientes estudados. Tal evidência pode explicar o fenômeno paradoxal em que o CPAP oronasal pode ser ineficaz a despeito de altas pressões terapêuticas, descrito previamente em alguns pacientes ${ }^{11,48,63,64,76}$. Westhoff et al. ${ }^{64}$ realizaram uma coorte com 65 pacientes que apresentavam IAH residual aumentado ou sono não restaurador com IAH residual normal utilizando CPAP com máscara oronasal. A simples troca para máscara nasal resultou em diminuição do IAH residual, dos níveis pressóricos de CPAP e melhora da qualidade do sono. Em 2016, $\mathrm{Ng}$ et al. ${ }^{69}$ descreveram quatro pacientes que apresentavam alto IAH residual a despeito de altas pressões de CPAP. Foi realizada troca para máscara nasal e houve estabilização dos eventos obstrutivos com pressões menores de CPAP.

Em nosso estudo, também avaliamos o desempenho do CPAP oronasal e nasal durante a limitação do fluxo estável. O desempenho inferior do CPAP oronasal ocorreu mesmo com baixa ou nenhuma porcentagem de fluxo oral (Figura 18 e 19, Tabela 2). A hipótese de que a transmissão de pressão para a cavidade oral existe e prejudica o desempenho do CPAP oronasal mesmo durante a respiração nasal foi confirmada pela observação de que a utilização de uma fita adesiva na boca eliminou as diferenças entre o desempenho de CPAP oronasal e nasal.

Estudos anteriores mostrando colapso retroglossal durante o CPAP oronasal levaram à hipótese de que a pressão oral empurrava a língua para trás ${ }^{48,65}$. Nosso estudo mostrou que o padrão de obstrução durante o CPAP oronasal é, na verdade, mais pronunciado na região retropalatal e, portanto, semelhante ao observado em pacientes com AOS durante pressão 
atmosférica $^{77,78}$. Essa observação é consistente com a hipótese de que a transmissão da pressão pela cavidade oral neutraliza a pressão positiva aplicada pelo nariz ${ }^{11}$.

Nosso estudo apresenta várias limitações. Primeiramente, estudamos um número relativamente pequeno de pacientes. No entanto, os pacientes foram bem instrumentados e os resultados consistentes em várias repetições e diferentes condições indicam claramente que a transmissão de pressão pela cavidade oral, associada ou não ao fluxo oral, compromete a eficácia do CPAP com máscara oronasal no tratamento da AOS. Em segundo lugar, devido ao nível de instrumentação, só temos dados na posição supina. Recentemente, publicamos um relato de caso de um paciente com AOS em quem o CPAP oronasal não era eficaz na posição supina, porém a respiração estabilizou quando o paciente assumiu a posição lateral ${ }^{79}$. Na posição lateral, é possível que a porcentagem de respiração oral durante o CPAP diminua e, consequentemente a eficácia do CPAP oronasal aumente. Esta hipótese não foi testada no presente estudo, mas concilia a observação de que todos os nossos pacientes estavam bem adaptados ao CPAP oronasal. Também é possível que o simples fato da colapsabilidade da via aérea reduzir na posição lateral ${ }^{80}$ aumente a eficácia da máscara oronasal.

Nosso estudo fornece uma teoria que unifica e explica o desempenho variável do CPAP oronasal. Nós fornecemos evidências de que a respiração oronasal compromete a eficácia do CPAP oronasal, mais acentuadamente entre os respiradores oronasais.

A Figura 22 resume o funcionamento variável da máscara oronasal. 

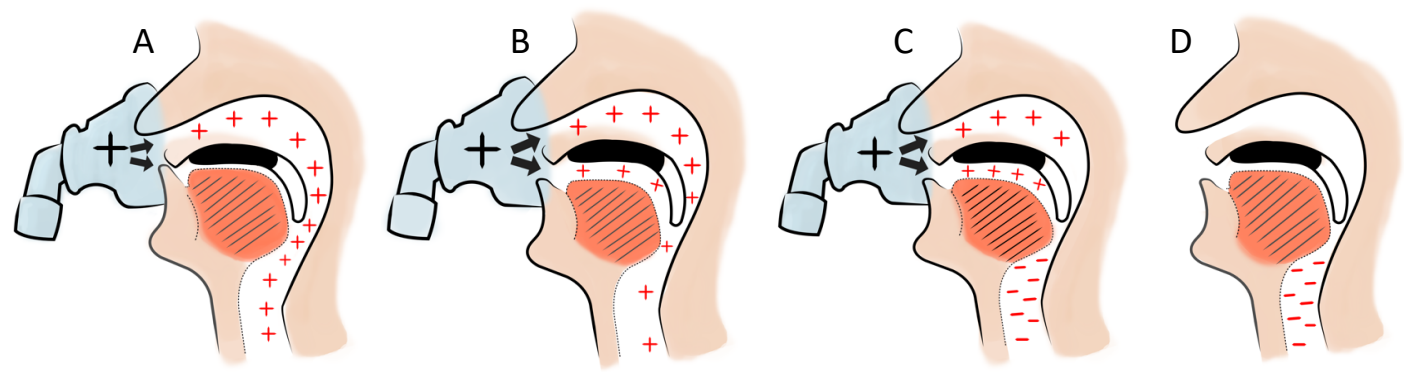

Figura 22: Representação do funcionamento variável da máscara oronasal. A: máscara oronasal funciona adequadamente. Paciente apresenta respiração exclusivamente nasal. Pode ocorrer perda discreta do gradiente pressórico sendo compensado com aumento discreto da pressão de CPAP. B: máscara oronasal com paciente apresentando respiração nasal e oral concomitantes, levando à maior perda do gradiente pressórico em relação à figura $A$. Essa situação pode ser compensada com aumento significativo de pressão de CPAP. C: máscara oronasal com paciente apresentando respiração oral $>25 \%$, levando à perda total do gradiente pressórico. Desta maneira, o paciente se comporta como um paciente com AOS sem tratamento com CPAP(D).

O uso generalizado da máscara oronasal é preocupante, principalmente porque a presença de respiração oronasal é ao mesmo tempo a principal indicação e a principal causa de falha do CPAP oronasal. Além disso, mesmo entre os respiradores predominantemente nasais, o desempenho do CPAP oronasal é pior do que o CPAP nasal devido à deletéria transmissão de pressão pela cavidade oral. Este efeito pode ser compensado por um nível mais elevado de CPAP oronasal. No entanto, quando o CPAP é subtitulado, a transmissão de pressão pela cavidade oral pode causar obstrução da VAS. Este cenário pode ocorrer durante o auto CPAP ou quando o tipo de máscara é alterado sem uma nova titulação de CPAP. 
6. CONCLUSÃO 


\section{Conclusão}

O desempenho do CPAP com máscara oronasal em pacientes com AOS se mostrou inferior a máscara nasal por apresentar:

1. Maior pressão de titulação;

2. Maior pressão de CPAP quanto maior a porcentagem de fluxo oral;

3. Desempenho inferior durante as mudanças agudas de rota de CPAP na limitação de fluxo estável, mesmo em pacientes respiradores nasais. Evidenciado por menor pico de fluxo inspiratório e áreas retropalatal e retroglossal, maior delta de pressão faríngea e resistência da via aérea superior durante a rota oronasal quando comparada à nasal.

O uso da fita selando a boca do paciente aboliu as diferenças no pico de fluxo inspiratório e na resistência inspiratória da VAS entre as rotas nasal e oronasal.

Portanto, a máscara nasal deve ser a primeira oferecida à pacientes com AOS iniciando o tratamento com CPAP. 
7. ANEXOS 


\section{Anexos}

7.1 Parecer comissão científica

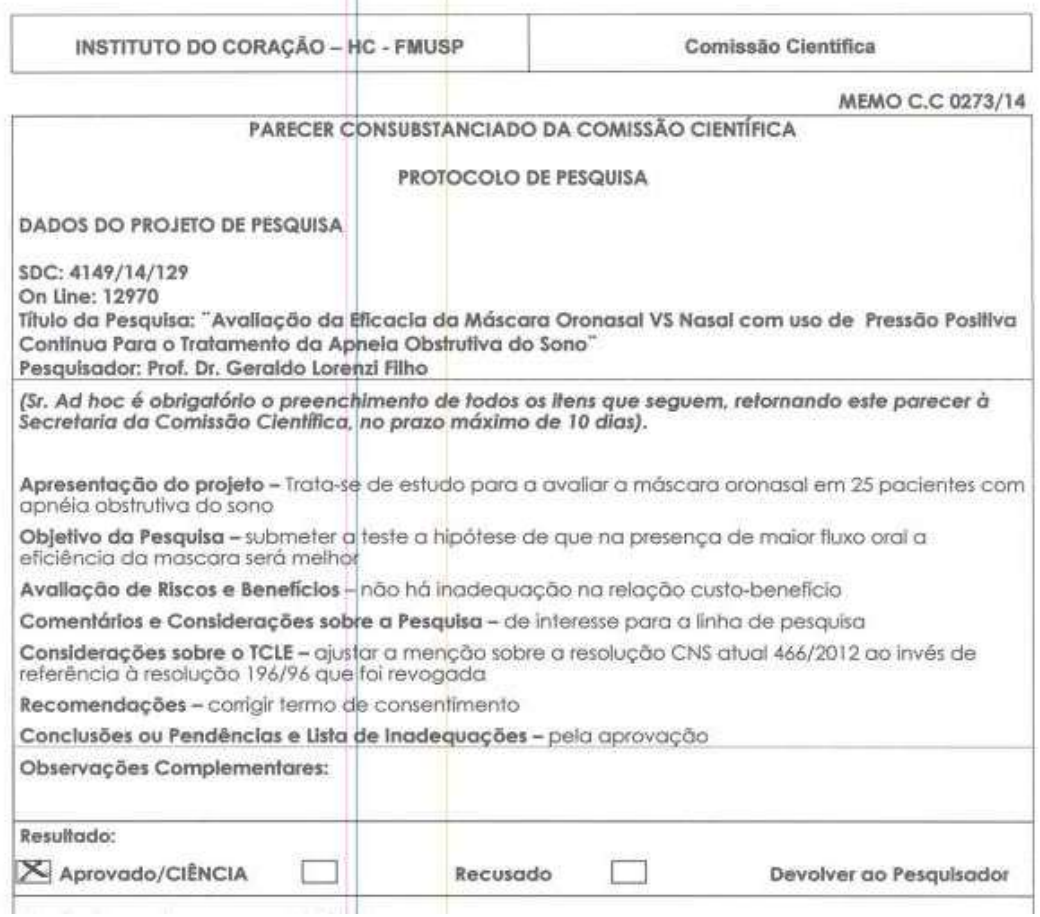

7.2 Termo de consentimento livre e esclarecido

HOSPITAL DAS CLÍNICAS DA FACULDADE DE MEDICINA DA UNIVERSIDADE DE SÃO PAULO-HCFMUSP

TERMO DE CONSENTIMENTO LIVRE E ESCLARECIDO

DADOS DE IDENTIFICAÇÃO DO SUJEITO DA PESQUISA OU RESPONSÁVEL LEGAL

1. NOME:

DOCUMENTO DE IDENTIDADE No : SEXO : .M $\square \quad F$ DATA NASCIMENTO: ........................ 
ENDEREÇO

$\mathrm{N}^{\circ}$

APTO:

BAIRRO:

CIDADE

CEP:

TELEFONE:

DDD

$(\ldots \ldots \ldots \ldots)$

2.RESPONSÁVEL

LEGAL

NATUREZA (grau de parentesco, tutor, curador etc.

DOCUMENTO DE IDENTIDADE

SEXO: $M \square \quad F \square$

DATA NASCIMENTO.: ....../.............

ENDEREÇO:

$\mathrm{N}^{\circ}$

APTO:

BAIRRO:

CIDADE:

CEP:

TELEFONE:

DDD

\section{DADOS SOBRE A PESQUISA}

1. TÍTULO DO PROTOCOLO DE PESQUISA: AVALIAÇAO DA EFICACIA DA MÁSCARA ORONASAL VS NASAL COM USO DE PRESSÃO POSITIVA CONTINUA PARA O TRATAMENTO DA APNEIA OBSTRUTIVA DO SONO

PESQUISADOR : Geraldo Lorenzi Filho

CARGO/FUNÇÃO: Prof. Livre docente/ Diretor do Laboratório do Sono InCor

INSCRIÇÃO CONSELHO REGIONAL N 52063

UNIDADE DO HCFMUSP: Serviço de Pneumologia

3. AVALIAÇÃO DO RISCO DA PESQUISA:

$\begin{array}{ll}\text { RISCO MíNIMO } \mathbf{X} & \text { RISCO MÉDIO } \\ \text { RISCO BAIXO } \quad \square & \text { RISCO MAIOR }\end{array}$

4.DURAÇÃO DA PESQUISA : 48 meses 


\section{HOSPITAL DAS CLÍNICAS DA FACULDADE DE MEDICINA DA UNIVERSIDADE DE SÃO PAULO-HCFMUSP}

Você está sendo convidado a participar de um estudo de pesquisa clínica. Os detalhes do estudo são fornecidos a seguir para que você possa decidir sobre sua participação, que é voluntária. O estudo que visa avaliar os efeitos da máscara que cobre só o nariz e da máscara que cobre o nariz e boca no tamanho da sua garganta quando o ar é empurrado delicadamente para os pulmões através do dispositivo de pressão positiva continua nas vias aéreas conhecido pelo nome de CPAP, que é o tratamento padrão para apneia obstrutiva do sono.

A apneia obstrutiva do sono caracteriza-se pelo fechamento repetido da garganta durante o sono. Esta doença pode acarretar diversos problemas para a saúde como, por exemplo, cansaço, sonolência durante o dia e doenças cardiovasculares. $O$ tratamento de $1^{\text {a }}$ opção para a apneia obstrutiva do sono é o aparelho de CPAP, ele empurra delicadamente uma quantidade de ar para os pulmões mantendo a garganta aberta durante todo o sono. Apesar de haver diversas opções de máscaras para serem usadas com o CPAP, a efetividade pode não ser igual. Alguns estudos mostraram que a máscara que cobre o nariz e a boca pode exigir maior pressão de CPAP do que a máscara que cobre só o nariz, por exemplo. No presente estudo pretendemos estudar a eficácia do CPAP para tratamento da AOS administrado por via oronasal em pacientes já usuários desta terapia. Iremos comparar o tamanho da área da sua garganta quando você estiver utilizando a máscara que cobre só o nariz, e uma que cobre a boca e nariz ao mesmo tempo. Caso concorde em participar do estudo, você responderá algumas perguntas sobre problemas de saúde passados e/ou atuais, medicamentos, que usa normalmente, problemas nasais e sobre o risco de cochilar durante o dia. Você fará uma série de exames para avaliar seu sono. Os exames são os seguintes:

Polissonografia noturna com titulação: Você irá realizar um estudo do sono onde o mesmo será monitorado através de eletrodos colocados na cabeça, e a respiração através de cintas no tórax e abdômen. Você utilizará uma máscara de nariz e boca parecida com a que faz uso em casa, essa máscara vai nos permitir avaliar por onde o você respira predominantemente a noite, se pela boca ou pelo nariz. Será também avaliada se sua apneia pode ser totalmente tratada com a máscara nariz e boca e qual a melhor pressão de CPAP para isso.

Avaliação endoscópica sob sono induzido: Caso na polissonografia não seja encontrada uma pressão ideal para tratar sua apneia, na manhã seguinte a este exame você deverá se manter em jejum ao acordar. O seu nariz e sua garganta serão anestesiados com xilocaína tópica. Será feita uma punção venosa para aplicação de soro com uma dose baixa de sedativo (midazolam) que vai fazer você dormir por aproximadamente 40 minutos. Durante este exame, seu sono será novamente monitorado através de eletrodos colocados na cabeça, e a respiração através de cintas no tórax e abdômen. O seu nariz e sua garganta serão examinados por um aparelho endoscópico fino e flexível que permite-nos olhar diretamente, através de uma câmera, o nariz e a garganta. Esse aparelho é parecido com o aparelho de endoscopia que é usado para quem tem problemas de estômago. A diferença é que esse aparelho é mais fino e é colocado diretamente em uma narina. Pela outra narina terá um outro aparelho 
( ainda mais fino ) para medir a pressão na garganta. Você usará uma máscara especial que cobrirá o seu nariz e boca. Esta máscara nos permitirá direcionar o fluxo de ar exclusivamente pelo nariz e pelo nariz e pela boca simultaneamente. O endoscópio será passado através da máscara e chegará até o seu nariz. A máscara será conectada a um aparelho de CPAP. Pode haver um pequeno desconforto quando for trocado o fluxo de ar do nariz e boca para o nariz, o que pode fazer com que você desperte do sono. Todo o exame será registrado no computador e filmado, o que nos permitirá medir o tamanho da área da sua garganta. O risco do exame é baixo, você estará acompanhado por um médico durante todo o exame e em caso de necessidade será administrado oxigênio pelo nariz. Não será realizado nenhum corte ou biópsia, ou até mesmo cirurgia durante o exame. O exame envolve apenas um desconforto (incômodo) à passagem dos aparelhos pelo nariz. Após o exame, será necessário um breve repouso de aproximadamente 30 minutos, no laboratório do sono até passar o efeito da medicação por completo. De forma semelhante a um exame de endoscopia do estômago, você precisará de um acompanhante para ir para casa após o exame. Você não deverá dirigir qualquer tipo de automóvel, operar máquinas ou nem mesmo exercer atividades que exijam muita atenção.

Em qualquer fase do estudo, você terá acesso aos profissionais responsáveis pela pesquisa para esclarecimento de eventuais dúvidas. O principal investigador é o Dr. Geraldo Lorenzi Filho, que pode ser encontrado no endereço Av. Dr. Enéas de Carvalho Aguiar, 44-7 ${ }^{\circ}$ andar (Laboratório do Sono), São Paulo, S.P., CEP 05403-000, ou pelo telefone: (11)2661-5486. Se você tiver alguma consideração ou dúvida sobre a ética da pesquisa, entre em contato com o Comitê de Ética em Pesquisa - Rua Ovidio Pires de Campos, 225- $5^{\circ}$ andar, São Paulo, S.P., CEP 05403-000, pelo telefone: (11)2661-6442 (ramais 16,17 ou 18), ou por email: cappesq.adm@hc.fm.usp.br

Os pesquisadores asseguram a privacidade dos voluntários quanto aos dados confidenciais envolvidos na pesquisa, sendo divulgados única e exclusivamente com finalidade científica sem a identificação dos participantes. $O$ (a) senhor (a) tem o direito de ser mantido atualizado sobre os resultados parciais da pesquisa, quando em estudos abertos, ou de resultados que sejam do conhecimento dos pesquisadores. O voluntário tem a liberdade de retirar seu consentimento a qualquer momento e deixar de participar do estudo, sem qualquer ônus e ou obrigação.

Não há despesas pessoais para o participante em qualquer fase do estudo, incluindo exames e consultas. Também não há compensação financeira relacionada à sua participação. Garantimos o ressarcimento por despesas decorrentes da pesquisa e indenização por eventuais danos decorrentes da pesquisa. Este termo de consentimento possui duas vias idênticas, sendo uma para o participante voluntário e outra para o pesquisador responsável.

Os pesquisadores se comprometem a utilizar os dados coletados somente para esta pesquisa.

Este termo de consentimento livre e esclarecido foi elaborado de acordo com as diretrizes e normas regulamentadas de pesquisa envolvendo seres humanos atendendo à Resolução $n^{\circ}$. 196, de 10 de Outubro de 1996, do Conselho Nacional de Saúde do Ministério de Saúde- Brasília-DF.

Acredito ter sido suficientemente informado a respeito das informações que li ou que foram lidas para mim, descrevendo o estudo" AVALIAÇAO DA EFICACIA DA MÁSCARA 
ORONASAL VS NASAL COM USO DE PRESSÃO POSITIVA CONTINUA PARA O TRATAMENTO DA APNEIA OBSTRUTIVA DO SONO."

Eu discuti com o Dr. Geraldo Lorenzi Filho. sobre a minha decisão em participar nesse estudo. Ficaram claros para mim quais são os propósitos do estudo, os procedimentos a serem realizados, seus desconfortos e riscos, as garantias de confidencialidade e de esclarecimentos permanentes. Ficou claro também que minha participação é isenta de despesas e que tenho garantia do acesso a tratamento hospitalar quando necessário. Concordo voluntariamente em participar deste estudo e poderei retirar o meu consentimento a qualquer momento, antes ou durante o mesmo, sem penalidades ou prejuízo ou perda de qualquer benefício que eu possa ter adquirido, ou no meu atendimento neste Serviço.

Assinatura do paciente/representante legal Data

11

Assinatura da testemunha

Data l

para casos de pacientes menores de 18 anos, analfabetos, semianalfabetos ou portadores de deficiência auditiva ou visual.

(Somente para o responsável do projeto)

Declaro que obtive de forma apropriada e voluntária o Consentimento Livre e Esclarecido deste paciente ou representante legal para a participação neste estudo.

Assinatura do responsável pelo estudo

Data

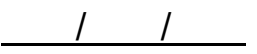

\subsection{Ficha de Avaliação}

COMPORTAMENTO DA FARINGE EM MÁSCARA ORONASAL 


\begin{tabular}{|ll|}
\hline RG HC: & $\begin{array}{l}\text { Data Avaliação: } \\
\text { Local do recrutamento: }\end{array}$ \\
\hline Endereço: & Data de Nascimento: $\quad$ Idade: \\
\hline Telefone: & Profissão: \\
\hline Estado Civil: & \\
\hline Queixa Principal : & \\
\hline & \\
\hline Antecedentes: & \\
\hline
\end{tabular}

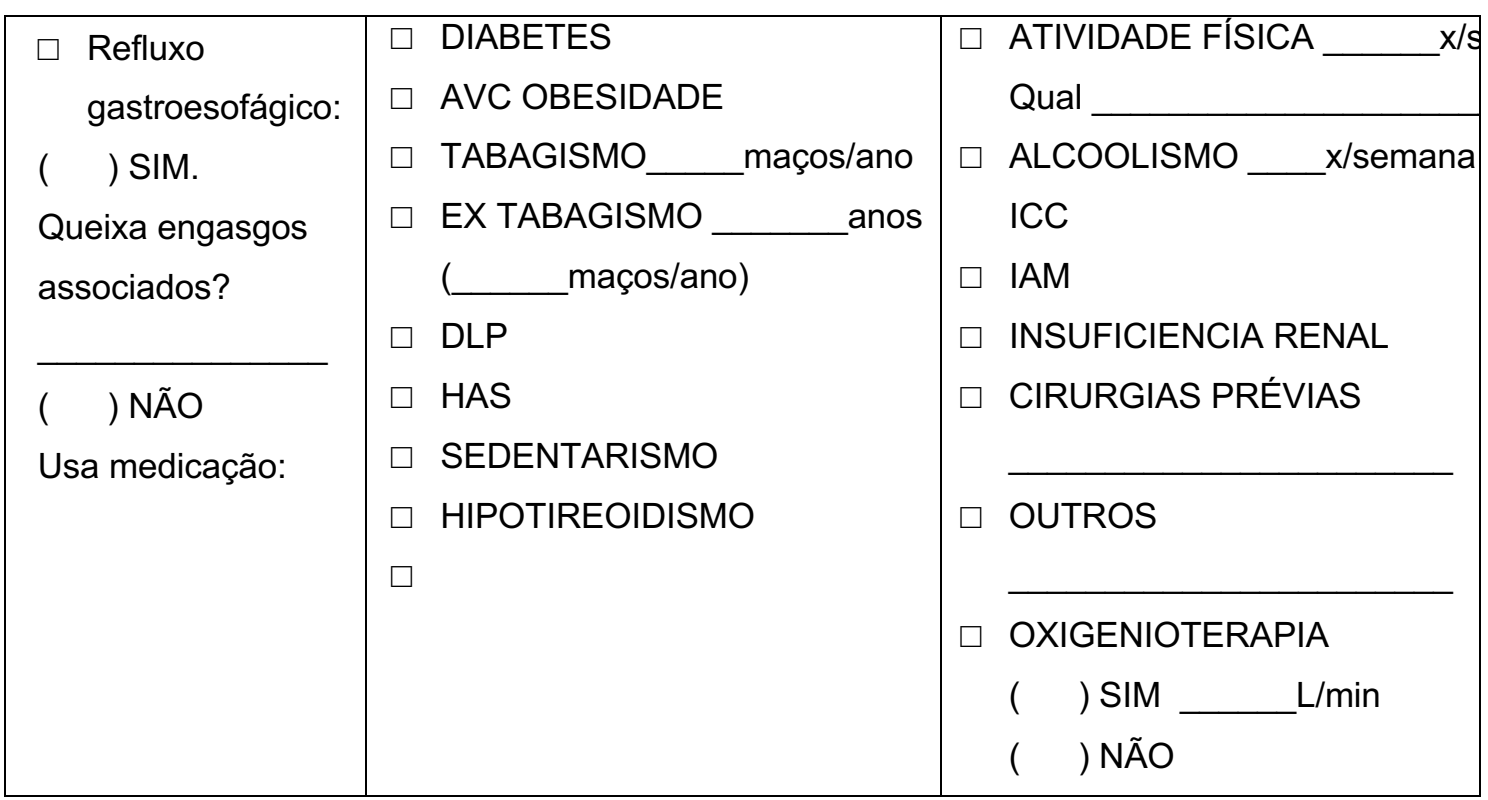

AVALIAÇÃO DO SONO

\begin{tabular}{|l|l|}
\hline Que horas vai dormir: & $\begin{array}{l}\text { Dificuldade em iniciar o sono: ( ) sim ( ) } \\
\text { não }\end{array}$ \\
\hline Que horas acorda: & $\begin{array}{l}\text { Dificuldade em manter o sono: ( ) sim ( ) } \\
\text { não }\end{array}$ \\
\hline
\end{tabular}


Medicamento para o sono:
Posição preferencial para dormir:

( ) supino ( ) lateral ( ) dorsal

\section{AVALIAÇÃO RESPIRAÇÃO}

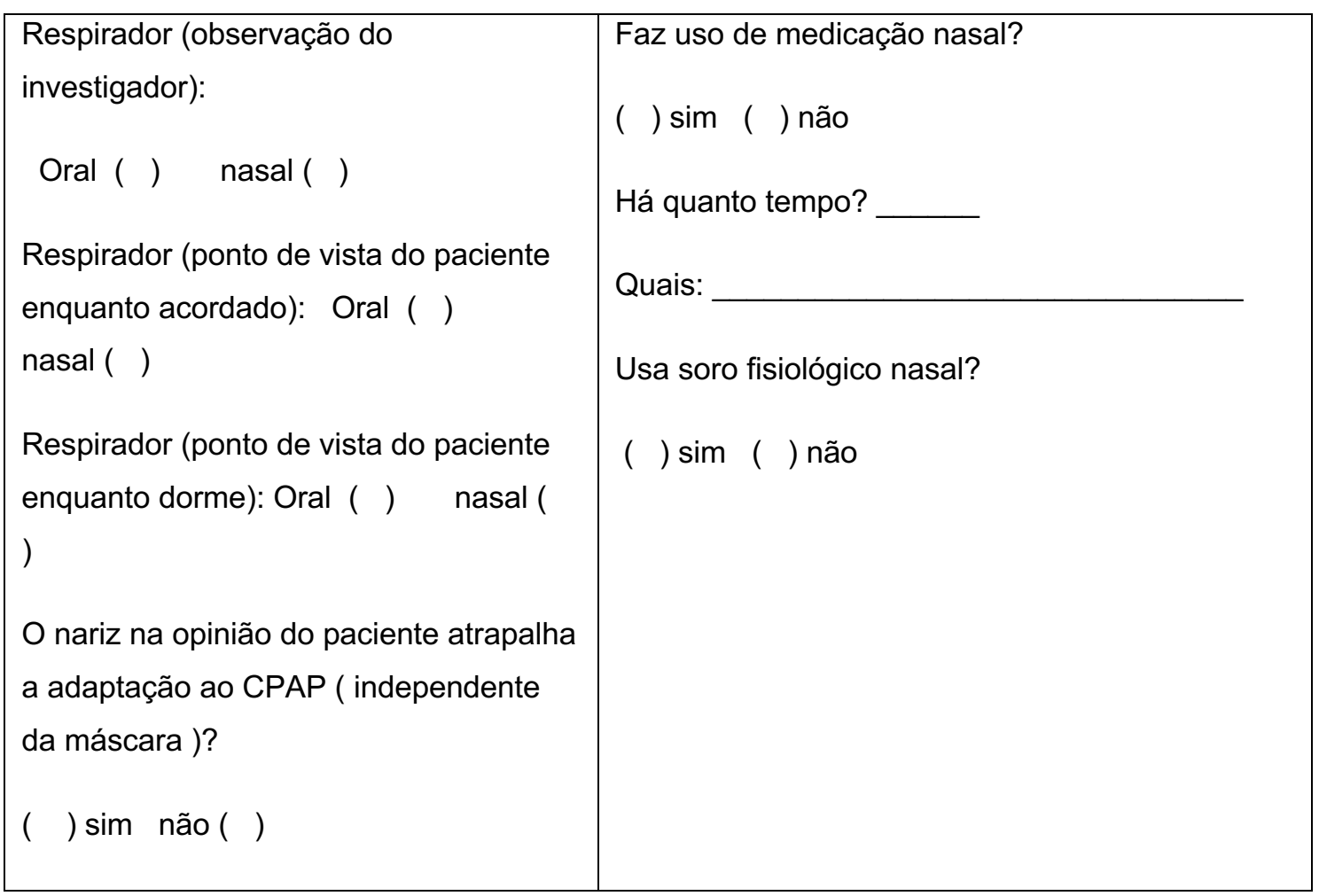

\section{CPAP PACIENTE}

\begin{tabular}{|l|l|}
\hline Usa CPAP desde: & Máscara(tamanho e modelo): \\
\hline Marca e modelo: & Pressão: \\
\hline Já utilizou outras máscaras: & Usa todos os dias: ( ) sim ( ) não \\
\hline Nível de satisfação: & Motivo: \\
\hline ( ) ótimo ( ) bom ( ) razoável ( ) ruim & \\
\hline Tem cartão de leitura com IAH residual? & \\
\end{tabular}


POLISSONOGRAFIA DIAGNOSTICA

\begin{tabular}{|l|l|l|}
\hline PSG (_____ & TTS (min): & Eficiência (\%): \\
\hline REM (\%): & $\mathrm{N} 3(\%):$ & N2 (\%): N1 (\%): \\
\hline $\mathrm{SO}_{2}$ mín (\%): & $\mathrm{SO}_{2}$ MÉDIA (\%): & $\begin{array}{l}\text { Despertares }\left(\mathrm{n}^{\circ}\right) \_ \\
\text {(índice): }\end{array}$ \\
\hline IAH: & $\mathrm{N}^{\circ}$ eventos: & HIPOPNEIAS: \\
\hline APNEIAS CENTRAIS: & A. OBSTRUTIVAS: & A. MISTAS: \\
\hline IAH SUPINA: & MOV DE PERNAS: & $\begin{array}{l}\text { MEDICAÇAO NO } \\
\text { EXAME: }\end{array}$ \\
& & \\
\hline
\end{tabular}

POLISSONOGRAFIA COM TITULAÇÃO

\begin{tabular}{|l|l|l|}
\hline PSG (____ & TTS (min): & Eficiência (\%): \\
\hline REM (\%): & $\mathrm{N} 3(\%):$ & N2 (\%): $\quad$ N1 (\%): \\
\hline $\mathrm{SO}_{2}$ mín (\%): & $\mathrm{SO}_{2}$ MÉDIA (\%): & $\begin{array}{l}\text { Despertares }\left(\mathrm{n}^{\circ}\right) \_/ \\
\text {(índice): }\end{array}$ \\
\hline IAH RES: & $\mathrm{N}^{\circ}$ eventos: & HIPOPNEIAS: \\
\hline APNEIAS CENTRAIS: & A. OBSTRUTIVAS: \\
\hline $\begin{array}{l}\text { RELAÇÃO COM } \\
\text { POSIÇÃO }\end{array}$ & & \\
\hline
\end{tabular}


( ) 1

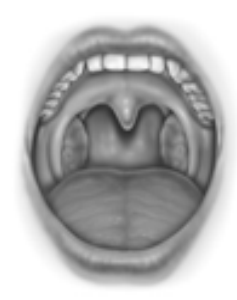

$(1) 2$

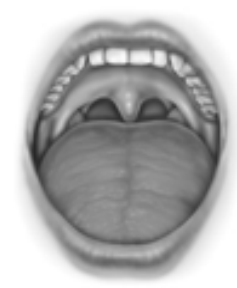

( ) 3

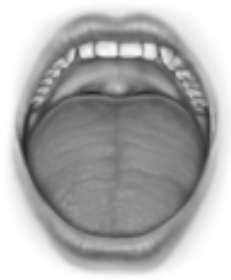

$(1) 4$

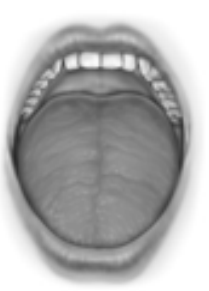

Amígdalas Hipertróficas

( ) SIM

( ) NÃO

\begin{tabular}{|c|c|}
\hline $\begin{array}{l}\text { Lábio inferior: } \\
\text { ( ) normal } \\
\text { ( ) eversão discreta } \\
\text { ( ) eversão acentuada }\end{array}$ & $\begin{array}{l}\text { Véu palatino: } \\
\text { Simétrico ( ) sim ( ) não } \\
\text { Extensão ( ) adequada ( ) longa }\end{array}$ \\
\hline $\begin{array}{l}\text { Lábios posição habitual durante } \\
\text { entrevista } \\
\text { ( ) fechados ( ) entreabertos ( ) abertos } \\
\text { ( ) fechados com tensão ( ) ora } \\
\text { aberto/fechado }\end{array}$ & $\begin{array}{l}\text { Palato duro } \\
\text { Profundidade ( ) adequada ( ) em ogiva } \\
\text { Largura ( ) adequada ( ) estreito ( ) } \\
\text { alargado }\end{array}$ \\
\hline $\begin{array}{l}\text { Úvula: } \\
\text { ( ) alongada, encosta em orofaringe } \\
\text { ( ) sim ( ) não } \\
\text { ( ) adequada }\end{array}$ & $\begin{array}{l}\text { Pilar posterior: } \\
\text { ( ) posição adequada anterior } \\
(\text { ) posteriorizado } \\
(\text { ) delgado ( ) grosso }\end{array}$ \\
\hline
\end{tabular}




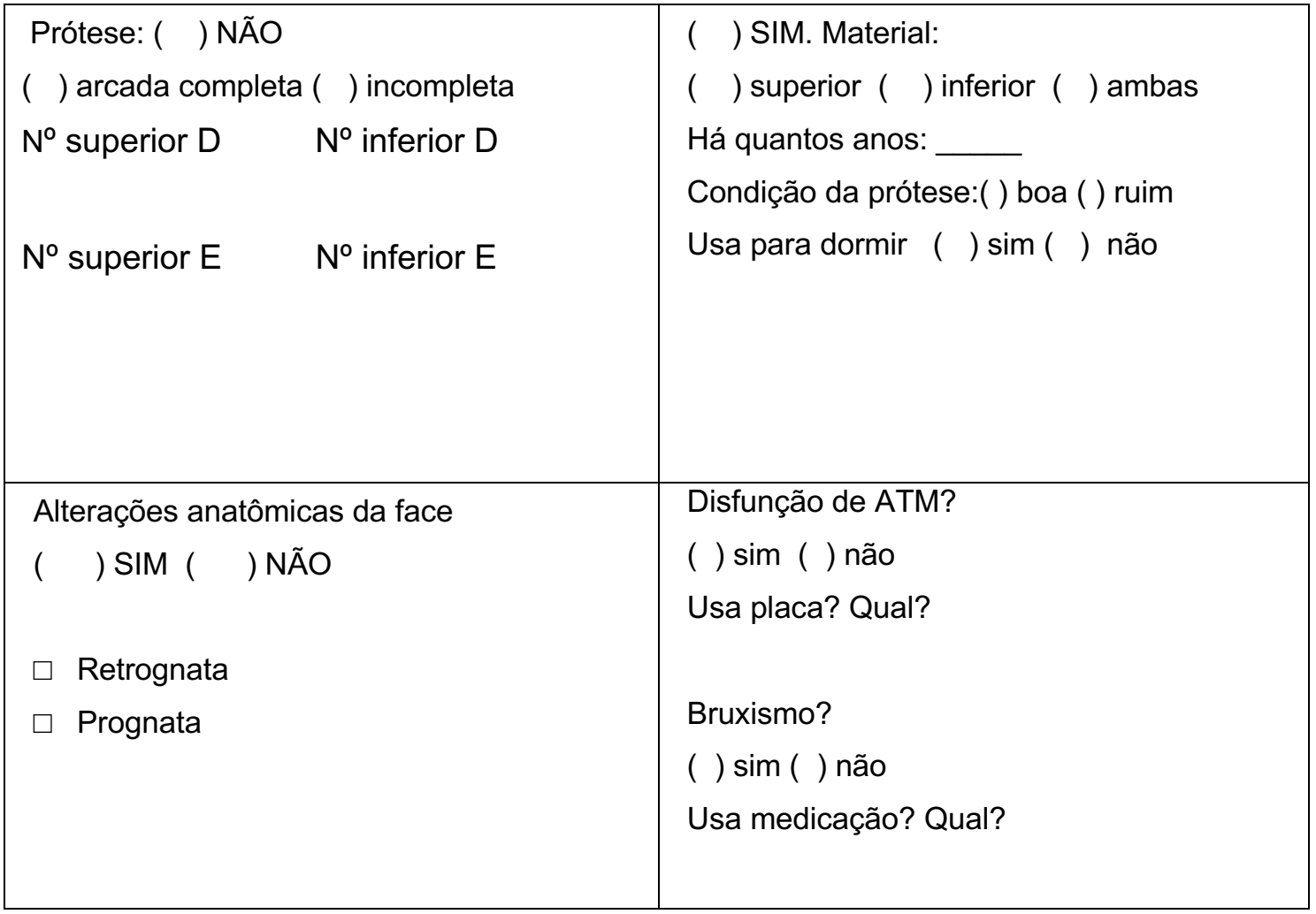

\begin{tabular}{|l|l|l|l|l|}
\hline $\begin{array}{l}\text { EXAME FÍSICO } \\
(1 / 2)\end{array}$ & Peso: & Alt: & IMC: & CA: \\
\hline CC: & PA: & & FC: & $\mathrm{SO}_{2}:$ \\
\hline
\end{tabular}

\subsection{Questionário de sintomas faríngeos}

\section{SINTOMAS NASOFARÍNGEOS}

Levando em consideração o último mês, marque a intensidade dos sintomas abaixo descritos:

\begin{tabular}{|c|c|c|c|c|}
\hline SINTOMAS & AUSENTE & LEVE & MODERADO & INTENSO \\
\hline Espirro & 0 & 1 & 2 & 3 \\
\hline Coriza & 0 & 1 & 2 & 3 \\
\hline Prurido & 0 & 1 & 2 & 3 \\
\hline
\end{tabular}




\begin{tabular}{|c|c|c|c|c|}
\hline Ressecamento & 0 & 1 & 2 & 3 \\
\hline Obstrução & 0 & 1 & 2 & 3 \\
\hline $\begin{array}{c}\text { Sangramento } \\
\text { nasal }\end{array}$ & 0 & 1 & & 3 \\
\hline
\end{tabular}

(1)Leve: presença esporádica, sem comprometimento da atividades diárias; (2)moderado: sintomas frequente com incômodo nas atividades diárias; (3) Intenso: sintomas constantes, com comprometimento das atividades diárias

7.5 Escala de Sonolência diurna de Epworth

Em cada situação abaixo, marque a chance de você cochilar

\begin{tabular}{|l|l|l|l|l|}
\hline SITUAÇÃO & \multicolumn{2}{|l|}{} \\
\hline Sentado e lendo. & 0 & 1 & 2 & 3 \\
\hline Assistindo TV. & 0 & 1 & 2 & 3 \\
\hline Sentado em um lugar público (cinema, igreja, sala de & 0 & 1 & 2 & 3 \\
\hline espera). & & & & \\
\hline Como passageiro de trem, carro ou ônibus, andando & 0 & 1 & 2 & 3 \\
\hline uma hora sem parar. & & & & \\
\hline Deitando-se para descansar à tarde, quando as & & & & \\
\hline circunstâncias permitem. & 0 & 1 & 2 & 3 \\
\hline Sentado e conversando com alguém. & & & & \\
\hline Sentado calmamente após o almoço (sem álcool). & 0 & 1 & 2 & 3 \\
\hline Dirigindo um carro, enquanto pára por alguns minutos ao & 0 & 1 & 2 & 3 \\
\hline
\end{tabular}


pegar um trânsito intenso.

Legendas: 0 - nenhuma chance de cochilar; 1 - pequena chance de cochilar; 2 moderada chance de cochilar; 3 - alta chance de cochilar.

Valores maiores que 10 pontos identificam indivíduos com significativa sonolência diurna.

TOTAL

7.6 Questionário de avaliação de resultados nasossinusais 


\section{AVALIACÃo de RESULtados NAsossinusais. (SNOT-20)}

Você encontrará abaixo uma lista de sintomas e conseqüências sociais e emocionais da sua rinossinusite. Gostaríamos de saber mais sobre estes problemas e pedimos que respondesse às seguintes perguntas da melhor maneira possível. Não há respostas certas ou erradas e somente você pode nos dar essas informações. Por gentileza, dê uma nota para seus problemas conforme se apresentaram nas duas últimas semanas. Obrigado por sua participação. Caso tenha alguma dúvida, peça a nossa ajuda imediatamente.

1. Considerando a gravidade do problema, quando aparece e a freqüência com que acontece; dê uma nota para cada item abaixo de acordo com o grau de intensidade do problema. Faça um círculo ao redor do número que corresponde ao que você sente. Use a escala ao lado:

\begin{tabular}{|c|c|c|c|c|c|c|}
\hline 1. Necessidade de assoar o nariz & 0 & 1 & 2 & 3 & 4 & 5 \\
\hline 2. Espirros & 0 & 1 & 2 & 3 & 4 & 5 \\
\hline 3. Nariz escorrendo & 0 & 1 & 2 & 3 & 4 & 5 \\
\hline 4. Tosse & 0 & 1 & 2 & 3 & 4 & 5 \\
\hline 5. Secreção nasal escorrendo para a garganta & 0 & 1 & 2 & 3 & 4 & 5 \\
\hline 6. Secreçao nasal grossa & 0 & 1 & 2 & 3 & 4 & 5 \\
\hline 7. Ouvido tampado & 0 & 1 & 2 & 3 & 4 & 5 \\
\hline 8. Tontura & 0 & 1 & 2 & 3 & 4 & 5 \\
\hline 9. Dor de Ouvido & 0 & 1 & 2 & 3 & 4 & 5 \\
\hline 10. Dor/ pressão na face & 0 & 1 & 2 & 3 & 4 & 5 \\
\hline 11. Dificuldade de pegar no sono & 0 & 1 & 2 & 3 & 4 & 5 \\
\hline 12. Acordar durante a noite & 0 & 1 & 2 & 3 & 4 & 5 \\
\hline 13. Falta de uma boa noite de sono & 0 & 1 & 2 & 3 & 4 & 5 \\
\hline 14. Acordar cansado & 0 & 1 & 2 & 3 & 4 & 5 \\
\hline 15. Fadiga & 0 & 1 & 2 & 3 & 4 & 5 \\
\hline 16. Produtividade diminuída & 0 & 1 & 2 & 3 & 4 & 5 \\
\hline 17. Concentração reduzida & 0 & 1 & 2 & 3 & 4 & 5 \\
\hline 18. Frustrado / Inquieto/ Irritado & 0 & 1 & 2 & 3 & 4 & 5 \\
\hline 19. Triste & 0 & 1 & 2 & 3 & 4 & 5 \\
\hline 20. Envergonhado com a doença & 0 & 1 & 2 & 3 & 4 & 5 \\
\hline
\end{tabular}

2. Favor marcar os itens mais importantes que estão prejudicando sua saúde (máximo de 5 itens) 
8. Referências

1. Sleep- related breathing disorders in adults: recommendations for syndrome definition and measurementtechniques in clinic al research. The Report of an American Academy of Sleep Medicine Task Force. Sleep. 1999;22(5):667-689.

2. Berry RB, Budhiraja R, Gottlieb DJ, et al. Rules for scoring respiratory events in sleep: Update of the 2007 AASM manual for the scoring of sleep and associated events. J Clin Sleep Med. 2012;8(5):597-619. doi:10.5664/jcsm.2172.

3. Jordan AS, McSharry DG, Malhotra A. Adult obstructive sleep apnoea. Lancet. 2014;383(9918):736-747. doi:10.1016/S0140-6736(13)60734-5.

4. Prentice AM. The emerging epidemic of obesity in developing countries. Int J Epidemiol. 2006;35(1):93-99. doi:10.1093/ije/dyi272.

5. Young, T, Shahar, E, Nieto, FJ, Redline S, Newman A. Predictors of sleepdisordered breathing in community- dwelling adults: the Sleep Heart Health Study. Arch Intern Med. 2002;162:893-900.

6. Tufik S, Santos-Silva R, Taddei JA, Bittencourt LRA. Obstructive Sleep Apnea Syndrome in the Sao Paulo Epidemiologic Sleep Study. Sleep Med. 2010;11(5):441-446. doi:10.1016/j.sleep.2009.10.005.

7. Heinzer R, Andries D, Bastardot F, et al. Prevalence of sleep disordered breathing in middle-aged general population: The HypnoLaus study. Lancet Respir Med. 2015;3(4):310-318. doi:10.1016/S22132600(15)00043-0.

8. Lorenzi Filho G, Genta PR, Pedrosa RP, Drager LF, Martinez D. Cardiovascular consequences of obstructive sleep apnea syndrome. $J$ Bras Pneumol. 2010;36:38-42. doi:10.1590/S1806-37132010001400011.

9. José M. Marin, MD, Alvar Agusti, MD, Isabel Villar, PhD, Marta Forner, PhD, David Nieto, MD, Santiago J. Carrizo, MD, Ferran Barbé, MD, Eugenio Vicente, MD, Ying Wei, PhD, F. Javier Nieto, MD, PhD, and Sanja Jelic, MDJosé M. Marin, MD, Alvar Agusti, MD, I M. Association Between Treated and Untreated Obstructive Sleep Apnea and Risk of Hypertension. 
Jama.

2015;307(20):2169-2176.

doi:10.1001/jama.2012.3418.Association.

10. Schwartz AR, Smith PL, Wise RA, Gold AR, Permutt S. Induction of upper airway occlusion in sleeping individuals with subatmospheric nasal pressure. J Appl Physiol. 1988;64(2):535-542. doi:10.1152/jappl.1988.64.2.535.

11. Smith PL, Wise RA, Gold AR, Schwartz AR, Permutt S. Upper airway pressure-flow relationships in obstructive sleep apnea. J Appl Physiol. 1988;64(2):789-795.

12. Gleadhill IC, Schwartz AR, Schubert N, Wise RA, Permutt S, Smith PL. Upper Airway Collapsibility in Snorers and in Patients with Obstructive Hypopnea and Apnea. Am Rev Respir Dis. 1991;143(6):1300-1303. doi:10.1164/ajrccm/143.6.1300.

13. Safiruddin F, Koutsourelakis I, de Vries N. Analysis of the influence of head rotation during drug-induced sleep endoscopy in obstructive sleep apnea. Laryngoscope. 2014;124(9):2195-2199. doi:10.1002/lary.24598.

14. Lee SH, Choi JH, Shin C, Lee HM, Kwon SY, Lee SH. How Does OpenMouth Breathing Influence Upper Airway Anatomy? Laryngoscope. 2007;117(June):1102-1106. doi:10.1097/MLG.0b013e318042aef7.

15. Fitzpatrick MF, McLean H, Urton AM, Tan A, O’Donnell D, Driver HS. Effect of nasal or oral breathing route on upper airway resistance during sleep. Eur Respir J. 2003;22(5):827-832. doi:10.1183/09031936.03.00047903.

16. Gleeson K, Zwillich C. Breathing route during sleep. Am Rev ... 1986;134:115-120. http://europepmc.org/abstract/MED/3729149.

17. Fitzpatrick MF, Driver HS, Chatha N, Voduc N, Girard AM. Partitioning of inhaled ventilation between the nasal and oral routes during sleep in normal subjects. J Appl Physiol. 2003;94(November 2002):883-890. doi:10.1152/japplphysiol.00658.2002.

18. Koutsourelakis I, Vagiakis E, Roussos C, Zakynthinos S, Roussos C. Obstructive sleep apnoea and oral breathing in patients free of nasal obstruction. Eur Respir J. 2006;28:1222-1228. doi:10.1183/09031936.00058406.

19. Verma M, Seto-Poon M, Wheatley JR, Amis TC, Kirkness JP. Influence of 
breathing route on upper airway lining liquid surface tension in humans. $J$ Physiol. 2006;574(3):859-866. doi:10.1113/jphysiol.2005.102129.

20. White DP, Cadieux RJ, Lombard RM, Bixler EO, Kales A, Zwillich CW. The effects of nasal anesthesia on breathing during sleep. Am Rev Respir Dis. 1985;132(5):972-975. doi:10.1164/arrd.1985.132.5.972.

21. Kim EJ, Choi JH, Kim KW, et al. The impacts of open-mouth breathing on upper airway space in obstructive sleep apnea: 3-D MDCT analysis. Eur Arch Oto-Rhino-Laryngology. 2011;268(4):533-539. doi:10.1007/s00405010-1397-6.

22. Hollowell DE, Suratt PM. Mandible position and activation of submental and masseter muscles during sleep. J Appl Physiol. 1991;71(6):2267-2273. doi:10.1152/jappl.1991.71.6.2267.

23. Tuomilehto HPI, Seppä JM, Partinen MM, et al. Lifestyle intervention with weight reduction: First-line treatment in mild obstructive sleep apnea. Am J Respir Crit Care Med. 2009;179(4):320-327. doi:10.1164/rccm.200805$6690 \mathrm{C}$.

24. Cuccia AM, Caradonna C. Mandibular advancement devices: indications and predictors of treatment outcome. A review. Minerva Stomatol. 2007;56(9):427-443.

25. Guimarães KC, Drager LF, Genta PR, Marcondes BF, Lorenzi-Filhoy G. Effects of oropharyngeal exercises on patients with moderate obstructive sleep apnea syndrome. Am J Respir Crit Care Med. 2009;179(10):962-966. doi:10.1164/rccm.200806-9810C.

26. leto $\mathrm{V}$, Kayamori $\mathrm{F}$, Montes MI, et al. Effects of oropharyngeal exercises on snoring: A randomized trial. Chest. 2015;148(3):683-691. doi:10.1378/chest.14-2953.

27. Aurora RN, Casey KR, Kristo D, et al. Practice parameters for the surgical modifications of the upper airway for obstructive sleep apnea in adults. Sleep. 2010;33(10):1408-1413. doi:10.1093/sleep/33.10.1408.

28. Cahali MB. Lateral pharyngoplasty: a new treatment for obstructive sleep apnea hypopnea syndrome. Laryngoscope. 2003;113(11):1961-1968. doi:10.1097/00005537-200311000-00020.

29. Strollo PJ, Soose RJ, Maurer JT, et al. Upper-Airway Stimulation for 
Obstructive Sleep Apnea. N Engl J Med. 2014;370(2):139-149. doi:10.1056/NEJMoa1308659.

30. Kushida CA, Littner MR, Hirshkowitz M, et al. Practice parameters for the use of continuous and bilevel positive airway pressure devices to treat adult patients with sleep-related breathing disorders. Sleep. 2006;29(3):375380. http://www.ncbi.nlm.nih.gov/pubmed/16553024.

31. Sullivan C, Issa F, Berthon-Jones M, Eves L. Reversal of obstructive sleep apnoea by continuous positive airway pressure applied through the nares. Lancet. 1981;1(8225):862-865.

32. Jenkinson C, Davies RJ, Mullins R, Stradling JR. Comparison of therapeutic and subtherapeutic nasal continuous positive airway pressure for obstructive sleep apnoea: a randomised prospective parallel trial. Lancet. 1999;353:2100-2105. doi:10.1016/S0140-6736(98)10532-9.

33. Sharma S, Agrawal S, Damodaran D, et al. CPAP for the metabolic syndrome in patients with obstructive sleep apnea. Engl $J$ Med. 2011;365(24):2277-2286.

34. Giles TL, Lasserson TJ, Smith BJ, White J, Wright J CC. Continuous positive airways pressure for obstructive sleep apnoea in adults. Cochrane database Syst Rev. 2006;(3):CD001106. doi:10.1002/14651858.CD001106.

35. Kribbs NB, Pack Al, Kline LR, et al. Objective Measurement of Patterns of Nasal CPAP Use by Patients with Obstructive Sleep Apnea. Am Rev Respir Dis. 1993;147(4):887-895. doi:10.1164/ajrccm/147.4.887.

36. Pépin JL, Krieger J, Rodenstein D, et al. Effective compliance during the first 3 months of continuous positive airway pressure: A European prospective study of 121 patients. Am J Respir Crit Care Med. 1999;160(4):1124-1129. doi:10.1164/ajrccm.160.4.9802027.

37. Weaver TE. Adherence to positive airway pressure therapy. Curr Opin Pulm Med. 2006;12(6):409-413. doi:10.1097/01.mcp.0000245715.97256.32.

38. Billings ME, Auckley D, Benca $R$, et al. Race and Residential Socioeconomics as Predictors of CPAP Adherence. Sleep. 2011;34(12):1653-1658. doi:10.5665/sleep.1428. 
39. Kohler M, Smith D, Tippett V, Stradling JR. Predictors of long-term compliance with continuous positive airway pressure. Thorax. 2010;65(9):829-832. doi:10.1136/thx.2010.135848.

40. Mortimore IL, Whittle a T, Douglas NJ. Comparison of nose and face mask CPAP therapy for sleep apnoea. Thorax. 1998;53(4):290-292.

41. Andrade RGS, Madeiro F, Genta PR, Lorenzi-Filho G. Oronasal mask may compromise the efficacy of continuous positive airway pressure on OSA treatment. Curr Opin Pulm Med. 2016;22(6):555-562. doi:10.1097/MCP.0000000000000318.

42. Lavie P. Rediscovering the importance of nasal breathing in sleep or, shut your mouth and save your sleep. J Laryngol Otol. 1987;101(6):558-563. doi:10.1017/S0022215100102245.

43. Borel JC, Tamisier R, Dias-Domingos $\mathrm{S}$, et al. Type of mask may impact on continuous positive airway pressure adherence in apneic patients. PLoS One. 2013;8(5):e64382. doi:10.1371/journal.pone.0064382.

44. Deshpande S, Joosten S, Turton A, et al. Oronasal Masks Require a Higher Pressure than Nasal and Nasal Pillow Masks for the Treatment of Obstructive Sleep Apnea. J Clin Sleep Med. 2016;12(09):1263-1268. doi:10.5664/jcsm.6128.

45. BaHammam AS, Singh T, George S, Acosta KL, Barataman K, Gacuan DE. Choosing the right interface for positive airway pressure therapy in patients with obstructive sleep apnea. Sleep Breath. 2017;21(3):569-575. doi:10.1007/s11325-017-1490-9.

46. Sanders MH, Kern NB, Stiller RA, Strollo PJ, Martin TJ, Atwood CW. CPAP therapy via oronasal mask for obstructive sleep apnea. Chest. 1994;106(3):774-779.

47. Prosise GL, Berry RB. Oral-nasal continuous positive airway pressure as a treatment for obstructive sleep apnea. Chest. 1994;106:180-186. doi:10.1378/chest.106.1.180.

48. Schorr F, Genta P, Gregorio M, Lorenzi-Filho G. Continuous positive airway pressure delivered by oronasal mask may not be effective for obstructive sleep apnoea. Eur Respir J. 2012;40(2):500-503. doi:10.1183/09031936.00009212. 
49. Andrade RGS, Piccin VS, Nascimento JA, Madeiro F, Genta PR, LorenziFilho G. Impact of the type of mask on the effectiveness of and adherence to continuous positive airway pressure treatment for obstructive sleep apnea. J Bras Pneumol. 2014;40(6):658-668.

50. Beecroft J, Zanon S, Lukic D, Hanly P. Oral Continuous Positive Airway Pressure for Sleep Apnea. Chest. 2003;124:2200-08.

51. Bettinzoli M, Taranto-Montemurro L, Messineo L, et al. Oronasal masks require higher levels of positive airway pressure than nasal masks to treat obstructive sleep apnea. Sleep Breath. 2014;18(4):845-849. doi:10.1007/s11325-014-0954-4.

52. Teo M, Amis T, Lee S, Falland K, Lambert S, Wheatley J. Equivalence of nasal and oronasal masks during initial CPAP titration for obstructive sleep apnea syndrome. Sleep. 2011;34(7):951-955. doi:10.5665/SLEEP.1134.

53. Bakker JP, Neill AM, Campbell AJ. Nasal versus oronasal continuous positive airway pressure masks for obstructive sleep apnea: a pilot investigation of pressure requirement, residual disease, and leak. Sleep Breath. 2012;16(3):709-716. doi:10.1007/s11325-011-0564-3.

54. Ebben MR, Oyegbile T, Pollak CP. The efficacy of three different mask styles on a PAP titration night. Sleep Med. 2012;13(6):645-649. doi:10.1016/j.sleep.2012.02.004.

55. Bachour A, Vitikainen $P$, Virkkula $P$, Maasilta P. CPAP interface: satisfaction and side effects. Sleep Breath. 2013;17:667-672. doi:10.1007/s11325-012-0740-0.

56. Massie C, Hart R. Clinical outcomes related to interface type in patients with obstructive sleep apnea/hypopnea syndrome who are using continuous positive airway pressure. Chest. 2003;123(4):1112-1118.

57. Ryan S, Garvey JF, Swan V, Behan R, Mcnicholas WT. Nasal pillows as an alternative interface in patients with obstructive sleep apnoea syndrome initiating continuous positive airway pressure therapy. $J$ Sleep Res. 2011;20(2):367-373. doi:10.1111/j.1365-2869.2010.00873.x.

58. Anderson FE, Kingshott RN, Taylor DR, Jones DR, Kline LR, Whyte KF. A randomized crossover efficacy trial of oral CPAP (Oracle) compared with nasal CPAP in the management of obstructive sleep apnea. Sleep. 
2003;26(6):721-726.

59. Khanna R, Kline LR. A prospective 8 week trial of nasal interfaces vs. a novel oral interface (Oracle) for treatment of obstructive sleep apnea hypopnea syndrome. Sleep Med. 2003;4(4):333-338. doi:10.1016/S13899457(03)00063-7.

60. Andrade RGS, Viana FM, Nascimento JA, et al. Nasal vs Oronasal CPAP for OSA Treatment. A meta-analysis. Chest. 2018;153(3):665-674. doi:10.1016/j.chest.2017.10.044.

61. Ebben MR, Narizhnaya M, Segal AZ, Barone D, Krieger AC. A randomised controlled trial on the effect of mask choice on residual respiratory events with continuous positive airway pressure treatment. Sleep Med. 2014;15(6):619-624. doi:10.1016/j.sleep.2014.01.011.

62. Casanova F, Leseux L, Fraysse J-L, Léophonte P, Muir J-F, Didier A. Impact of facial versus nose mask on the length of use of CPAP in patients with Sleep Apnea Syndrome. Rev Mal Respir. 2013;30(5):441-442. doi:10.1016/j.rmr.2013.01.006.

63. Kaminska M, Montpetit A, Mathieu A, Jobin V, Morisson F, Mayer P. Higher effective oronasal versus nasal continuous positive airway pressure in obstructive sleep apnea: Effect of mandibular stabilization. Can Respir J. 2014;21(4):234-238.

64. Westhoff M, Litterst P. Obstructive sleep apnoea and non-restorative sleep induced by the interface. Sleep Breath. 2015;19(4):1317-1325. doi:10.1007/s11325-015-1173-3.

65. Andrade RGS, Madeiro F, Piccin VS, et al. Impact of Acute Changes in CPAP Flow Route in Sleep Apnea Treatment. Chest. 2016;150(6):11941201. doi:10.1016/j.chest.2016.04.017.

66. Bachour A, Maasilta P. Mouth Breathing Compromises Adherence to Nasal Continuous Positive Airway Pressure Therapy. Chest. 2004;126:12481254. doi:10.1016/S8756-3452(08)70196-8.

67. Ruhle $\mathrm{KH}$, Nilius $\mathrm{G}$. Mouth breathing in obstructive sleep apnea prior to and during nasal continuous positive airway pressure. Respiration. 2008;76(1):40-45. doi:10.1159/000111806.

68. Senny F, Maury G, Cambron L, Leroux A, Destine J, Poirrier R. Mandible 
Behavior in Obstructive Sleep Apnea Patients Under CPAP Treatment. Open Sleep J. 2012;5(1):1-5. doi:10.2174/1874620901205010001.

69. Ng JR, Aiyappan V, Mercer J, et al. Choosing an oronasal mask to deliver continuous positive airway pressure may cause more upper airway obstruction or lead to higher continuous positive airway pressure requirements than a nasal mask in some patients: A case series. J Clin Sleep Med. 2016;12(9):1227-1232. doi:10.5664/jcsm.6118.

70. Genta PR, Eckert DJ, Gregorio MG, et al. Critical closing pressure during midazolam-induced sleep. J Appl Physiol. 2011;111:1315-1322. doi:10.1152/japplphysiol.00508.2011.

71. Cottle $\mathrm{MH}$, Loring RM, Fischer GG GI. The maxillapremaxilla approach to extensive nasal septum surgery. AMA Arch Otolaryngol. 1958;68:301 - 13.

72. Shirlaw T, Duce B, Milosavljevic J, Hanssen K, Hukins C. A randomised crossover trial comparing nasal masks with oronasal masks: No differences in therapeutic pressures or residual apnea-hypopnea indices. J Sleep Res. 2018;(e12760). doi:10.1111/jsr.12760.

73. Goh KJ, Soh RY, Leow LC, et al. Choosing the right mask for your Asian patient with sleep apnoea: A randomized, crossover trial of CPAP interfaces. Respirology. 2018. doi:10.1111/resp.13396.

74. Borel J-C, Gakwaya S, Masse J-F, Melo-Silva CA, Sériès F. Impact of CPAP interface and mandibular advancement device on upper airway mechanical properties assessed with phrenic nerve stimulation in sleep apnea patients. Respir Physiol Neurobiol. 2012;183:170-176. doi:10.1016/j.resp.2012.06.018.

75. Lebret M, Arnol N, Martinot JB, et al. Nasal Obstruction Symptom Evaluation Score to Guide Mask Selection in CPAP-Treated Obstructive Sleep Apnea. Otolaryngol - Head Neck Surg. 2018;159(3):590-592. doi:10.1177/0194599818773993.

76. Schellhas V, Glatz C, Beecken I, et al. Upper airway obstruction induced by non-invasive ventilation using an oronasal interface. Sleep Breath. 2018. doi:10.1007/s11325-018-1640-8.

77. Vroegop A V., Vanderveken OM, Boudewyns AN, et al. Drug-induced sleep endoscopy in sleep-disordered breathing: Report on 1,249 cases. 
Laryngoscope. 2014;124(3):797-802. doi:10.1002/lary.24479.

78. Ravesloot M, De Vries N. One Hundred Consecutive Patients Undergoing Drug Induced Sleep Endoscopy (DISE): Results and Evaluation. Laryngoscope. 2011;121(12):2710-2716. doi:10.1002/lary.22369.

79. Nascimento JA, Carvalho TDS, Moriya HT, et al. Body Position May Influence Oronasal CPAP Effectiveness to Treat OSA. J Clin Sleep Med. 2016;12(3):447-448.

80. Isono S, Tanaka A, Nishino T. Lateral position decreases collapsibility of the passive pharynx in patients with obstructive sleep apnea. Anesthesiology. 2002;97(4):780-785. http://www.ncbi.nlm.nih.gov/pubmed/12357140. 